
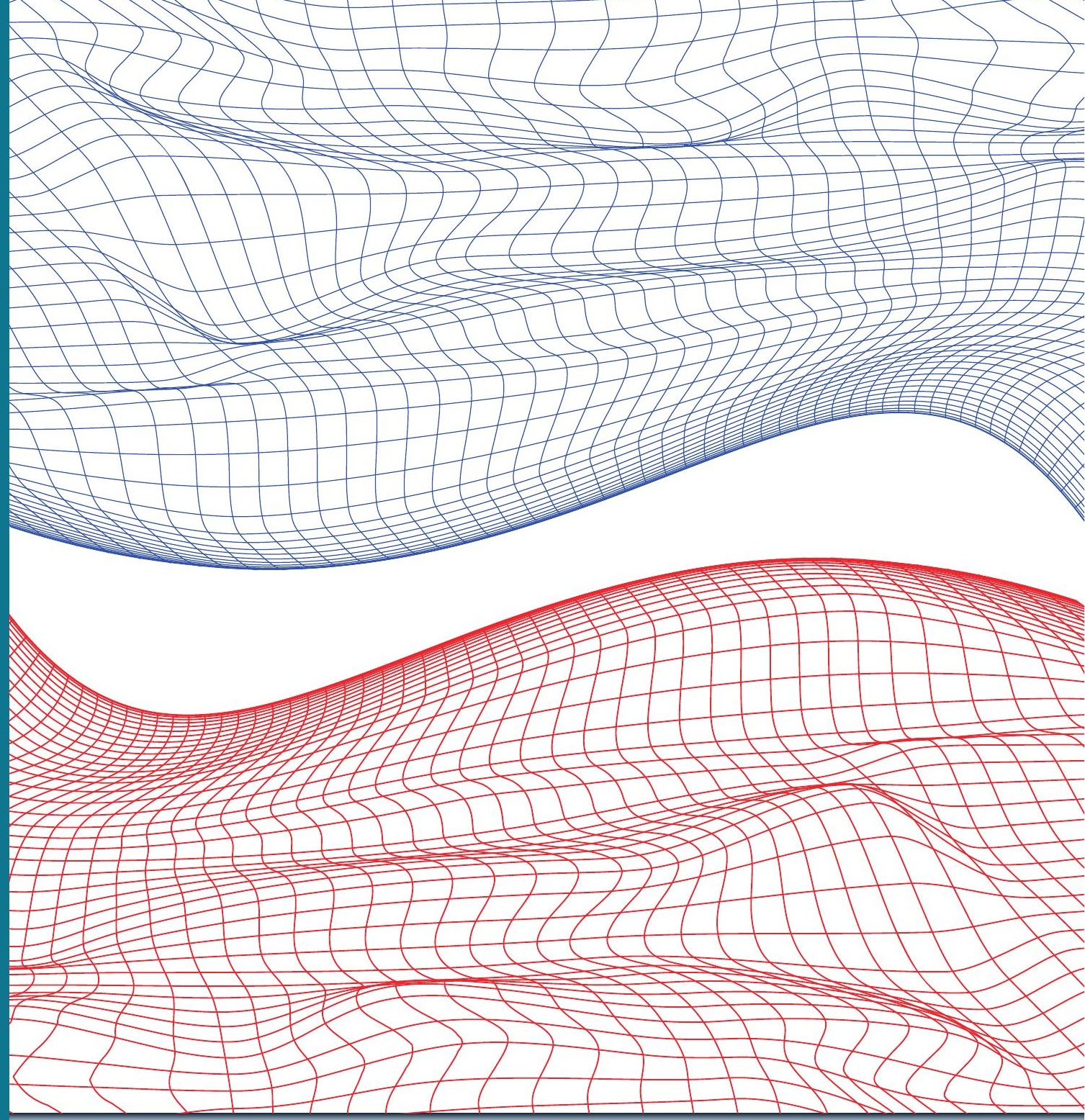

\title{
Diseño y Construcción de Prácticas Para el Estudio de Movimiento Ondulatorio
}

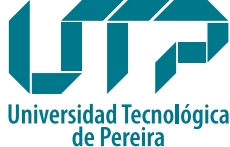

de Pereira

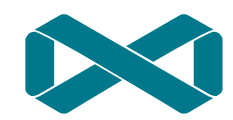

Editorial UTP

Sebastián Martínez García Diego Fernando Salazar Andrés Felipe Osorio Ramírez Leonardo Bohórquez Santiago Hugo Armando Gallego Becerra 
Sebastián Martínez García, (Cartago, Valle, Colombia,1988)

Magister en Instrumentación Física, Ingeniero Físico, Universidad Tecnológica de Pereira. Profesor transitorio de medio tiempo, asistente, facultad de ingenierías de la Universidad Tecnológica de Pereira.

Ha publicado artículos en revistas especializadas nacionales. Miembro de los grupos de investigación DICOPED y BIOIF. smartinez@utp.edu.co

Diego Fernando Salazar Patiño, (Pereira, Risaralda Colombia ,1973) Magister en Instrumentación Física, Ingeniero Electricista, Universidad Tecnológica de Pereira. Profesor transitorio de medio tiempo, auxiliar de la Universidad Tecnológica de Pereira. Ha publicado artículos en revistas especializadas nacionales. Miembro del grupo de investigación DICOPED

$$
\text { dfs@utp.edu.co }
$$

Andrés Felipe Osorio Ramírez, (Villavicencio, Meta, Colombia,1988).

Magister en Pedagogía y Desarrollo Humano, Ingeniero Físico, Universidad Tecnológica de Pereira. Profesor Catedrático, Facultad de Ingenierías de la Universidad Tecnológica de Pereira.

Miembro de los grupos de investigación DICOPED y BIOIF anfeosorio@utp.edu.co

Hugo Armando Gallego Becerra, (Pereira, Risaralda Colombia ,1958 ) Licenciado en Física-Matemáticas. Universidad Tecnológica de Pereira. Magister en Física. Universidad de Antioquia. Profesor de tiempo completo en la Facultad de Ciencias Básicas de la Universidad Tecnológica de Pereira. Ha publicado artículos en revistas especializadas nacionales. Director del grupo de Investigación "DICOPED”

Diseño y Construcción de Prototipos Para Experimentos de Demostración ugo@utp.edu.co

Leonardo Bohorquez Santiago, (Roldanillo, Valle, Colombia, 1988).

Magister en Instrumentación física e Ingeniero Físico de la universidad tecnológica de Pereira. Docente Asistente facultad de Ciencias Básicas Departamento de Fisica de la Universidad Tecnológica de Pereira.

Ha publicado artículos en revistas especializadas nacionales.

Miembro del grupo de investigación DICOPED

Lbohorquez@utp.edu.co

La Editorial de la Universidad Tecnológica de Pereira tiene como política la divulgación del saber científico, técnico y humanístico para fomentar la cultura escrita a través de libros y revistas científicas especializadas.

Las colecciones de este proyecto son: Trabajos de Investigación, Ensayos, Textos Académicos y Tesis Laureadas. 


\section{Diseño y Construcción de Prácticas para el Estudio de Movimiento Ondulatorio}

Sebastián Martínez García

Diego Fernando Salazar Andrés Felipe Osorio Ramírez Leonardo Bohórquez Santiago Hugo Armando Gallego Becerra

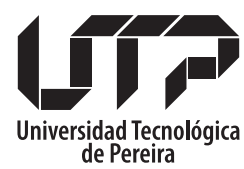

Facultad de Ciencias Básicas

Colección Trabajos de Investigación 2020 
Diseño y construcción de prácticas para el estudio de

movimiento ondulatorio / Sebastián Martínez García y otros

Pereira : Editorial Universidad Tecnológica de Pereira,

2020.

132 páginas. -- (Colección Trabajos de investigación)

ISBN: 978-958-722-507-5

1. Teoría del movimiento ondulatorio 2 . Física para ciencias e ingenierías 3. Metrología 4. Vibración - Medición 5. Ondas electromagnéticas 6 . Ondas mecánicas - Procesamiento digital de imágenes 7. Mecánica ondulatoria

CDD. 530.124

Diseño y Construcción de Prácticas para el Estudio de Movimiento Ondulatorio

C Sebastián Martínez García

(c) Diego Fernando Salazar

(C) Andrés Felipe Osorio Ramírez

(C) Leonardo Bohórquez Santiago

(C) Hugo Armando Gallego Becerra

(C) Universidad Tecnológica de Pereira

ISBN: 978-958-722-507-5

Proyecto de Investigación: “Diseño y Construcción de Prácticas Para el Estudio de Movimiento Ondulatorio” código 3-17-3

Universidad Tecnológica de Pereira

Vicerrectoría de Investigaciones, Innovación y Extensión

Editorial Universidad Tecnológica de Pereira

Pereira, Colombia

Coordinador editorial:

Luis Miguel Vargas Valencia

luismvargas@utp.edu.co

Teléfono 3137381

Edificio 9, Biblioteca Central "Jorge Roa Martínez"

Cra. 27 No. 10-02 Los Álamos, Pereira, Colombia

www.utp.edu.co

Montaje y producción:

María Alejandra Henao Jiménez

Universidad Tecnológica de Pereira

Pereira 
Este libro es el resultado del esfuerzo conjunto de todos los que formamos parte del grupo de investigación DICOPED, un grupo de trabajo basado en el fruto de ideas, esfuerzo e investigación, producto del reconocimiento y del apoyo vital que nos ofrecen las personas que nos estiman, para poseer la fuerza y energía que nos anima a crecer como investigadores y profesionales.

La concepción de este proyecto está dedicada a la Vicerrectoría de Investigaciones, Innovación y Extensión de la Universidad Tecnológica de Pereira, por las convocatorias internas para la financiación de proyectos de investigación, innovación o desarrollo tecnológico de los años 2016 - 2018. Queremos dar las gracias también a todas esas personas que nos aportaron, en especial a aquellos que nos abrieron las puertas y compartieron sus conocimientos para la elaboración de los productos expuestos en este libro; especialmente, a Angélica Franco Arias y a nuestro editor Jeiner Orlando Moreno Soto.

Sabemos que estas palabras no son suficientes para expresar nuestros agradecimientos, pero esperamos que, con ellas, se den a entender nuestros sentimientos de aprecio y cariño a todos ellos. 

"Agradezco ante todo a Dios por permitirnos estar bien para realizar cada una de nuestra actividades personales y académicas, a mi familia por el apoyo y la motivación que día tras día generan en mi diario quehacer, a una nueva luz celestial que ilumina nuestros hogares, generando en nuestros corazones paz, amor, ternura y mucha felicidad...

Y a mí Universidad, que, a través de cada una de las dependencias que se encuentran en ella y de cada uno de sus directivos, se convirtió en un camino más para obtener los logros que hemos conseguido a través del tiempo".

Hugo A. Gallego B. 



\section{CONTENIDO}

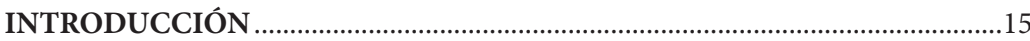

\section{CAPÍTULO UNO}

1. Diseño y Construcción del Prototipo Experimental para la Cuerda Tensa.......19

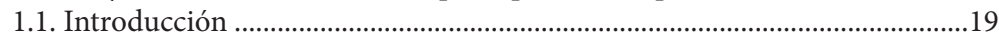

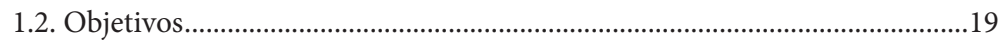

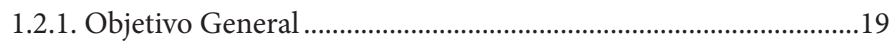

1.2.2. Objetivos Específicos ...................................................................... 19

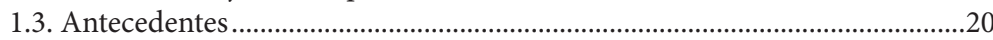

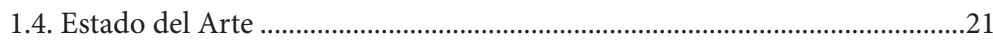

1.4.1 Equipo Experimental de la Ley de Snell .................................21

1.4.2 Equipo Experimental de la Ley de Hooke ............................21

1.4.3 Equipos Existentes para Experimentos Ondulatorios ......22

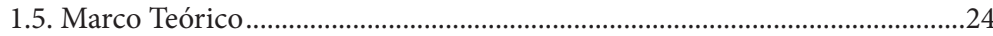

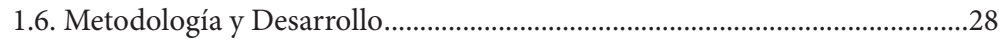

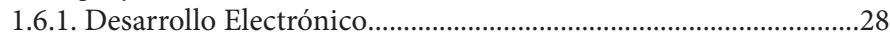

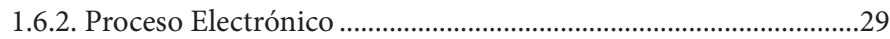

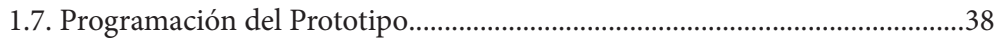

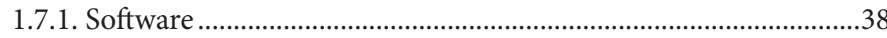

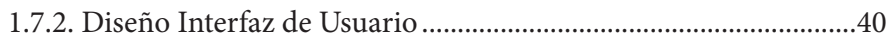

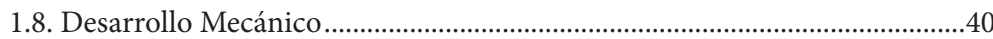

1.8.1. Diseño y construcción del esquema mecánico del prototipo......40

1.8.2. Diseño del Vástago en donde se sujeta la Cuerda al Parlante.....41

1.8.3. Parlante de $15 \mathrm{~cm} 20 \mathrm{w} 12 \mathrm{v}$ con Vástago ya Pegado........................42

1.8.4. Caja para Generador de Señales.......................................................42

1.8.5. Soporte Base Equipo.......................................................................4

1.8.6. Caja para el Parlante y Amplificador de Señal. ..............................44

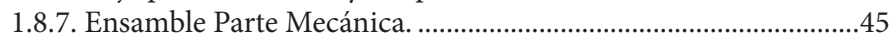

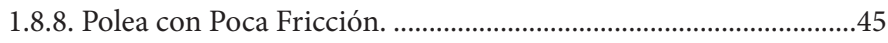

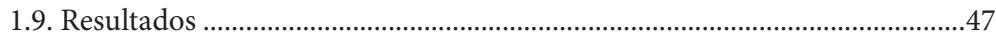

1.9.1. Generador Mecánico de Ondas.........................................................

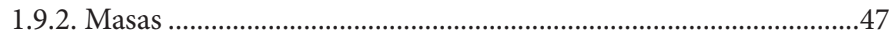

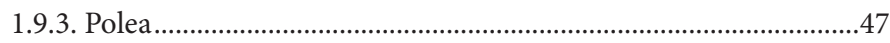

1.9.4. Generador de Señales Parte Frontal ................................................4

1.9.5. Generador de Señales Parte Lateral ...................................................48

1.9.6. Parte Trasera del Generador de Señales..........................................49

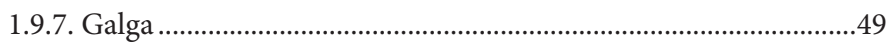

1.9.8. Equipo Ensamblado .......................................................................4

1.9.9. Resultados de la Práctica Ondas Estacionarias en una

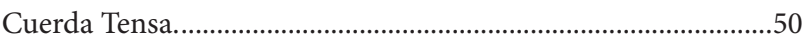

1.9.10. Comparación Laboratorio de Metrología de Variables

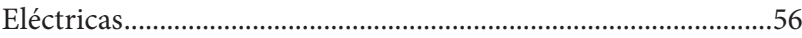

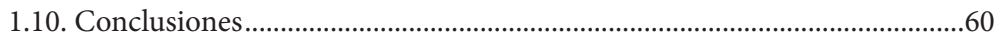




\section{CAPÍTULO DOS}

2. Diseño, Construcción e Implementación de una Cubeta de Ondas para el Estudio de la Frecuencia, Velocidad y Longitud de Onda de Ondas Mecánicas mediante Procesamiento Digital de Imágenes.........................................................65

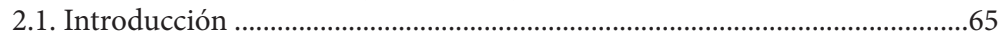

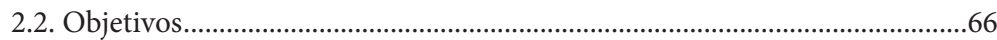

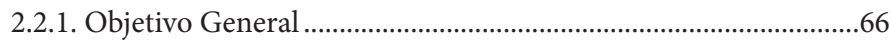

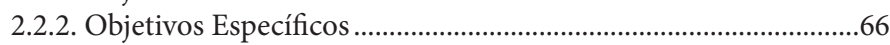

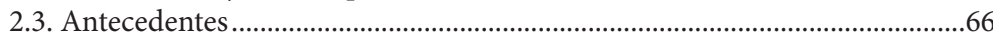

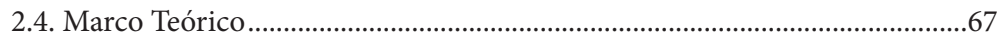

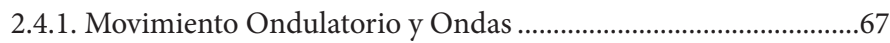

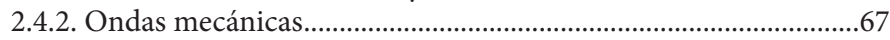

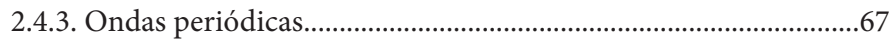

2.4.4. Descripción matemática de una onda ...........................................67

2.4.5. Imágenes digitales .........................................................................69

2.4.6. Propuesta para el desarrollo ..............................................................70

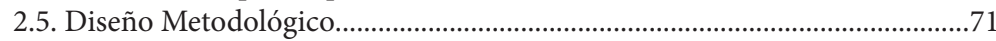

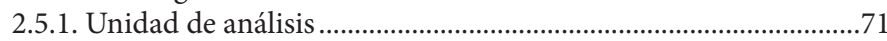

2.5.2. Variables ...........................................................................................

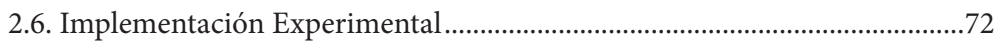

2.6.1. Diseño e Implementación de un generador de ondas...................73

2.6.2. Diseño e Implementación de la estructura de cubeta

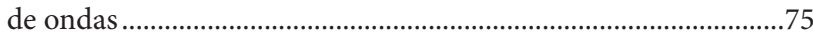

2.6.3. Diseño e implementación adicional sistema de riel

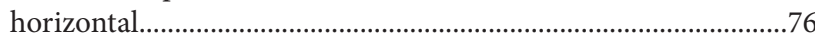

2.6.4. Diseño e implementación de una plataforma virtual para el control del equipo.....................................................................

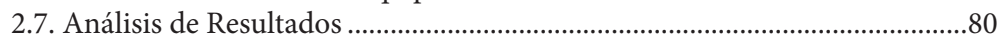

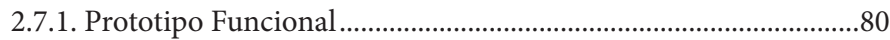

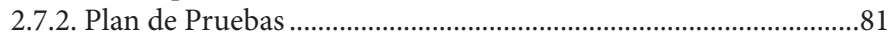

2.7.3. Software de Control del Equipo ..................................................82

2.7.4. Manual de usuario .............................................................................. 82

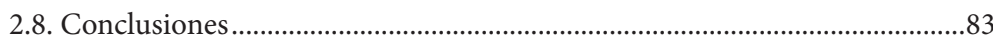

\section{CAPÍTULO TRES}

3. Diseño, Construcción e Implementación de un Equipo Experimental para el

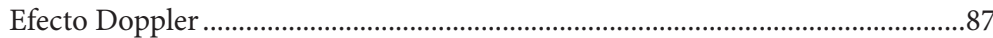

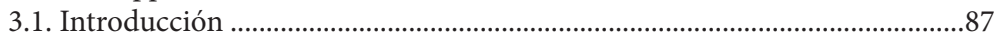

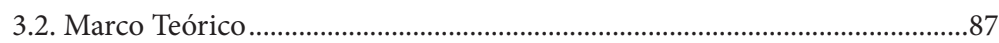

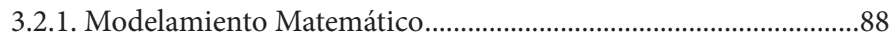

3.3. Metodología y Desarrollo..............................................................................92

3.3.1. Desarrollo Del Software ................................................................94

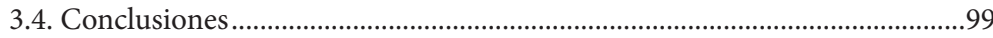

\section{CAPITULO CUATRO}

4. Guías de Laboratorio para los Prototipos Experimentales Desarrollados por el Grupo DICOPED 
4.2. Guía Física III: Ondas Estacionarias en una Cuerda Tensa....................... 103

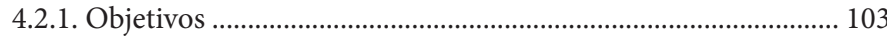

4.2.2. Marco Conceptual........................................................................ 104

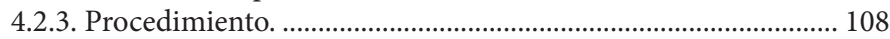

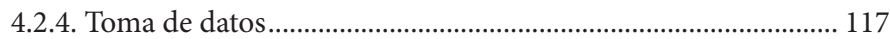

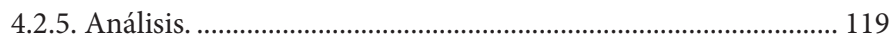

4.3. Guía Experimental Física III: Cubeta de Ondas ......................................... 120

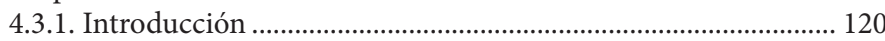

4.3.2. Objetivos ............................................................................... 120

4.3.3. Marco Conceptual........................................................................ 120

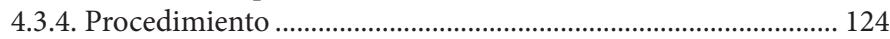

4.3.5. Montaje del prototipo............................................................... 124

4.3.6. Manipulación del Software .......................................................... 124

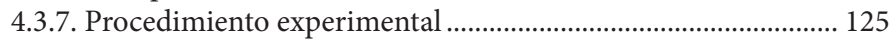

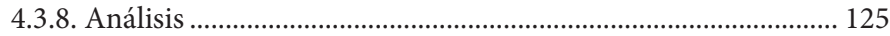

4.4. Guía Experimental para el Efecto Doppler ................................................. 125

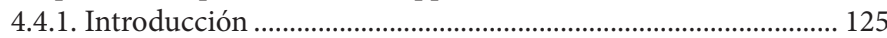

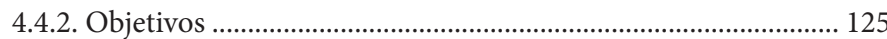

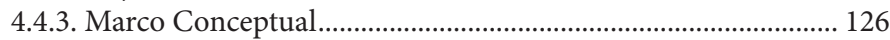

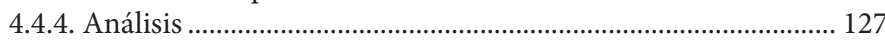

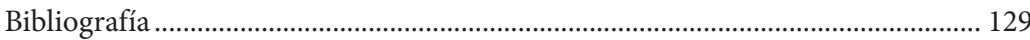

\section{Índice de Ilustraciones}

Figura 1 Diseño del equipo de la Ley de Snell (DICOPED, 2018).......................21

Figura 2 Equipo De La Ley De Hooke (Arcos et al., 2011).................................22

Figura 3 Materiales Para Experimento Cuerda Tensa (Arenas, 2018)...............22

Figura 4 Tecnoedu- impulsor de ondas mecánicas (TecnoEdu, 2018)................23

Figura 5 Economy Wave Driver (TecnoEdu, 2018)..............................................23

Figura 6 Generador de Ondas Pasco (Pasco, 2018).............................................23

Figura 7 Equipo Xplorer GLS (Arcos et al., 2011)..............................................24

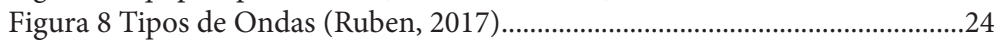

Figura 9 Amplitud de una Onda (Serway \& Jawett, 2008a).................................25

Figura 10 Numero de Onda [Autor] ...................................................................25

Figura 11 Modos de Oscilación de una cuerda Tensa

(Serway \& Jawett, 2008a) ......................................................................................26

Figura 12 Ciclo de una Onda [Autor] ................................................................27

Figura 13 Longitud de Onda (Young \& Freedman, 2009) ...................................27

Figura 14 Periodo de una Onda (Young \& Freedman, 2009) ................................27

Figura 15 Velocidad de una Onda (Young \& Freedman, 2009) ..........................28

Figura 16 Oscilación (Young \& Freedman, 2009) .................................................28

Figura 17 Esquema del Circuito [Autor] ..............................................................29

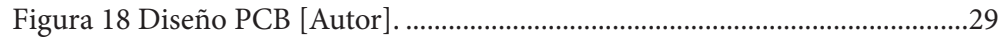

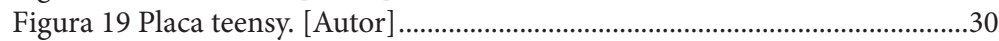

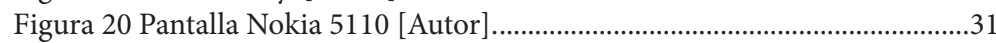

Figura 21 Amplificador TDA2030A $18 \mathrm{~W}$ [Autor].................................................31

Figura 22 Amplificador Ensamblado Con El Chip Tda2050 36w [Autor]..........32

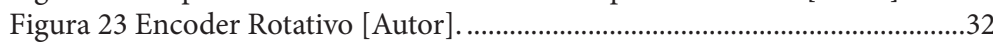


Figura 24 Adaptador AC/DC 110VAC 12VDC 2A [Autor]...................................33

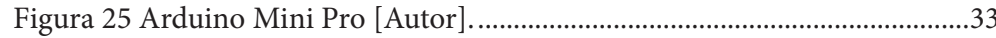

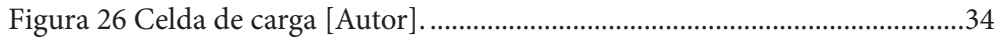

Figura 27 Conversor Análogo A Digital [Autor]. .................................................34

Figura 28 Disipador Raspberry [Autor] ................................................................

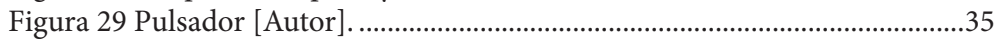

Figura 30 Fabricación tarjeta electrónica [Autor] ................................................35

Figura 31 Tarjeta electrónica terminada [Autor].................................................36

Figura 32 Montaje electrónico terminado y funcionando correctamente

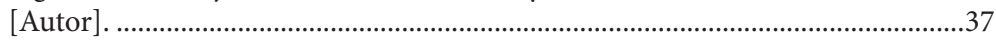

Figura 33 Circuito electrónico completo [Autor]. ................................................38

Figura 34 Esquema del dispositivo diseñado de Generador De

Onda [Autor]............................................................................................................

Figura 35 Primer y Segunda Etapa del Software de control del generador de

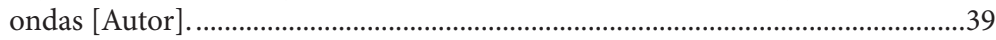

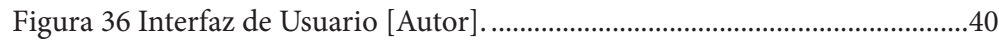

Figura 37 Programa de la Impresa 3D [Autor] ....................................................41

Figura 38 Esquema de piezas software DesignSpark Mechanical 2.0. [Autor]. 41

Figura 39 Vástago [Autor]................................................................................42

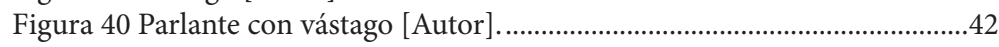

Figura 41 Diseño caja para generador de señales [Autor] . ...................................43

Figura 42 Caja para generador de señales [Autor]...............................................4

Figura 43 Caja para generador de señales ensamblada [Autor] ...........................43

Figura 44 Diseño base equipo [Autor] .................................................................4

Figura 45 Caja para el parlante y amplificador de señal en estado de

impresión [Autor].......................................................................................................44

Figura 46 Caja para el parlante y amplificador de señal en ensamble [Autor]..45

Figura 47 Ensamble mecánico [Autor] ...............................................................45

Figura 48 Diseño de polea lateral [Autor]............................................................46

Figura 49 Diseño de polea frontal [Autor] ...........................................................46

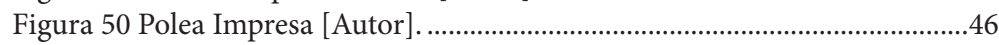

Figura 51 Generador mecánico de ondas ensamblado [Autor]. ..........................47

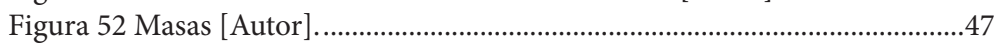

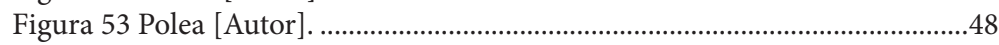

Figura 54 Generador de señales parte frontal [Autor] . .........................................48

Figura 55 Generador de señales parte lateral [Autor]...........................................48

Figura 56 Parte trasera generador de señales [Autor]. .........................................49

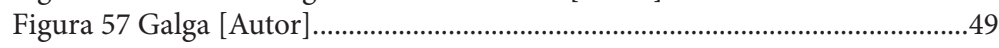

Figura 58 Equipo ensamblado [Autor] ..............................................................50

Figura 59 Frecuencia en función del número de armónicos [Autor]..................51

Figura 60 Frecuencia en función de la raíz cuadrada de la tensión [Autor]......53

Figura 61 Frecuencia en función del inverso de la longitud [Autor]...................54

Figura 62 Comparación tablas de datos con longitud y tensión constante

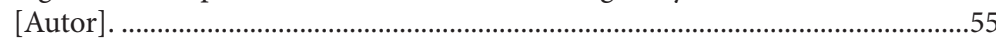

Figura 63 Comparación de graficas de los equipos de laboratorio con el equipo

de Dicoped [Autor] ...............................................................................................5

Figura 64 Comparación de Resultados de los equipos bajo Prueba [Autor].....56

Figura 65 Primera Parte del Certificado de Calibración [Autor]...........................57 
Figura 66 Segunda Parte del Certificado de Calibración [Autor].........................58

Figura 67 Tercera Parte del Certificado de Calibración [Autor]...........................59

Figura 68 Efecto del estroboscopio sobre la cuerda tensa vibrando [Autor].....59

Figura 69 Estroboscopio diseñado e implementado [Autor]. ................................60

Figura 70 Propagación de onda (Young \& Freedman, 2000).................................68

Figura 71 Imagen proyectada en el arreglo de un sensor e imagen muestreada y

cuantificada (Gonzalez \& Woods, 2002).

Figura 72 Dos regiones separadas por un borde vertical. Perfil del nivel de gris

y primer y segunda derivada (Gonzalez \& Woods, 2002)......................................70

Figura 73 Esquema general del sistema propuesto [Autor] ..................................71

Figura 74 Esquema del Prototipo de Cubeta de Ondas [Autor] . ...........................72

Figura 75 Software de la impresora 3D Wanhao [Autor] ......................................73

Figura 76 Circuito integrado del generador de ondas (Electronica, 2018)........73

Figura 77 Sistema de transmisión de onda VCM (Voice Coil Motor) [Autor].74

Figura 78 Elementos de transmisión de Onda al Fluido [Autor].........................74

Figura 79 Cabezales intercambiables para estudio de diferentes tipos de frente

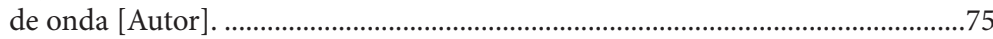

Figura 80 Esquema de cubeta secundaria (izquierda) y pieza finalizada

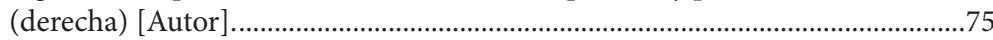

Figura 81 Esquema de cubeta primaria (izquierda) y pieza finalizada (derecha)

[Autor].

Figura 82 Muestra de una Shield instalada en un microcontrador Arduino

(Arduino, 2018) ....................................................................................................

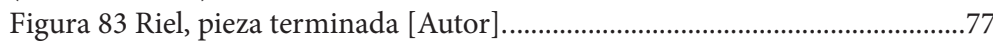

Figura 84 Vista de la pantalla principal del software [Autor].............................78

Figura 85 Vista del módulo de Teoría del Movimiento Ondulatorio [Autor]...78

Figura 86 Vista del módulo de Evaluación [Autor].............................................79

Figura 87 Vista del Módulo del software de control de la cubeta de ondas

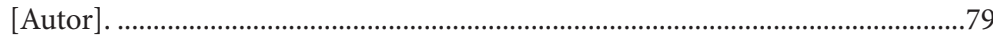

Figura 88 Vista del módulo de Administración del software [Autor] .................80

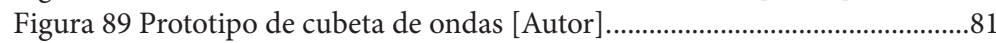

Figura 90 Frente de Onda (Young \& Freedman, 2013).........................................8

Figura 91 Expansión de frentes de onda (Young \& Freedman, 2013).................89

Figura 92 Distancia entre frentes de onda cuando el observador está (Young \&

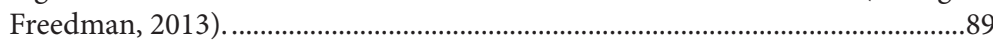

Figura 93 Cuando la fuente se mueve en el medio de transmisión (Young \&

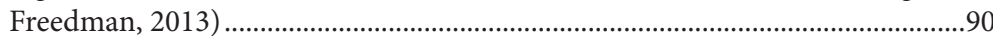

Figura 94 Receptor y fuente acercándose (Young \& Freedman, 2013)..............91

Figura 95 Receptor y fuente alejándose (Young \& Freedman, 2013). .................91

Figura 96 Equipo instalado para el laboratorio de Efecto Doppler [Autor] ......92

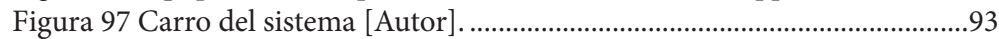

Figura 98 Sistema microcontrolado [Autor] ....................................................93

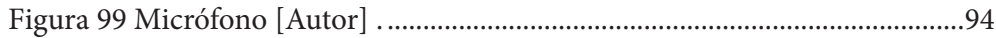

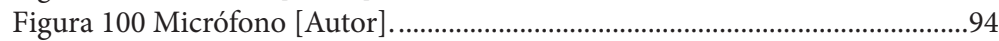

Figura 101 Panel de diagramación [Autor] .........................................................95

Figura 102 Programa en LabView [Autor] ...........................................................95

Figura 103 Subvi de configuración Input [Autor] ...............................................96

Figura 104 Subvi de configuración Output [Autor] ..............................................96 
Figura 105 Subvi de configuración samples [Autor]............................................96

Figura 106 Subvi de configuración [Autor] .........................................................97

Figura 107 Subvi de configuración Waveform [Autor]........................................97

Figura 108 Subvi de configuración Sound Output [Autor] ..................................97

Figura 109 Subvi de configuración Generación de Onda [Autor].......................98

Figura 110 Subvi de configuración Sound Input [Autor]......................................98

Figura 111 Subvi de configuración Tone Measurements [Autor]........................98

Figura 112 Subvi de configuración Frecuencia Emitida y Recibida [Autor].....99

Figura 113 Prototipo Final Funcional [Autor] .....................................................99

Figura 114 Modos de oscilación en una cuerda tensa (Young \& Freedman,

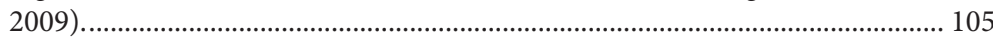

Figura 115 Ciclo de una Onda [Autor] ............................................................... 105

Figura 116 Amplitud de una Onda (Serway \& Jawett, 2008b) ........................ 106

Figura 117 Longitud de Onda (Young \& Freedman, 2009) ............................... 106

Figura 118 Periodo de una Onda (Young \& Freedman, 2009) ........................... 106

Figura 119 Velocidad de una Onda (Young \& Freedman, 2009) ...................... 107

Figura 120 Oscilación (Young \& Freedman, 2009) ........................................... 107

Figura 121 Prototipo ensamblado con todas sus partes [Autor]....................... 108

Figura 122 Varillas de acero en el generador mecánico de ondas [Autor]. .... 109

Figura 123 Varillas de acero en el soporte de la galga [Autor] ......................... 109

Figura 124 Varillas en su respectivo soporte [Autor]......................................... 109

Figura 125 Figura 6. Ranura en la parte trasera del generador [Autor] .......... 110

Figura 126 Polea insertada en el generador mecánico de ondas [Autor]....... 110

Figura 127 Galga con cuerda [Autor] ............................................................ 111

Figura 128 Vástago vista superior [Autor] .........................................................11

Figura 129 Vástago Vista lateral [Autor]........................................................... 112

Figura 130 Tapa del vástago [Autor] .............................................................. 112

Figura 131 Polea vista superior [Autor] ......................................................... 113

Figura 132 Polea vista lateral [Autor]............................................................... 113

Figura 133 Masas colgando de la cuerda [Autor] ............................................... 114

Figura 134 Cable conector de tres patas [Autor].............................................. 114

Figura 135 Conector del generador mecánico de ondas, donde irá uno de los

conectores del cable [Autor].............................................................................. 115

Figura 136 Forma correcta de conectar el cable [Autor]................................... 115

Figura 137 Conector de 3 patas en el generador de señales [Autor]............... 116

Figura 138 Cable que viene por defecto para soporte de la galga [Autor]...... 116

Figura 139 Conector en la parte trasera del generador de señales [Autor].... 117

Figura 140 Cargado conectado al generador de señales [Autor] ...................... 117

Figura 141 Armónico \# 2 expuesto a luz estroboscópica [Autor]..................... 119

Figura 142 Propagación de onda (Young \& Freedman, 2000)......................... 121

Figura 143 Prototipo Cubeta de Ondas [Autor] ................................................ 124

Figura 144 Onda y componentes (Lab, 2019).................................................. 126

Figura 145 Efecto Doppler (Lab, 2019).......................................................... 127

\section{Índice de Tablas}

Tabla 1 Frecuencias de armónicos con $\mathrm{L}=1.26$ y $\mathrm{T}=2.09 \mathrm{~N}$ [Autor] ................51

Tabla 2 Registro de los datos suministrados para el cambio de

tensión [Autor] 
Tabla 3 Datos de cambio de longitud y sus respectivas frecuencias [Autor].....54

Tabla 4 Datos de Frecuencias según el armónico [Autor].................................. 118

Tabla 5 Datos de longitud y frecuencia [Autor] .................................................. 118

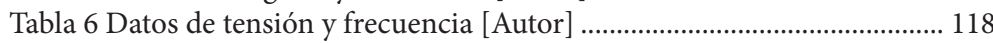

Tabla 7 Datos para Masa [Autor] ....................................................................... 118

Tabla 8 Efecto Doppler Datos de Laboratorio [Autor] ....................................... 127 



\section{INTRODUCCIÓN}

Desde hace varios años, el grupo de investigación DICOPED (Diseño y Construcción de Prototipos Para Experimentos de Demostración) se ha propuesto, como proyecto general, el diseño y la construcción de equipos de laboratorio con el objetivo de que, en su realización, estos equipos no resulten ser demasiado costosos, que sean fáciles de manejar y de almacenar; además, ha buscado tener en cuenta que su mantenimiento, debido a que su desarrollo y construcción se hace en la región, no tenga ningún inconveniente de carácter económico ni de pérdida de tiempo.

Dentro de este contexto, se han presentado convocatorias realizadas por nuestra Universidad, donde la participación en las mismas nos ha permitido desarrollar algunos equipos, los cuales se han podido utilizar en muestras tecnológicas, visitas a diferentes Instituciones Educativas con el objetivo de retroalimentar los conceptos de la física vistos en clase. Al mismo tiempo, hemos podido comparar algunos equipos con los adquiridos en el exterior, a través de licitaciones que hace la Universidad, con empresas de la región, que distribuyen equipos a nivel nacional, encontrando resultados muy positivos desde el punto de vista de la experimentación. 
Estas comparaciones se han hecho realidad mediante el uso de las herramientas que conocemos, para llevar a cabo la incertidumbre de medición de cada uno de los equipos diseñados y construidos por el grupo.

Es de anotar que la gran mayoría de equipos que se utilizan en las Instituciones Educativas para la experimentación en Física, son traídos del exterior, especialmente de Estados Unidos y Alemania, lo cual hace mucho más difícil su implementación, debido a que las guías son demasiado complejas. Así mismo, el almacenamiento acarrea dificultades, ya que se construyen equipos muy robustos $y$, lógicamente, su mantenimiento también es complejo, incluyendo en ello el aumento significativo en lo que se refiere a los costos.

Ha sido para nosotros una ardua labor poder implementar equipos de laboratorio innovadores y que tengan la misma o mejor precisión que los equipos comprados en el exterior; sin embargo, el hecho de poder fusionar la física, los conocimientos en electrónica e implementar los fundamentos de la mecánica para el desarrollo de las partes de los equipos ha permitido que nuestro grupo de investigación haya convertido esta labor en una prueba piloto para el diseño y la construcción de equipos de laboratorio en la enseñanza de la física.

Por lo anterior, y basados en la misma metodología, se hace a continuación un resumen sobre la forma cómo se diseñaron y construyeron tres prácticas para el Estudio de Movimiento Ondulatorio. Estas prácticas son las siguientes: Cuerda tensa, Cubeta de ondas y Efecto Doppler, prácticas que permiten la demostración experimental de la teoría ondulatoria vista generalmente en los cursos de física III. 


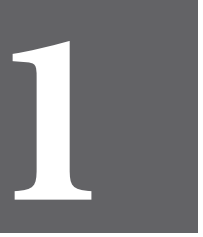

CAPÍTULO

UNO 



\section{Diseño y Construcción del Prototipo Experimental para la Cuerda Tensa}

\subsection{Introducción}

El estudio de la física es fundamental para todas las áreas del conocimiento científico, desde ingenierías hasta las matemáticas puras, teniendo como prioridad la asimilación del conocimiento sobre los conceptos básicos que permitan iniciar estudios más fuertes, posteriormente, de mayor envergadura y aplicabilidad al mundo real.

Partiendo de los conceptos físicos adquiridos en un aula de clase, muchos de los fenómenos y sucesos de nuestra vida cotidiana tienen una explicación. Sin embargo, para poder interiorizar un concepto es necesario crear prácticas experimentales o vivenciales que muestren de una manera más clara un fenómeno físico.

En este contexto, el estudio y análisis del movimiento de una onda estacionaria es de gran importancia para la física, las prácticas experimentales en las instituciones y universidades buscan demostrar y aplicar los diferentes comportamientos de la naturaleza, para de este modo lograr observar y comprender cuáles son los cambios que se generan; por ejemplo, una onda estacionaria en una cuerda tensa, sometida a diferentes medios de propagación (material de la cuerda), mostrando la importancia estudiar los cambios en la frecuencia, la amplitud, la tensión y la longitud. Es así como una onda en movimiento, que presenta una propagación a través de un medio (cuerda, agua, aire) produce, a su vez, uno o más armónicos o nodos de oscilación.

El presente trabajo propone, con la creación de un prototipo para la experimentación del fenómeno de ondas en una cuerda, que los estudiantes y docentes evidencien los conceptos básicos sobre una onda estacionaria aplicados en una cuerda tensa y, de este modo, consolidar un conocimiento partiendo de la práctica experimental mientras se cumple con características de fácil manejo y portabilidad.

\subsection{Objetivos}

\subsubsection{Objetivo General}

- Diseñar e implementar un prototipo para la práctica experimental de ondas estacionarias en una cuerda tensa.

\subsubsection{Objetivos Específicos}

- Diseñar e implementar un software que sea interactivo para el usuario, que permita el manejo del prototipo y que realice los cálculos pertinentes a la práctica.

- Diseñar e implementar un sistema mecánico óptimo que integre todos los elementos del prototipo 
- Diseñar e implementar un sistema electrónico que se adapte al prototipo planteado.

- Elaborar un manual de usuario que facilite el manejo del prototipo.

- Diseñar una guía para la práctica experimental de ondas estacionarias en una cuerda tensa.

\subsection{Antecedentes}

El presente trabajo realza la importancia de la experimentación como una herramienta que permite la asimilación de los conceptos básicos de la física para alumnos y docentes, como es el caso de las ondas en una cuerda tensa. Igualmente, los avances tecnológicos surgen a partir de la interiorización de estos conceptos y su puesta en práctica como solución a los problemas del mundo.

Con las nuevas tecnologías y todo el avance en investigación, se llega a la necesidad de encontrar nuevos mecanismos que ayuden a crear una forma más clara y sencilla de transmitir el conocimiento y, a su vez, compartir experiencias que nos lleve a construir mejores contenidos de las asignaturas. Por esto, nos centramos en el estudio del funcionamiento mecánico y electrónico de la cuerda tensa para poder encontrar las oportunidades que brinda el diseño y construcción de prototipos que fomenten el aprendizaje de leyes físicas y la aplicabilidad de los contenidos en un aula de clase.

En este contexto, el trabajo de D. Gómez titulado "Sobre los cuasi-nodos en las oscilaciones de cuerdas reales" (Gómez \& Welti, 2004), advierte la importancia del uso de un equipo de cuerda tensa para el estudio de los cuasi-nodos presentados en las oscilaciones forzadas. Contempla dentro de sus conclusiones, la importancia de la experimentación como una herramienta clave para el aprendizaje de fenómenos físicos. Así mismo, concluye que la experiencia le permitió introducir el concepto de amplitud de respuesta, o curva de resonancia del sistema, que relaciona la entrada (fuerza impulsora) y la salida (amplitud de las oscilaciones de un dado punto de la cuerda) en función de la frecuencia.

Por otra parte, el trabajo de Roatta "Efecto Doppler para pulsos y su representación en el plano (x, t)" (Roatta \& Welti, 2009), utiliza el esquema teórico de ondas en una cuerda tensa para analizar el efecto Doppler, como es sabido, siempre se le ha atribuido este efecto como único de las ondas armónicas, pero Roatta logra demostrar que el efecto está vinculado con las compresiones y expansiones en el dominio del espacio y el tiempo de cualquier tipo de onda. De este modo, realza la importancia del estudio y análisis previo de ondas mecánicas que se propagan a través de una cuerda tensa, como base, antes de introducir conceptos como el de efecto Doppler.

Igualmente, Alvarado et al. en su trabajo "Modos de oscilación en cuerdas con densidad constante por mitades: análisis y demostración experimental" (Rodriguez Zureta, Alvarado Bustos, Alvarado Bustos y Zavala Ramírez, 2002) estudia algunas soluciones propias de una cuerda, caracterizada por una densidad de masa constante en sus mitades (homogénea por mitades), sujeta por sus dos extremos y sometida a tensión constante, lo que resulta análogo al del planteamiento de la ecuación de Schrödinger para potenciales constantes por tramos, de modo que la solución buscada admite el uso de métodos de acoplamiento de soluciones, usuales en mecánica cuántica introductoria. De esta forma, concluyen que el uso de demostraciones experimentales como el de la onda tensa unido con el método propuesto es una forma amena de aplicar conocimientos que requerirán en cursos posteriores (mecánica cuántica) a cursos fundamentales como el de mecánica de ondas.

Por último, Gómez et al. en su trabajo "Efectos de la inserción de elementos de parámetros concentrados sobre los modos normales de oscilación de un medio finito continuo" (Gómez \& Welti, 2004) realza la importancia del estudio de la influencia de parámetros concentrados sobre los modos normales de oscilación de un medio continuo de dimensiones finitas, además realiza una analogía entre el comportamiento de estos parámetros en los fenómenos ondulatorios de una cuerda cargada con una masa puntual, una antena dipolo cargada con una inductancia concentrada y un tubo con una cámara de expansión, muestra que las ecuaciones que determinan las frecuencias propias de estos tres sistemas son prácticamente idénticas entre sí.

Se presentan algunos referentes de diferentes equipos que comprueban leyes físicas, entre ellos tenemos el Equipo experimental de la ley de Snell y Ley de Hooke, los cuales se describen a continuación, importantes para el presente trabajo por estar contenidos dentro del inventario del grupo de investigación DICOPED (DICOPED, 2018). 


\subsection{Estado del Arte}

\subsubsection{Equipo Experimental de la Ley de Snell}

Es un prototipo electrónico que tiene como función mostrar experimentalmente qué sucede con un rayo cuando traspasa un medio, en este caso se quiere probar la ley de Snell, para ello se diseña y se construye un equipo que posee todos los elementos necesarios para trabajar la óptica geométrica y demuestra experimentalmente el comportamiento de un haz de luz en un medio.

Del mismo modo, se tiene un experimento donde se observa el comportamiento de un rayo incidente y un rayo reflejado al pasar por un medio como el acrílico o el agua.

Con el fin de encontrar respuestas a el comportamiento de un haz de luz en el momento de pasar por diferentes elementos, el grupo de investigación DICOPED diseña y construye un equipo autónomo llamado ley de Snell, el cual demuestra de una forma didáctica la interacción entre un rayo de luz y el acrílico teniendo en cuenta el cambio del medio, el ángulo incidente y refractado del rayo (DICOPED, 2018)

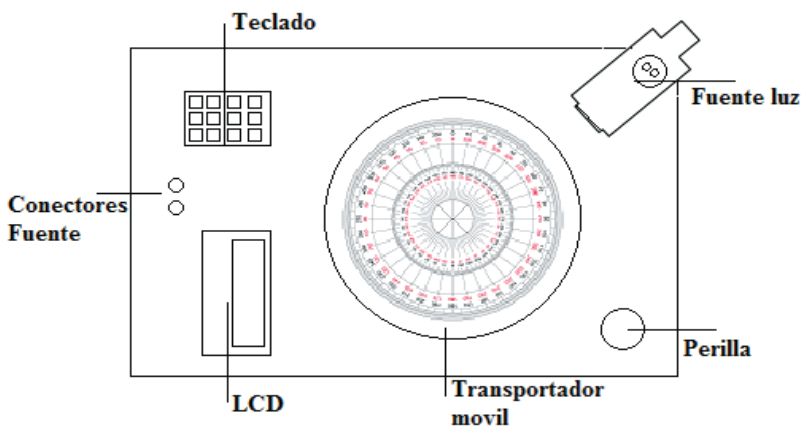

Figura 1 Diseño del equipo de la Ley de Snell (DICOPED, 2018).

\subsubsection{Equipo Experimental de la Ley de Hooke}

Uno de los elementos mecánicos que puede almacenar energía es el resorte, este elemento almacena energía dependiendo de su compresión o elongación, un ejemplo claro de ello lo constituye el sistema masa-resorte.

En términos generales, el sentido de diseñar y construir un prototipo autónomo para la práctica experimental de la ley de Hooke radica en que, actualmente, existen gran cantidad de falencias instrumentales en el contexto de las prácticas de laboratorio de física en la academia.

El equipo desarrollado está conformado por un circuito electrónico microcontrolador, un sensor de distancia y un sistema mecánico masa-resorte, que permite determinar la elongación del resorte en función de la masa y, a partir de ellas, calcular la constante del mismo.

El aprendizaje comprende diferentes formas y métodos, basándose en la interpretación absoluta y significativa de una temática en particular, por ello, el propósito del proyecto se direcciona al ámbito escolar como a nivel de educación superior, con el fín de afianzar los conocimientos adquiridos. Todos los participantes de este proceso de aprendizaje (docentes, estudiantes, directivos, etc.) de alguna u otra manera están en la búsqueda de mejoras para la construcción y difusión del conocimiento, aplicando estrategias didácticas que fomenten la generación de espacios idóneos para la interacción entre los sujetos involucrados (Arcos, Cruz Muñoz, Marín Ramírez, Quiroga Hurtado y Medina, 2011). 


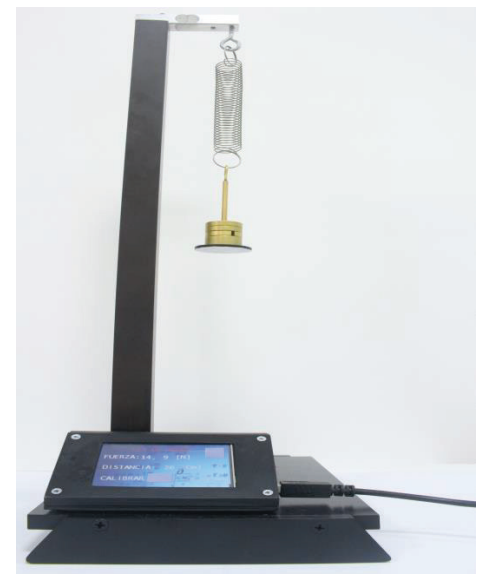

Figura 2 Equipo De La Ley De Hooke (Arcos et al., 2011).

\subsubsection{Equipos Existentes para Experimentos Ondulatorios}

Las prácticas realizadas en las diferentes instituciones educativas, en lo concerniente a las relacionadas con el movimiento ondulatorio, pudo evidenciar el uso de herramientas de un elevado valor económico, dado que no se cuenta con herramientas en el medio que permitan de forma fácil y económica generar ondas mecánicas para el estudio de los fenómenos en cuestión.

Dentro de los experimentos observados, se pueden encontrar algunas posibilidades como la implementación de un timbre para la excitación puntual de la cuerda tensada en ambos extremos (Arenas, 2018).

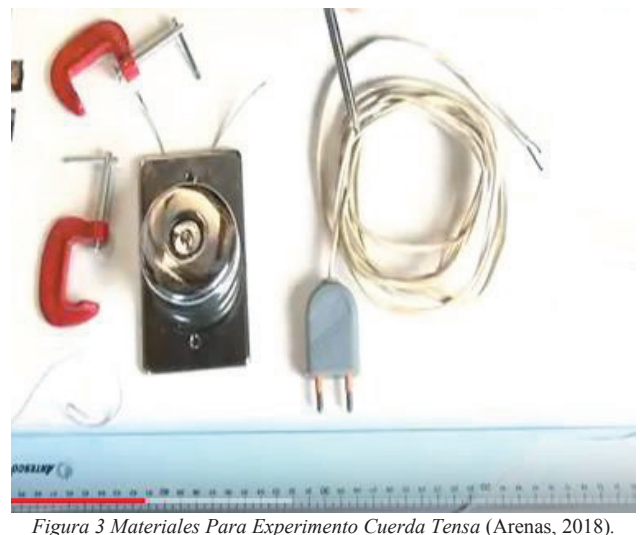

Así mismo, se encontraron dispositivos que se encargan de dicha labor, entre ellos se pueden enumerar.

1. Tecnoedu- impulsor de ondas mecánicas. 
Sebastián Martínez García - Diego Fernando Salazar - Andrés Felipe Osorio Ramírez

Leonardo Bohórquez Santiago - Hugo Armando Gallego Becerra

Leonardo Bohórquez Santiago - Hugo Armando Gallego Becerra

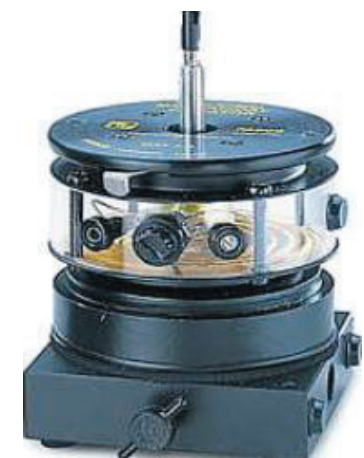

Figura 4 Tecnoedu- impulsor de ondas mecánicas (TecnoEdu, 2018),

Este generador de ondas mecánicas de marca Pasco es utilizado en el laboratorio de física 3 donde los estudiantes lo conectan a un generador de señales para su funcionamiento.

2. Economy Wave Driver

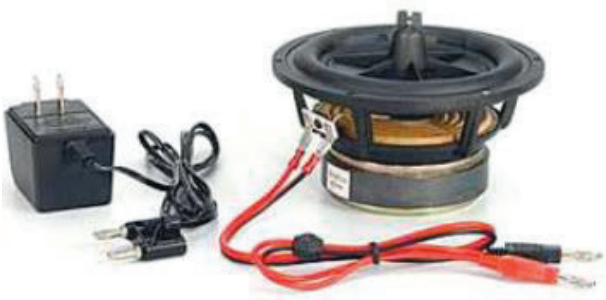

Figura 5 Economy Wave Driver (TecnoEdu, 2018).

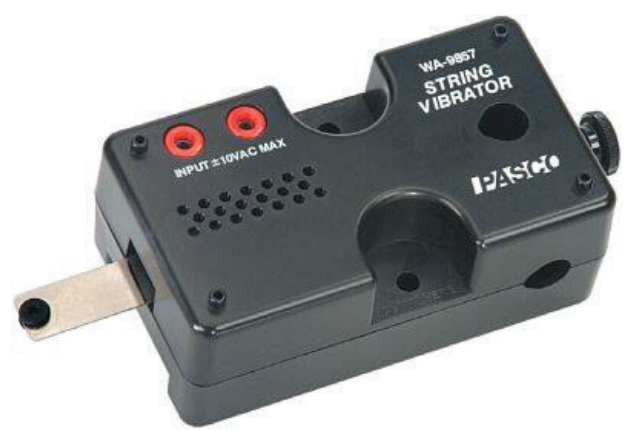

Figura 6 Generador de Ondas Pasco (Pasco, 2018). 
Finalmente, se observó el desarrollo de la práctica en el laboratorio de física 3 de la UTP, donde se pudo apreciar que se utiliza un equipo de la marca Xplorer que se muestra en la siguiente figura:

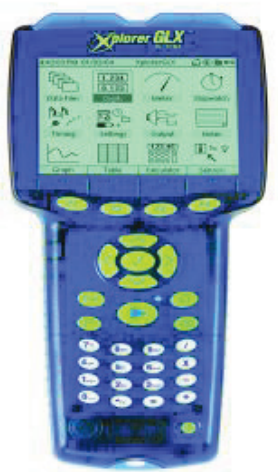

Figura 7 Equipo Xplorer GLS (Arcos et al., 2011)

De lo anterior se puede evidenciar que la mayor dificultad de desarrollo del prototipo se basa en la construcción del generador de ondas mecánicas, dado que es una herramienta muy costosa y de la cual se encuentra poca información en la bibliografia.

De igual forma, tanto el generador de ondas mecánicas como el generador de frecuencias son equipos que en el mercado tienen un alto costo y a su vez los problemas que surgen cuando uno de estos equipos falla son muchos; por ejemplo, encontrar un generador con una buena resolución y que se caractericen por tener los mejores armónicos posibles.

\subsection{Marco Teórico}

En el marco del presente proyecto, es importante reconocer los conceptos básicos conectados con las ondas en una cuerda tensa, desde el punto de vista de la electrónica y la programación, por esto se plantea una breve descripción de los conceptos que fueron considerados como los más importantes, expresados a continuación.

Onda: es un movimiento o alteración que se produce y se propaga a través de los diferentes medios donde se pueda generar, como el agua, aire, cuerda, entre otras; dichas ondas se clasifican según el medio donde se produce las cuales se pueden distinguir como ondas mecánicas y ondas electromagnéticas. Además existen diferentes formas de ondas, onda senoidal, onda cuadrada, entre otras (Serway \& Jawett, 2008b).

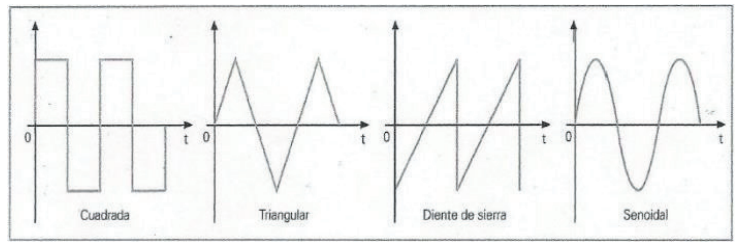

Figura 8 Tipos de Ondas (Ruben, 2017)

En la onda no hay nada material que se esté propagando, se trata del movimiento coordinado de muchos elementos como por ejemplo cuando se acoplan muelles unos con otros, cuando varias capas de aire se mueven unas a otras, también sucede cuando 
un campo eléctrico induce uno magnético y viceversa. Se debe tener en cuenta que el punto de una onda cambia en cada lugar del espacio y del tiempo de esta forma se crea una ecuación matemática que cumpla con esas condiciones (Serway \& Jawett, 2008b).

Onda Mecánica: se conoce como onda mecánica a la perturbación que viaja a través de un medio elástico, transportando energía. Se consideran dos tipos de ondas, ondas transversales donde las partículas que conforman el medio se mueven perpendicular a la dirección de la propagación, y ondas longitudinales donde las partículas que conforman el medio se mueven en un va y viene en la misma dirección de la propagación (Serway \& Beinncher, 2005).

Una onda trasversal es periódica, es decir, que tenemos un movimiento armónico simple donde su ecuación, la función general de la onda, se puede describir de la siguiente manera:

Donde

$$
y(x, t)=A \cdot \operatorname{sen}(k x \pm \omega t+\emptyset)
$$

A: amplitud de la onda

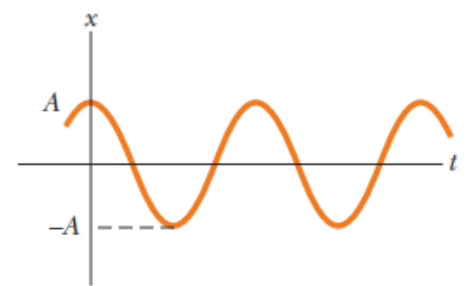

Figura 9 Amplitud de una Önda (Serway \& Jawett, 2008a)

K: el número de veces que se encuentra la onda de 0 a $2 \pi$, observar figura 10 , y está dado por la ecuación:

$$
K=\frac{2 \pi}{\lambda}
$$

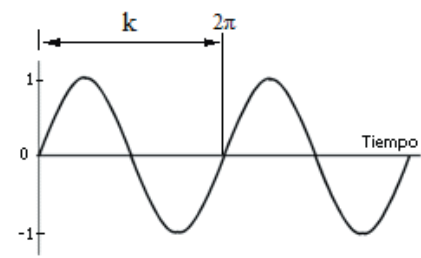

Figura 10 Numero de Onda [Autor]

$\omega$ : frecuencia angular dada por la fórmula

$$
\omega=k \cdot v=2 \pi f=\frac{2 \pi}{T}
$$

Teniendo en cuenta que en una onda están presentes la longitud $\lambda$, la frecuencia $f$ y la velocidad $v$, se puede apreciar una relación entre ellas de la siguiente manera:

$$
\begin{aligned}
& \lambda=v / f \\
& f=v / \lambda \\
& v=\lambda . f
\end{aligned}
$$

Si se considera una cuerda de longitud $\mathrm{L}$ y densidad de masa $\mu$ sujeta por sus extremos donde su posición inicial es $\mathrm{X}=0 \mathrm{y}$ Su posición Final es $\mathrm{X}=\mathrm{L}$, la cuerda se le integra una alteración llamada vibración por medio de un generador mecánico, conectado 
a un generador de ondas sinodales, las cuales al ir variando su frecuencia mostrará una serie de vientres o armónicos donde dos señales se superponen, mostrando así los nodos y puntos máximos de oscilación (Alonzo \& Finn, 1970).

Cuando la cuerda perturbada entra en resonancia con el generador mecánico que produce el movimiento, se presentan los distintos modos propios de oscilación y los desplazamientos transversales tendrán su máxima amplitud. Para encontrar las frecuencias $f_{n}$ que corresponden a cada modo propio de oscilación se deben tener en cuenta las siguientes condiciones de frontera (Young \& Freedman, 2009).

$$
\begin{aligned}
& y(0, t)=0 \\
& y(L, t)=0
\end{aligned}
$$

Si tenemos que $K L=n \pi$ con $n=1,2,3 \ldots$ y consideramos las ecuaciones (2) y (6) obtenemos la ecuación de las frecuencias correspondientes a los modos propios de oscilación de la cuerda.

$$
f_{n}=\frac{n v}{2 L}
$$

De las ondas transversales en una cuerda podemos tener que la velocidad de propagación a lo largo de la cuerda es:

$$
v=\sqrt{\frac{T}{\mu}}
$$

Siendo T la tensión de la cuerda, la expresión para las frecuencias de los modos de vibración quedaran definidas por:

$$
f_{n}=\frac{n}{2 L} \sqrt{\frac{T}{\mu}}
$$

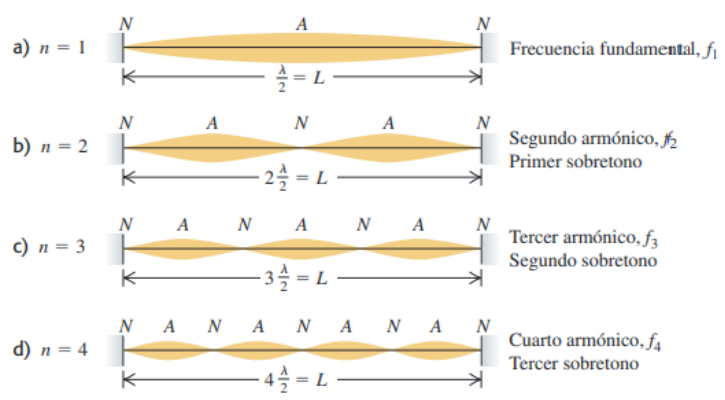

Figura 11 Modos de Oscilación de una cuerda Tensa (Serway \& Jawett, 2008a)

Onda estacionaria: se conoce como estacionaria a la presencia de puntos que son inmóviles los cuales son llamados nodos, consiste en una onda que viaja a través de una cuerda tensa, tubo de aire, entre otros, donde interfieren dos ondas con la misma amplitud y frecuencia, pero en sentido contrario (Young \& Freedman, 2009).

Frecuencia: término asignado cuando un suceso se repite bajo las mismas condiciones en un periodo determinado de tiempo. La unidad de medida para la frecuencia es en $\operatorname{Hertz}(\mathrm{Hz}=1 / \mathrm{s})$ y respectiva fórmula es (Serway \& Beinncher, 2005):

$\mathrm{f}=$ frecuencia $f=\frac{1}{T}$

$\mathbf{T}=$ periodo

Ciclo: suceso que se repite en cierto periodo de tiempo, son fenómenos periódicos que siempre vuelven a su configuración inicial (Young \& Freedman, 2009). 


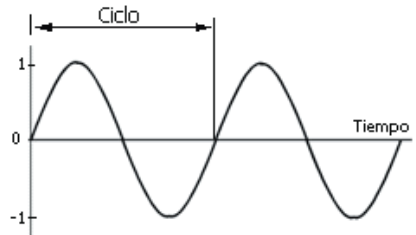

Figura 12 Ciclo de una Onda [Autor]

Amplitud: es una medida que está presente en una onda debido a su oscilación, y de acuerdo con esta oscilación se genera una variación a lo largo de la onda: la amplitud nos ayuda a determinar dicha variación (Young \& Freedman, 2009) (ver figura 9).

Longitud de Onda: teniendo en cuenta que en una onda se puede formar una función seno o una función coseno, en las cuales se generan picos, la distancia que hay entre pico y pico se le denomina longitud de onda (Young \& Freedman, 2009).

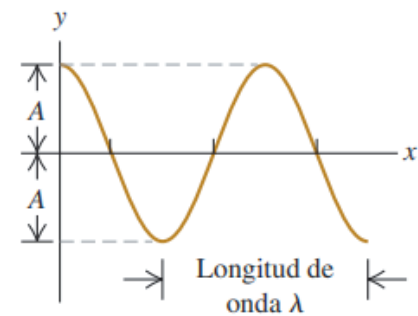

Figura 13 Longitud de Onda (Young \& Freedman, 2009)

Periodo: es el tiempo que transcurre a lo largo de un fenómeno hasta que este nuevamente se repite (Young \& Freedman, 2009).

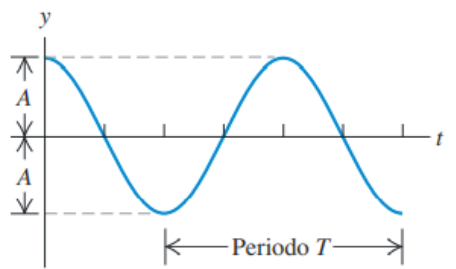

Figura 14 Periodo de una Onda (Young \& Freedman, 2009)

Velocidad: es el ritmo con el cual la onda viaja. Esta velocidad está dada por (Young \& Freedman, 2009):

$$
V=\frac{\lambda}{T}=f \cdot \lambda
$$




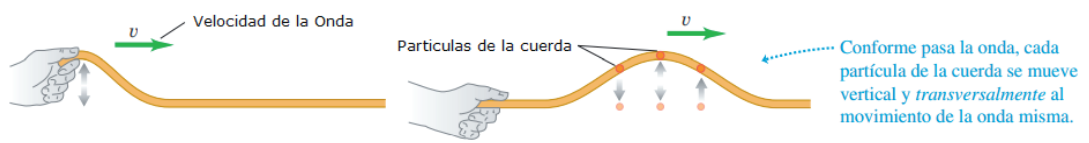

Figura 15 Velocidad de una Onda (Young \& Freedman, 2009)

Oscilación: es el movimiento de un lado a otro partiendo de su punto o eje central que se presenta cuando ocurre una perturbación o variación de un sistema (Young \& Freedman, 2009).
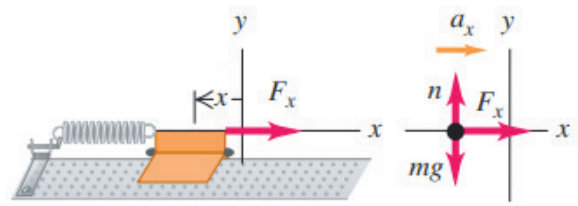

Figura 16 Oscilación (Young \& Freedman, 2009)

Nodos: son los puntos inmóviles a lo largo de la onda estacionaria (Young \& Freedman, 2009).

Antinodos: en una cuerda tensa se puede producir un antinodo o también llamados vientres, los cuales al ir variando la frecuencia de oscilación producen puntos donde tienen una máxima amplitud (Young \& Freedman, 2009).

Armónicos: los armónicos de una cuerda tensa se presentan cuando se generan frecuencias de resonancia donde las dos ondas que se encuentran están vibrando a la misma frecuencia, pero en sentido contrario (Young \& Freedman, 2009).

\subsection{Metodología y Desarrollo}

Dada las necesidades del prototipo en cuanto a las variables físicas que se deben manipular (frecuencia, amplitud, periodo, masas, tensiones), se optó por dividir el diseño y construcción en dos (2) partes significativas. Por un lado, el diseño y construcción de un generador de ondas mecánicas conectado a un generador de señales para el control de la frecuencia, amplitud de oscilación y, por el otro, la implementación y acondicionamiento de un sensor que permita realizar la medición de la tensión presente en la cuerda en tiempo real.

Así mismo, se definió el uso de dos barras de acero inoxidable para las estructuras principales del prototipo, y el diseño e impresión en 3D de las piezas que requieran de un mayor detalle para su funcionalidad.

\subsubsection{Desarrollo Electrónico}

\subsubsection{Diseño y Construcción del sistema electrónico}

El diseño electrónico del prototipo se basa en una placa de desarrollo Teensy 3.2 y una tarjeta micro controlada Arduino, con el fin de controlar cada uno de los periféricos (Celda de carga, parlante o timbre para la amplificación de los pulsos).

Para el desarrollo electrónico se diseñó el esquemático del circuito que nos describe cada uno de los componentes y sus puntos de conexión de una forma sencilla e intuitiva de comprender. 
Sebastián Martínez García - Diego Fernando Salazar - Andrés Felipe Osorio Ramírez Leonardo Bohórquez Santiago - Hugo Armando Gallego Becerra

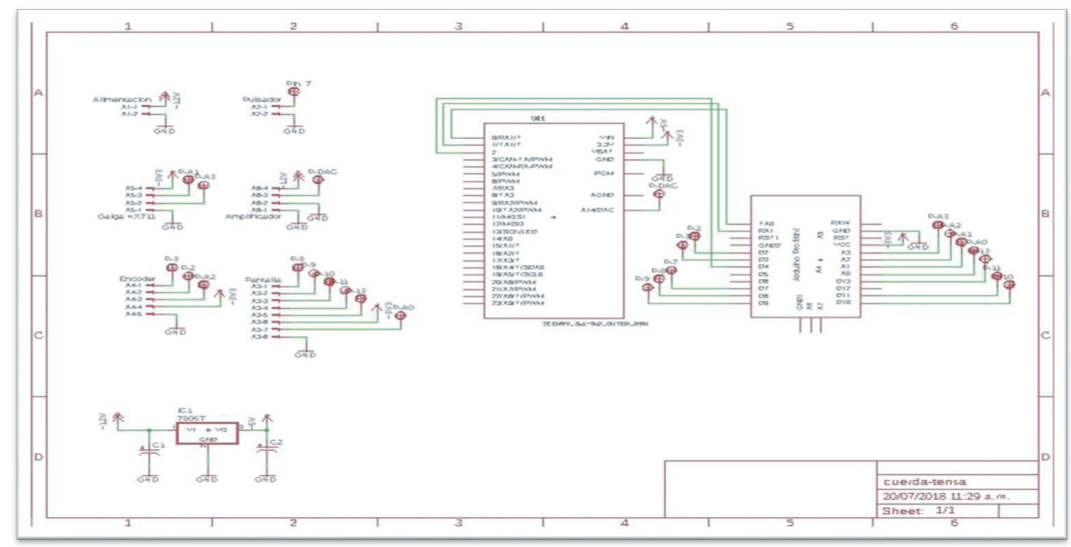

Figura 17 Esquema del Circuito [Autor].

Del mismo modo, se realizó el diseño del PCB culminado en el software de desarrollo de tarjetas impresas con sus respectivas conexiones lista para el proceso de fabricación.

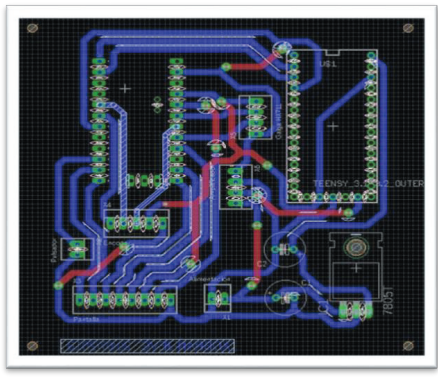

Figura 18 Diseño PCB [Autor]

\subsubsection{Proceso Electrónico}

Para el desarrollo del proyecto es necesario dar claridad de los elementos a utilizar para la creación del generador de ondas mecánicas y el generador de señales, del mismo modo es necesario mostrar el ensamble mecánico del equipo. 


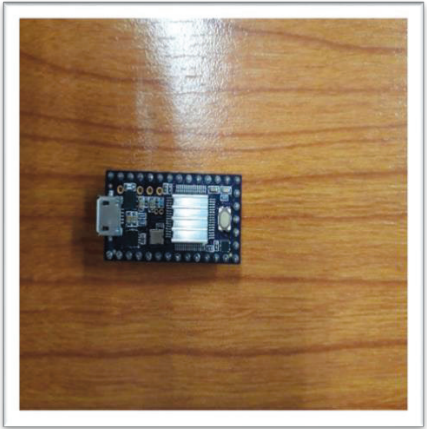

Figura 19 Placa teensy. [Autor]

La placa Teensy es un Sistema completo de Desarrollo de microcontroladores de 32 bits con puerto USB de forma nativa, convirtiendo a estas placas en un sistema de espacio muy pequeño. Estas placas cuentan con alto rendimiento, gran memoria, recursos abundantes. En el caso de la cuerda tensa, la placa que se implemento fue la Teensy 3.2. que cuenta con las siguientes especificaciones:

- $\quad$ Procesador: 32-bit ARM Cortex-M4 96 MHz CPU (MK20DX256VLH7)

- Memoria: 256K, 64K RAM, 2K EEPROM

- 14 pines analógicos de alta resolución (13 bits usables y 16 bit en hardware)

- 34 pines digitales I/O (10 son compartidos con los analógicos)

- DMA de 16 canales

- 12 salidas PWM

- 7 temporizadores (Timers)

- $\quad$ DMA dedicado para USB

- 3 puertos UARTs (serie)

- Protocolos soportados: SPI, I2C, I2S, modulador IR

- $\quad$ I2S (para interfaz de audio de alta calidad)

- $\quad$ Soporta RTC añadiendo un cristal de $32.768 \mathrm{KHz}$ y batería externa

- 4 canales DMA para uso general (separados del USB)

- Dimensiones: $35 \times 18 \mathrm{~mm}$

- Entradas táctiles 


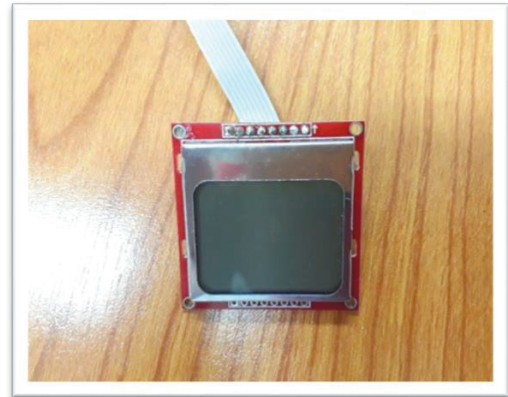

Figura 20 Pantalla Nokia 5110 [Autor].

Esta pequeña pantalla de 84 x 48 pixeles fue una alternativa muy económica y práctica para mostrar información de cualquier tipo de proyecto que se esté realizando. Las ventajas de esta pequeña pantalla son: graficar imágenes, funciones, texto, figuras, etc.

Fácil de programar (su programación es muy similar a la lcd 16x2 que es un clásico en el mundo de la programación de microcontroladores), muy económica para la gran cantidad de prestaciones que nos ofrece esta pequeña pantalla.

\subsubsection{Amplificador de Audio Tda2030a 18w}

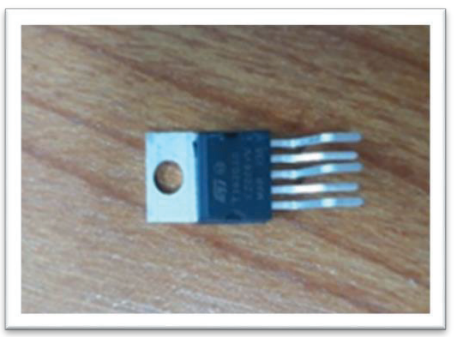

Figura 21 Amplificador TDA2030A 18 W [Autor].

A la placa se le reemplazó el chip por el TDA2050 36w debido a que la amplitud que generaba el otro era insuficiente para poder observar el fenómeno de la cuerda vibrando.

Este amplificador es un simple chip que es capaz de aumentar la ganancia de reproductores de audio para manejar parlantes de mediana potencia con muy baja distorsión en el sonido y poca perdida de potencia en calor. 


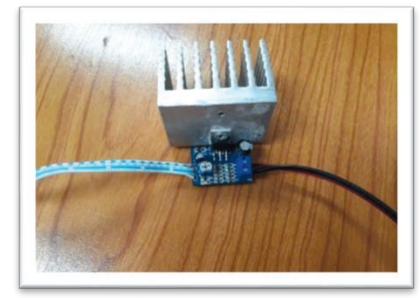

Figura 22 Amplificador Ensamblado Con El Chip Tda2050 36w [Autor].

\subsubsection{Encoder Rotativo}

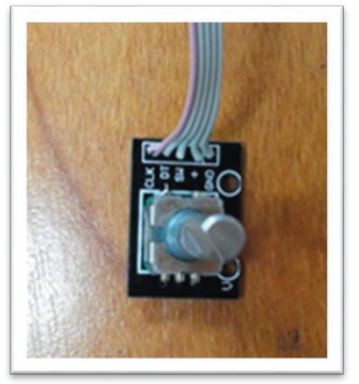

Figura 23 Encoder Rotativo [Autor].

El encoder es un dispositivo electromecánico que permite codificar el movimiento mecánico en distintos tipos de impulsos eléctricos: digitales binarias, analógicos en función de una onda, pulsos, etcétera. De este modo, un encoder es una interfaz entre un dispositivo mecánico móvil y un controlador.

En este proyecto se implementó un encoder incremental, el cual genera pulsos que codifican la rotación, ya sea en ciclo horario o antihorario, con 20 pulsos por ciclo. A diferencia de un potenciómetro, este encoder no posee topes mecánicos, por lo que puede girar libremente. El encoder puede ser pulsado, de modo que se puede usar para seleccionar algo.

Es muy útil para proyectos de audio, HMI, búsqueda y selección de archivos. 


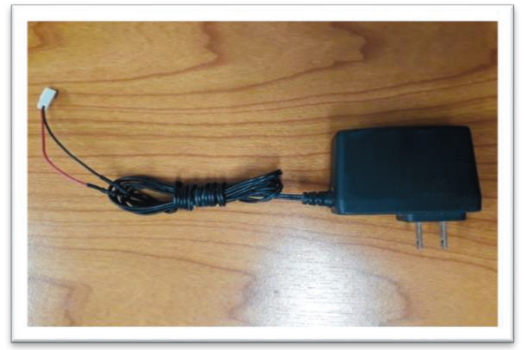

Figura 24 Adaptador AC/DC 110VAC 12VDC 2A [Autor].

Este adaptador toma los $120 \mathrm{v}$ AC de la red de energía local y los convierte en $12 \mathrm{v}$ DC a $2 \mathrm{~A}$ para alimentar todo el sistema

\subsubsection{Arduino Mini Pro Mega328 5v 16mhz}

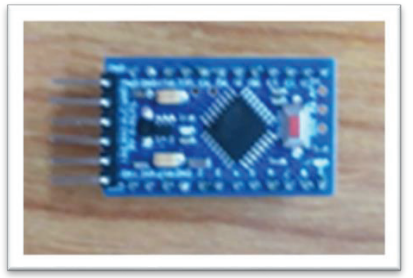

Figura 25 Arduino Mini Pro [Autor].

Esta pequeña placa de desarrollo cuenta con las mismas prestaciones del Arduino UNO, pero no cuenta con puerto USB. Esta placa, básicamente, cuenta con los componentes necesarios para que el microcontrolador funcione de forma ideal: para poder programar esta pequeña placa es necesario un conversor USB a serial ttl (Arduino, 2018).

Esta placa cuenta con las siguientes prestaciones:

- Chip ATmega328 a $16 \mathrm{MHz}$ con cristal de cuarzo externo (tolerancia: $0.5 \%$ )

- $\quad$ Auto-reset

- Regulador $5 \mathrm{~V}$ integrado

- Max: $150 \mathrm{~mA}$ por salida

- Protección de sobrecarga

- Protección contra inversión de polaridad

- Entrada DC de 5V hasta $12 \mathrm{~V}$

- LED de power y estado 


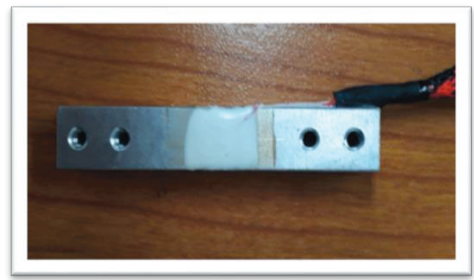

Figura 26 Celda de carga [Autor].

Una celda de carga es un transductor utilizado para convertir una fuerza en una señal eléctrica. Esta conversión empieza a partir de un dispositivo mecánico, es decir, la fuerza que se desea medir deforma la galga extensiométrica y por medio de medidores de deformación (galgas) obtenemos una señal eléctrica con la cual podemos obtener el valor de la fuerza que deseamos medir.

\subsubsection{Módulo Conversor Análogo a Digital Hx711}

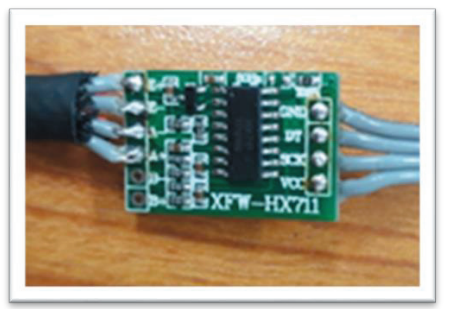

Figura 27 Conversor Análogo A Digital [Autor].

Este módulo es una interfaz entre las celdas de carga y el microcontrolador, permitiendo poder leer el peso de manera sencilla Internamente se encarga de la lectura del puente wheatstone formado por la celda de carga, convirtiendo la lectura analógica a digital con su conversor A/D interno de 24 bits. Es muy utilizado en procesos industriales, sistemas de medición automatizada e industria médica, se comunica con el microcontrolador mediante 2 pines (Clock y Data) de forma serial.

\subsubsection{Disipador Raspberry Pi X3}

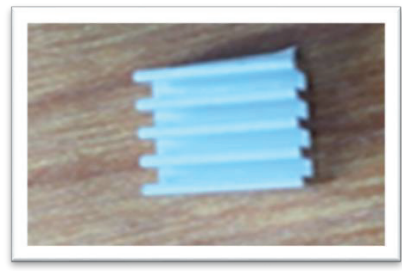

Figura 28 Disipador Raspberry [Autor].

Es un pequeño disipador que cumple la función de refrigerar el microcontrolador de la placa Teensy 3.2 por el motivo de que se está trabajando con el microcontrolador en un rango superior de ciclo de reloj. 
1.6.2.10 Pulsador Normalmente Abierto para Chasis

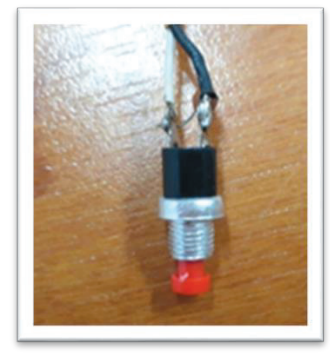

Figura 29 Pulsador [Autor].

Un pulsador es un dispositivo mecánico que al ser accionado cierra un circuito permitiendo el flujo de la corriente hasta que lo soltemos o hasta que lo oprimamos, es decir existen pulsadores normalmente abiertos que son los que dan el paso de corriente cuando son accionados o normalmente cerrados que permiten el paso de la corriente una vez son accionados

\subsubsection{Proceso de Fabricación del Pcb (Printed Circuit Board)}

El PCB se fabricó en una ruteadora CNC de muy alta resolución con el fin de lograr el mejor acabado posible, sin ningún error en las pistas del circuito.

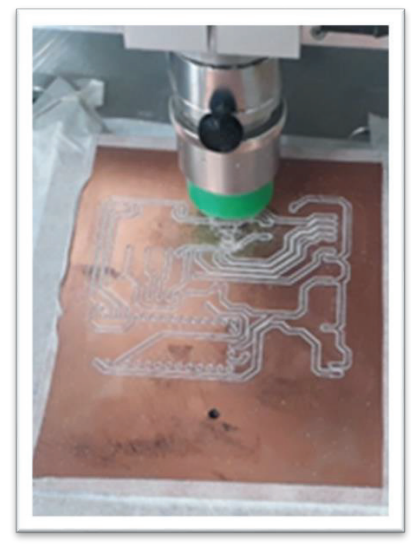

Figura 30 Fabricación tarjeta electrónica [Autor].

1.6.2.12 PCB culminado por ambos lados 

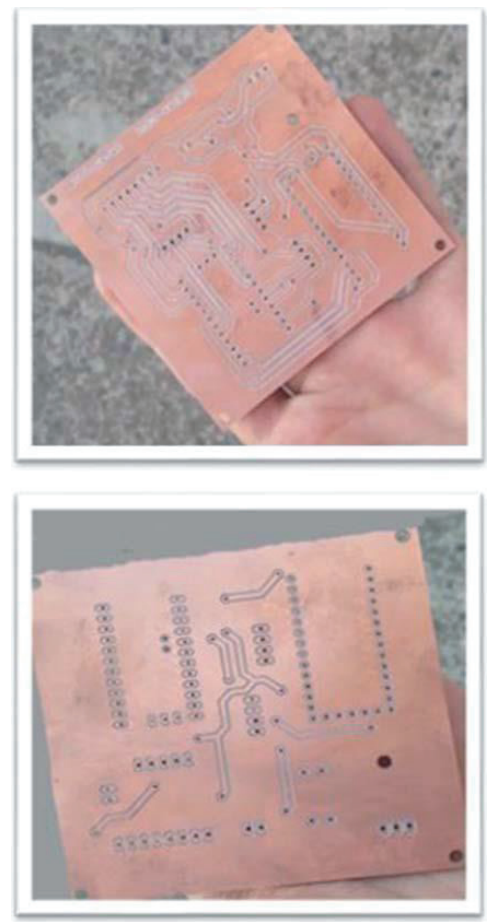

Figura 31 Tarjeta electrónica terminada [Autor].

En la figura 23 se observa la tarjeta terminada, la imagen superior muestra la cara posterior y, en la parte inferior de la imagen, se encuentra la cara anterior de la tarjeta electrónica.

\subsubsection{PCB fabricada en ruteadora CNC y con los componentes extras ya soldados}

Un PCB o Printed Circuit Board, es la superficie constituida por caminos, pistas o buses de material conductor laminadas sobre una base no conductora. El circuito impreso se utiliza para conectar eléctricamente a través de las pistas conductoras, y sostener mecánicamente por medio de la base un conjunto de componentes electrónicos. Las pistas son generalmente de cobre mientras que la base se fabrica de resinas de fibra de vidrio reforzada, pertinax, cerámica, plástico, teflón o polímeros como la vaquela. 
Sebastián Martínez García - Diego Fernando Salazar - Andrés Felipe Osorio Ramírez Leonardo Bohórquez Santiago - Hugo Armando Gallego Becerra
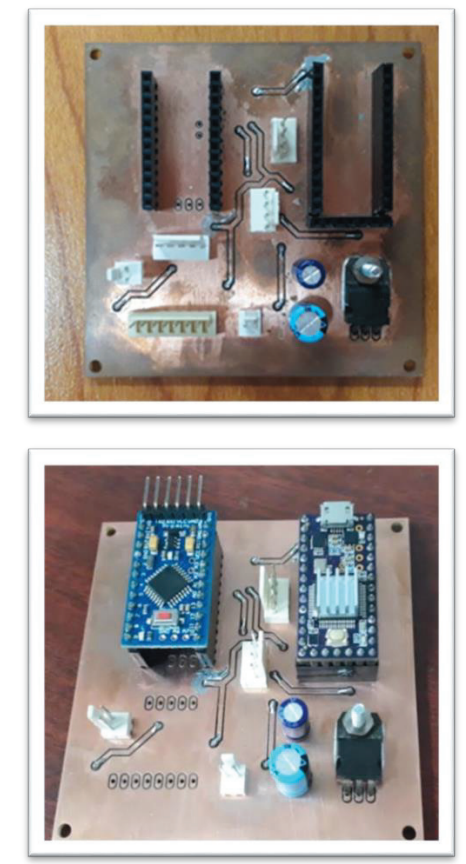

Figura 32 Montaje electrónico terminado y funcionando correctamente [Autor].

En la figura 24 se observan todos los elementos montados en la placa impresa previamente, en la parte superior de la imagen, se observa la cara anterior de la placa y, en la parte inferior, se observa la cara posterior. 


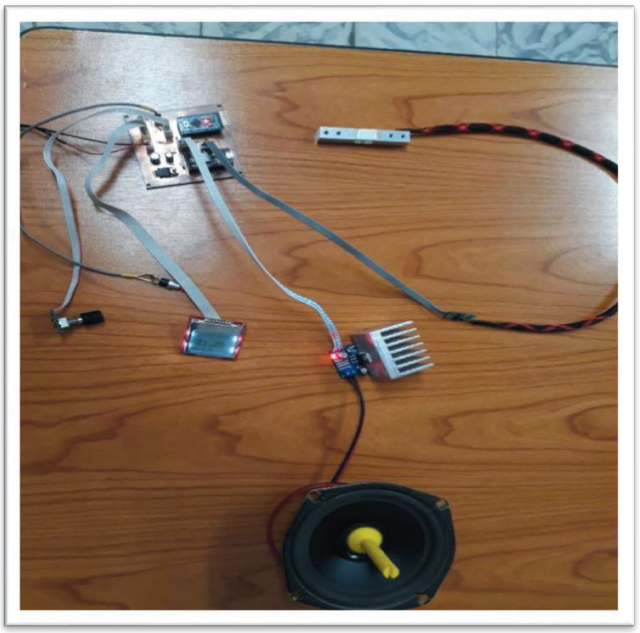

Figura 33 Circuito electrónico completo [Autor].

En el montaje del circuito, se tienen en cuenta dos partes: una de ellas es el generador mecánico unido al amplificador de señal, mientras que, la segunda parte, tiene el PCB con todos los elementos del generador de señales.

\subsection{Programación del Prototipo}

\subsubsection{Software}

Teniendo en cuenta que se emplearán técnicas sobre creación de tecnología, debemos tener los conocimientos básicos sobre lo que se necesita para esto, uno de los módulos del prototipo es el desarrollo de software. Cuando hablamos de software, nos estamos refiriendo a la parte lógica e intangible de un sistema informático, donde se generan las entradas, procesamientos y salidas de los datos.

Se entiende como software un programa o sistema que está conformado por componentes lógicos e instrucciones que tienen un fin en específico, dichos componentes se relacionan entre sí para llevar a cabo una función, un proceso o una petición hecha por el usuario.

Existe un estándar que debemos tener en cuenta a la hora de seleccionar, implementar y monitorear el ciclo de vida del software, es el estándar internacional ISO/IEC 12207 (Information Technology / Software Life Cycle Processes) es el estándar para los procesos de ciclo de vida del software, siendo el proceso un conjunto de tareas que involucran actividades, restricciones y recursos relacionados que al ejecutarse conjuntamente transforman una entrada en una salida.

Fue necesario la programación del generador de onda, debido a que este consta de dos microcontroladores, un Arduino Mini Pro, el cual está encargado de adquirir los datos del encoder y el pulsador, mostrando las configuraciones en la LCD, está conectado de forma directa al segundo microcontrolador el cual es una placa Teency 3.2, esta placa es la que cumple la tarea de generar la señal senoidal de $1 \mathrm{~Hz}$ a $150 \mathrm{~Hz}$ con una resolución de $0.1 \mathrm{hz}$ aproximadamente, para enviar esta esta señal a través de su conversor DAC(conversor análogo digital) y reflejándose en una onda senoidal que varía en tensión eléctrica, llegando esta señal a un amplificador de audio y amplificada por un parlante, el cual cumple la tarea de hacer vibrar la cuerda.

A continuación, se presenta el esquema del generador de señales y parte del código que fue necesario implementar para el correcto funcionamiento del dispositivo de generación de ondas, que es el corazón del prototipo experimental. 


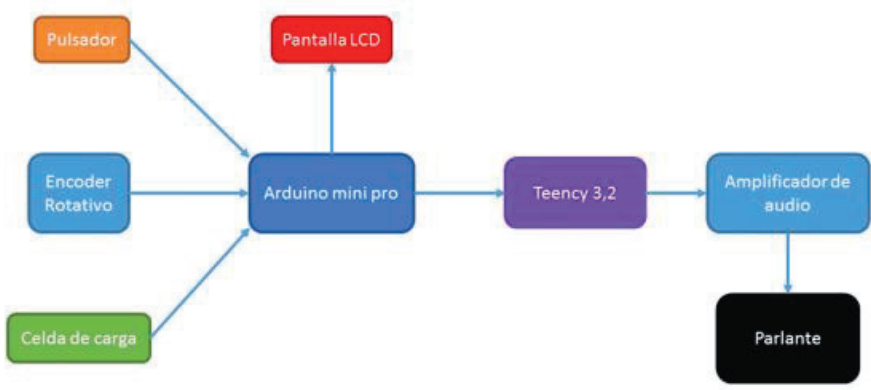

Figura 34 Esquema del dispositivo diseñado de Generador De Onda [Autor].

En la figura 26, se observa el esquema de construcción del generador que fue necesario tener en cuenta para su posterior programación El diseño del software se realizó con base en este esquema, teniendo en cuenta cada una de las etapas de la señal antes de ser entrega a la cuerda tensa.

\begin{tabular}{|c|c|}
\hline $\begin{array}{l}\text { Primera Etapa } \\
\text { float tenc }=0 \text { : }\end{array}$ & $\begin{array}{l}\text { Segunda Etapa } \\
\text { void setup() }\end{array}$ \\
\hline boolean up = false; & 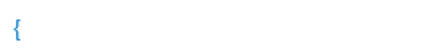 \\
\hline boolean down = false; & Serial.begin (230400); \\
\hline boolean middle = true; & display.begin () \\
\hline ClickEncoder *encoder; & display.clearDisplay(); \\
\hline $\begin{array}{l}\text { int16_t last, value; } \\
\text { int } \mathrm{nP}=0\end{array}$ & setContrast(); \\
\hline int sal =0; & encoder = new ClickEncoder (3, 2, A1); \\
\hline int $\mathrm{C} 1=1$ & encoder->setAcceleration Enabled(false); \\
\hline int $\mathrm{C} 2=0$; & Timer1.initialize(1000); \\
\hline int $\mathrm{C} 3=0$; & Timer1.attachlnterrupt(timerlsr); \\
\hline $\begin{array}{l}\text { \#define Hzout } 4 \\
\text { int oP1 = } 0\end{array}$ & last = encoder->getValue(); \\
\hline int nP1 = 0; & pinMode(RP, INPUT_PULLUP); \\
\hline
\end{tabular}

Figura 35 Primer y Segunda Etapa del Software de control del generador de ondas [Autor].

Con el fin de lograr la sincronización y el funcionamiento correcto de los elementos que componen el generador de ondas, se diseñó un software de control por etapas. Se observa, en la figura 27, dos de las etapas presentes en el software, cabe resaltar que 
el prototipo diseñado cuenta con un manual de usuario donde aparece en detalle el contenido del software diseñado, sus etapas y el código fuente instalado en los microcontroladores.

\subsubsection{Diseño Interfaz de Usuario}

Se diseñó una interfaz de usuario a través de una pantalla Nokia 5110, con el fin de hacer amigable la interfaz de usuario al momento del usuario interactuar con la aplicación y que a la vez este se sienta cómodo y de fácil manejo.

La interfaz de usuario es la parte donde interactúa el usuario con la aplicación o equipo, allí es donde el usuario realiza las peticiones que desea pedir a la aplicación por medio de una pantalla que consta de menús, ventanas, botones, ratón, sonidos, entre otros. Por medio de estos elementos es como se genera el canal de comunicación entre usuario-máquina. Esta interfaz gráfica genera un ambiente cómodo, intuitivo y de fácil manejo para el usuario.

Dicha interfaz cuenta con un menú principal, como se muestra en la siguiente figura.

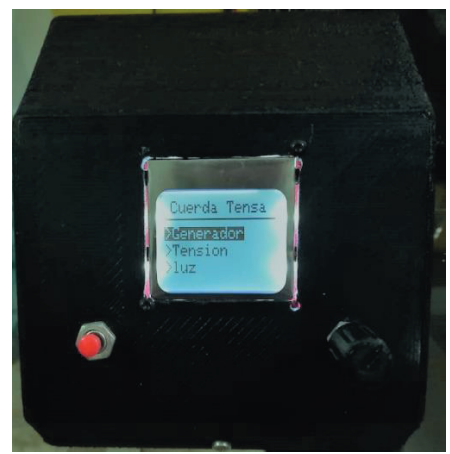

Figura 36 Interfaz de Usuario [Autor].

Como se observa en la figura 28 , en el menú principal se podrán observar las diferentes opciones que se tienen para configurar los armónicos o diferentes frecuencias a las que se quiere llegar, saber qué tensión hay en el momento en la cuerda tensa, como también se podrá configurar la luz y el contraste de la pantalla.

El funcionamiento del generador de onda senoidal del prototipo de cuerda tensa consta de una interfaz de usuario, la cual tiene un encoder rotativo y dos pulsadores estos dispositivos tiene la tarea de acceder a las múltiples funciones del generador: e dispositivo cuenta con una pantalla LCD en la cual se visualizan esas múltiples configuraciones del generador y también consta de una celda de carga para medir la tensión que se está aplicando en una cuerda.

Para desplazarnos en el menú principal giraremos el encoder hacia la izquierda para ir avanzando hacia las otras opciones del menú o giraremos hacia la derecha para regresar.

\subsection{Desarrollo Mecánico}

Para el desarrollo mecánico se utilizó la impresora 3D Wanhao Duplicator I3 para hacer las piezas necesarias para el ensamble.

\subsubsection{Diseño y construcción del esquema mecánico del prototipo.}

Teniendo en cuenta que el equipo debe ser de fácil manejo y portátil, se diseñaron las piezas mecánicas en el software libre llamado DesignSpark Mechanical 2.0, que brinda al usuario la posibilidad de crear piezas a la medida utilizando formas geométricas, del mismo modo, el software es compatible a la impresora 3D Wanhao en la cual se imprimieron los soportes $y$ demás piezas del equipo. 


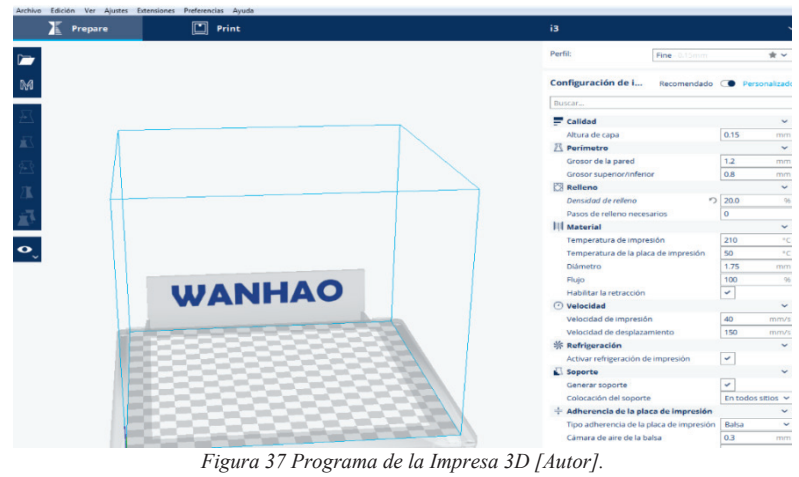

A continuación, se muestra el esquema de piezas realizado para el prototipo de oscilaciones en una cuerda tensa.
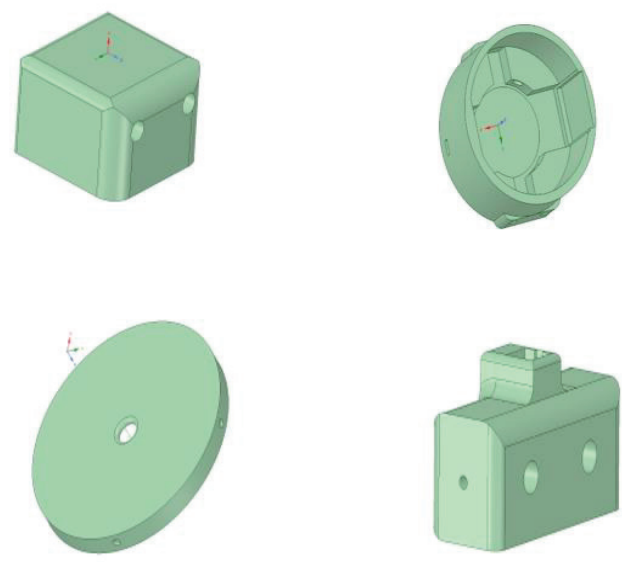

Figura 38 Esquema de piezas software DesignSpark Mechanical 2.0. [Autor].

\subsubsection{Diseño del Vástago en donde se sujeta la Cuerda al Parlante}

Esta pieza se diseñó con el fin de sujetar la cuerda donde se podrá apreciar el fenómeno de vibraciones y la membrana del parlante que generará las oscilaciones. 


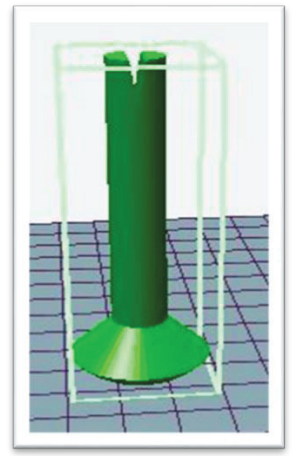

Figura 39 Vástago [Autor].

\subsubsection{Parlante de 15cm 20w 12v con Vástago ya Pegado}

Este parlante cumplirá la con la tarea de generar un movimiento mecánico a la frecuencia que le asignemos para poder verlo reflejado en la cuerda tensa y apreciar los armónicos de este experimento.

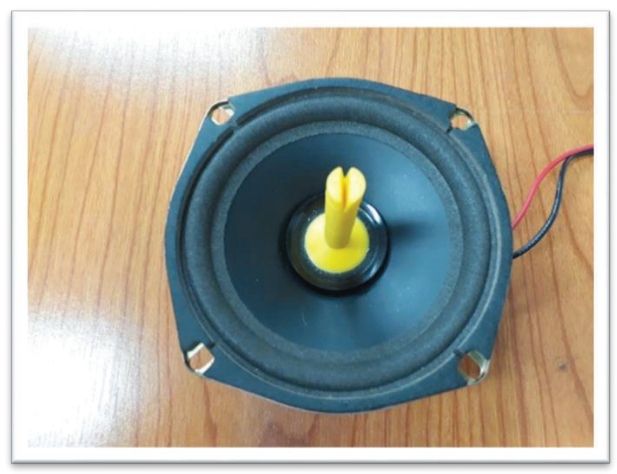

Figura 40 Parlante con vástago [Autor].

\subsubsection{Caja para Generador de Señales}

Se realizó una pieza mecánica agradable que contuviera la parte electrónica del generador de señales donde el usuario puede interactuar con el equipo. 
Sebastián Martínez García - Diego Fernando Salazar - Andrés Felipe Osorio Ramírez Leonardo Bohórquez Santiago - Hugo Armando Gallego Becerra

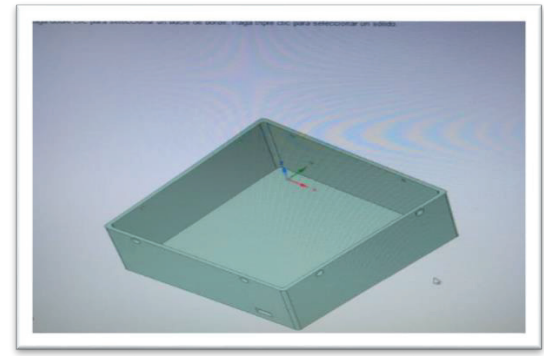

Figura 41 Diseño caja para generador de señales [Autor].

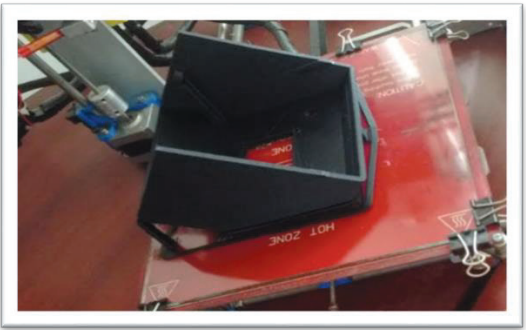

Figura 42 Caja para generador de señales [Autor].

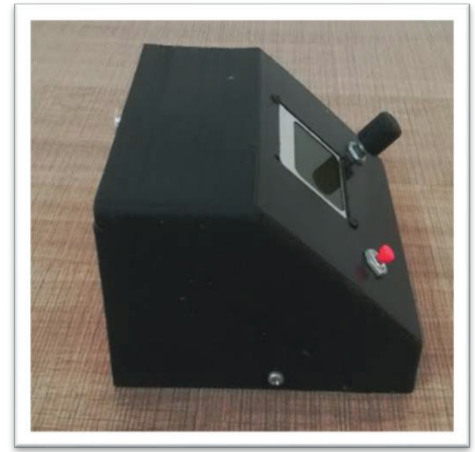

Figura 43 Caja para generador de señales ensamblada [Autor].

\subsubsection{Soporte Base Equipo}

Se diseñó y ensambló una pieza que será el soporte de la base del equipo de cuerda tensa con dos agujeros a una altura determinada para darle estabilidad al equipo. 


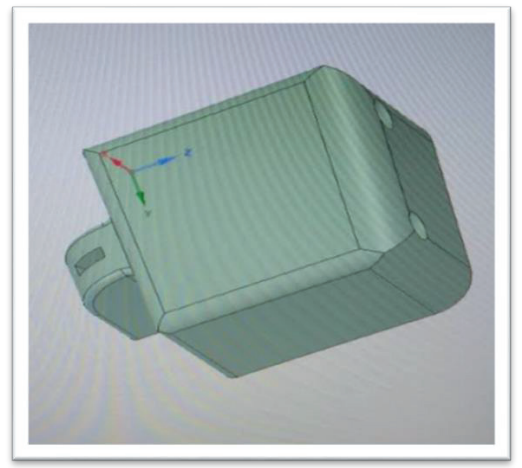

Figura 44 Diseño base equipo [Autor].

\subsubsection{Caja para el Parlante y Amplificador de Señal.}

Unos de los corazones del equipo es su generador mecánico el cual consta de un parlante y su amplificador de señal, para este generador se diseñó e imprimió un soporte que tuviera el espacio necesario para contener todos los elementos y de igual manera fuera soporte para la base del equipo.

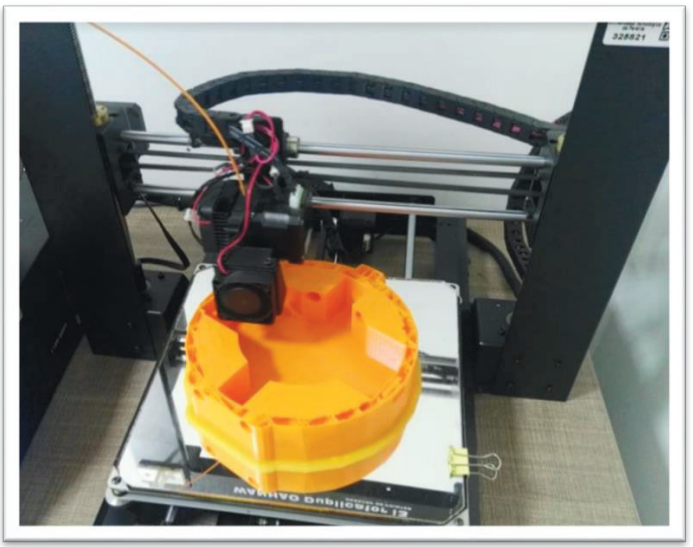

Figura 45 Caja para el parlante y amplificador de señal en estado de impresión [Autor]. 


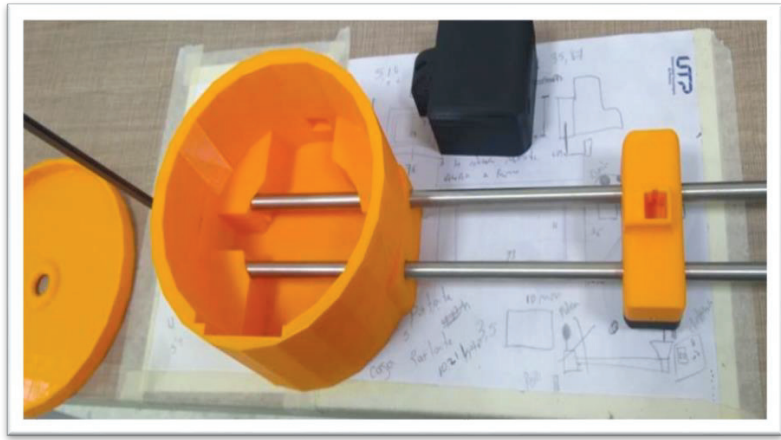

Figura 46 Caja para el parlante y amplificador de señal en ensamble [Autor].

\subsubsection{Ensamble Parte Mecánica.}

Luego de tener las piezas impresas y los elementos electrónicos, se realizó el ensamble de los diferentes microsistemas del equipo: el generador de señales, la pantalla, galga para la tensión, el amplificador de la señal y el generador mecánico.

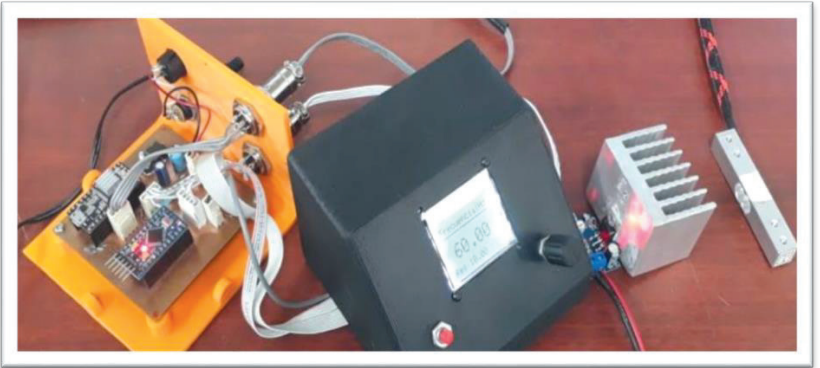

Figura 47 Ensamble mecánico [Autor].

1.8.8 Polea con Poca Fricción.

Para generar la tensión de la cuerda se tuvo la necesidad de crear una polea con baja fricción, a la cual se le diseñaron dos piezas en la impresora 3D y luego se unieron con rodamientos a una varilla de acero, como se muestra a continuación. 
Diseño y Construcción de Prácticas para el Estudio de Movimiento Ondulatorio

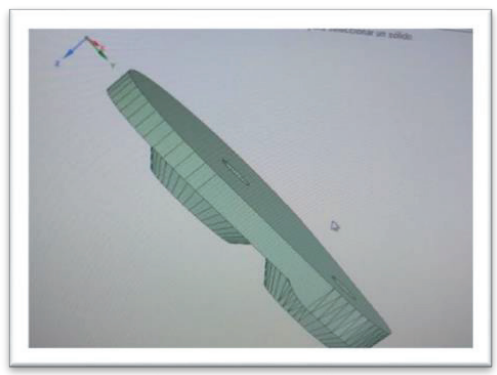

Figura 48 Diseño de polea lateral [Autor].

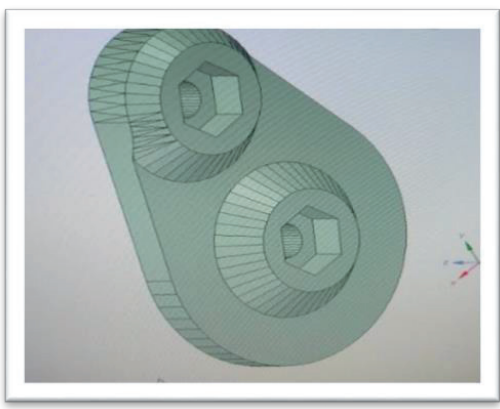

Figura 49 Diseño de polea frontal [Autor].

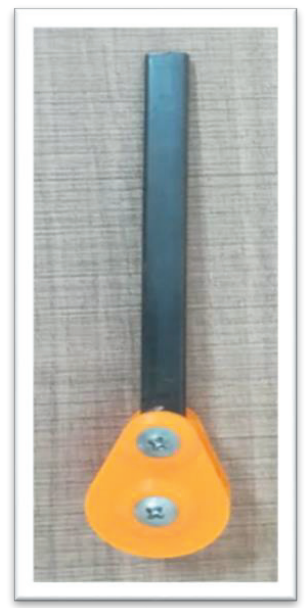

Figura 50 Polea Impresa [Autor]. 


\subsection{Resultados}

Como resultado principal de este proyecto obtuvimos un prototipo autónomo para la experimentación de ondas estacionarias en una cuerda tensa, el cual está dividido en varias piezas que son de fácil manejo y portabilidad.

A continuación, se nombran las piezas del equipo y se da una breve descripción de cada una de ellas.

\subsubsection{Generador Mecánico de Ondas}

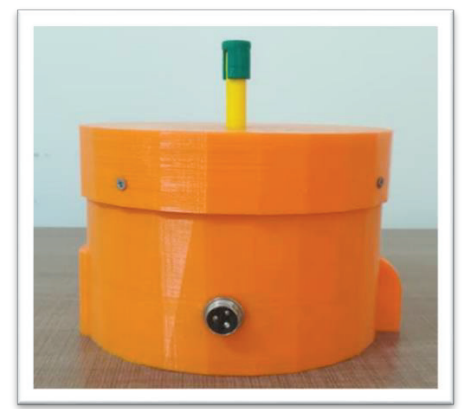

Figura 51 Generador mecánico de ondas ensamblado [Autor].

Esta pieza fue construida con la finalidad de generar una onda mecánica por medio de la vibración, está compuesta por un bajo de $8 \mathrm{ohm}$ y $20 \mathrm{~W}$ de potencia a su vez se encuentra conectado con un amplificador de señal que hace que el bafle incremente su amplitud de onda.

1.9.2 Masas

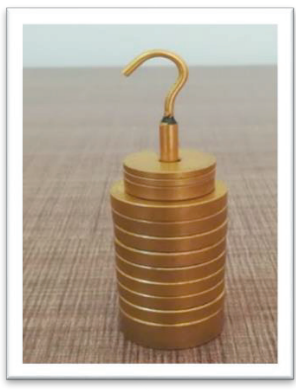

Figura 52 Masas [Autor].

El prototipo cuenta con un juego de masa las cuales son las que permiten que la cuerda se encuentre tensionada.

\subsubsection{Polea}




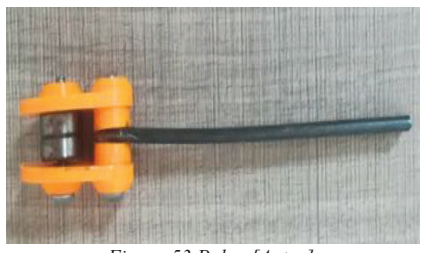

Figura 53 Polea [Autor].

La polea sirve como punto de apoyo de una cuerda la cual ejerce una fuerza

\subsubsection{Generador de Señales Parte Frontal}

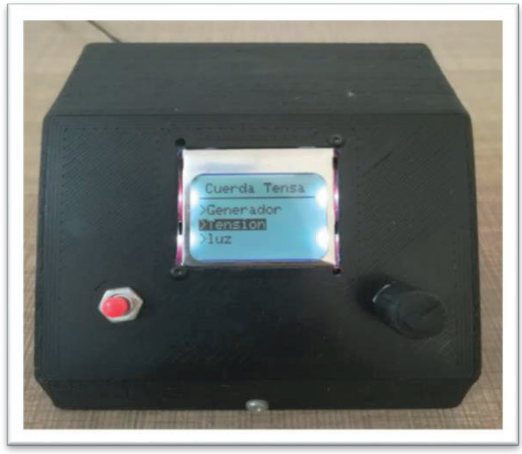

Figura 54 Generador de señales parte frontal [Autor].

El generador de señales es un dispositivo electrónico, que genera o produce diferentes tipos de señales (sinusoidal, cuadrada) según las características propias de cada dispositivo, las cuales pueden servir en laboratorios de estudio de ondas, académicamente, o ya sea para probar o comparar con dispositivos electrónicos.

\subsubsection{Generador de Señales Parte Lateral}

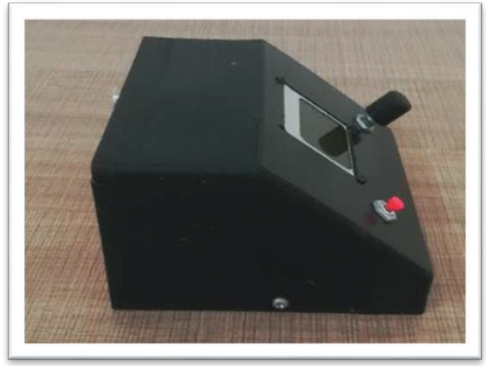

Figura 55 Generador de señales parte lateral [Autor]. 


\subsubsection{Parte Trasera del Generador de Señales}

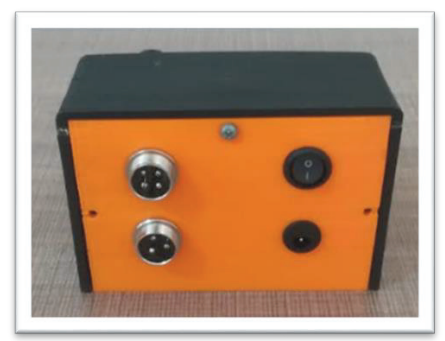

Figura 56 Parte trasera generador de señales [Autor].

El generador GS2018 posee en su parte trasera dos conectores, uno es para la entrada de la medida de tensión que viene de la galga, la otra es la salida de la señal hacia el generador mecánico. De igual modo cuenta con un botón de encendido y apagado.

\subsubsection{Galga}

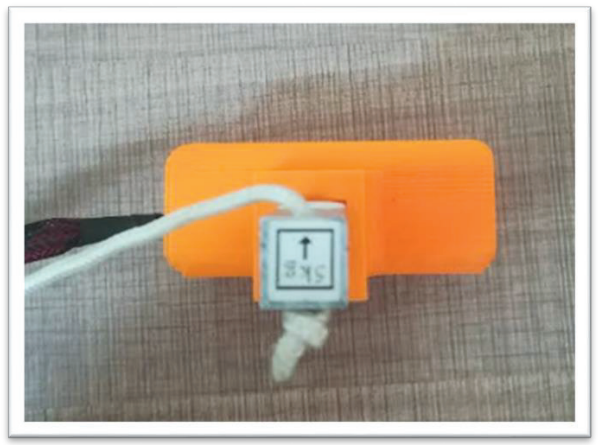

Figura 57 Galga [Autor].

La galga es una unidad de longitud, la cual sirve para medir grosores muy pequeños o finos.

\subsubsection{Equipo Ensamblado}

A continuación, se entrará en discusión acerca de los resultados obtenidos con el equipo para la práctica experimental de laboratorios de física, es importante resaltar que se realizaron varias pruebas de funcionamiento, donde se evidenció de forma clara los diferentes modos normales de vibración y se pudo identificar los cambios implícitos en la práctica a la hora de modificar las variables de longitud y tensión en el prototipo diseñado que se muestra en la figura 50. 


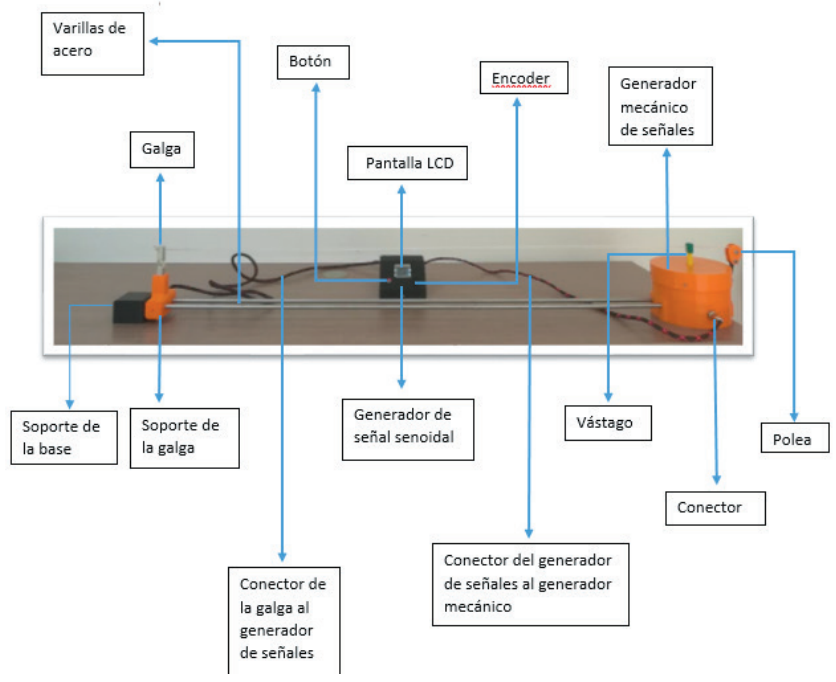

Figura 58 Equipo ensamblado [Autor].

Es de gran importancia aclarar que, una vez terminadas las piezas del prototipo se integraron de forma que el usuario tenga un equipo de fácil uso y práctico para la experimentación de la práctica de cuerda tensa.

Cabe destacar que el prototipo fue desarrollado para realizar la práctica de ondas estacionarias de cuerda tensa, expuesto en el laboratorio de física 3 y a su vez analizar los resultados arrojados por el equipo para verificar su funcionamiento, compatibilidad, facilidad y confiabilidad de los resultados.

A continuación, se muestran los resultados obtenidos para la práctica una vez el equipo fue integrado y al mismo tiempo, una comparación de los resultados del equipo, con los resultados de las prácticas ya existentes.

\subsubsection{Resultados de la Práctica Ondas Estacionarias en una Cuerda Tensa.}

Para empezar a realizar la práctica, los estudiantes deben ensamblar el equipo con ayuda del manual y/o guía de la práctica. En la práctica se pretende encontrar la densidad de una cuerda mediante la relación de frecuencias propias de oscilación con el número de armónicos, la raíz cuadrada de la tensión y el inverso de la longitud, cuando los parámetros no permanezcan constantes.

A continuación, se configuran con las condiciones iniciales donde la longitud de la cuerda L seria la máxima permitida (1.26 m) y una tensión de $(2.09 \mathrm{~N})$, posteriormente, los estudiantes tuvieron que encender el generador de señales e incrementar poco a poco la frecuencia hasta encontrar el modo fundamental de resonancia y sus armónicos para generar la tabla 1 . 


\begin{tabular}{|c|c|}
\hline \# Armónicos & Frecuencia $(\mathrm{Hz})$ \\
\hline 1 & 10,1 \\
\hline 2 & 20.1 \\
\hline 3 & 29.1 \\
\hline 4 & 35.1 \\
\hline 5 & 48.1 \\
\hline
\end{tabular}

Tabla 1 Frecuencias de armónicos con $L=1.26$ y $T=2.09 \mathrm{~N}$ [Autor]

Teniendo en cuenta esta información se generó el análisis correspondiente que certifique la toma de datos y el buen funcionamiento del equipo. Para ello se construye una gráfica de Frecuencia en función del número de armónicos la cual se muestra en la Figura 51.

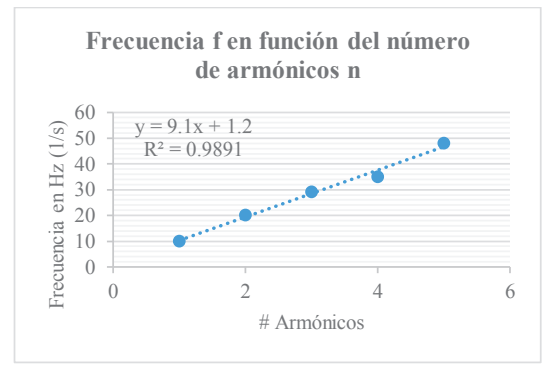

Figura 59 Frecuencia en función del número de armónicos [Autor].

Posteriormente, el estudiante refleja el resultado arrojado por la gráfica y da una respuesta de ella donde la gráfica obtenida anteriormente es una línea recta, y la frecuencia varía de acuerdo con la ecuación:

$$
f=9,1 X+1,2
$$

Por otra parte, la expresión teórica que relaciona la frecuencia de las oscilaciones en una cuerda tensa, en función de las variables que afectan dicho comportamiento, está dada por:

Donde:

$$
f_{n}=\frac{n}{2 L} \sqrt{\frac{T}{\mu}}
$$

$n:$ Es el número de armónico

L: Es la longitud de la cuerda

$T:$ Es la tensión en la cuerda

$\mu$ : Es la densidad de la cuerda

Posteriormente, si se tiene la ecuación de la recta y la expresión teórica de la frecuencia en función de las variables, luego se realiza un análisis correspondiente para obtener el valor de la densidad de masa $\mu$ (Valor experimental) con su correspondiente incertidumbre.

Nota: Las incertidumbres calculadas en la elaboración del laboratorio se realizaron con la metodología Distribución Normal tipo B según el trabajo Tratamiento Estadístico De Datos Experimentales Y Aplicación Del Método General Para El Cálculo De Incertidumbre De Medición (Cruz Muñoz, Llamosa, \& Medina, 2019)

Con $\mathrm{n}=1$

$$
\begin{aligned}
f_{n} & =n\left(\frac{1}{2 L} \sqrt{\frac{T}{\mu}}\right)+1,2 \\
9,1 & =n\left(\frac{1}{2 L} \sqrt{\frac{T}{\mu}}\right)+1,2
\end{aligned}
$$


Con $\mathrm{T}=2,09 \mathrm{~N}$ y $\mathrm{L}=1,26 \mathrm{~m}$

$$
\begin{aligned}
& \left(\frac{1}{2 L} \sqrt{\frac{T}{\mu}}\right)=9,22 \\
& \sqrt{\frac{T}{\mu}}=2 L(9,22) \\
& \frac{T}{\mu}=[2 L(9,22)]^{2} \\
& \mu=\frac{T}{4 L^{2}(9,22)^{2}}
\end{aligned}
$$

Con $\mathrm{k}=1,96$

$$
\begin{gathered}
\mu=\frac{2,09}{(4)(1,26)^{2}(9,22)^{2}} \\
\mu=3,87 * 10^{-3} \mathrm{~kg} / \mathrm{m} \\
U_{b}=\frac{0,001 \mathrm{~m}}{\sqrt{3}}=5,77 * 10^{-4} \\
U_{E}=k * U_{b}
\end{gathered}
$$

$\mathrm{L}=1,26 m \pm 1,13 * 10^{-3} \mathrm{~m}$

$$
\begin{gathered}
U_{E}=1,96 * 5,77 * 10^{-4} \\
U_{E}=1,13 * 10^{-3} \mathrm{~m}
\end{gathered}
$$

Con $\mathrm{T}=2,09$ y $\Delta l=1,13 * 10^{-3} \mathrm{~m}$

$$
\Delta \mu=\frac{\partial \mu}{\partial L}=\frac{2 T \Delta l}{4 L^{3}(10,1)^{2}}
$$

$$
\begin{gathered}
\Delta \mu=5,78 * 10^{-6} \frac{\mathrm{kg}}{\mathrm{m}} \\
\mu=3,87 * 10^{-3} \frac{\mathrm{kg}}{\mathrm{m}} \pm 5,78 * 10^{-6} \frac{\mathrm{kg}}{\mathrm{m}}
\end{gathered}
$$

Luego, se procedió a determinar el dato teórico de la densidad de la cuerda calculada a partir de su masa y longitud, mediante la expresión $\mu=\mathrm{m} / \mathrm{L}$, donde $\mathrm{m}$ es la masa de la cuerda y $\mathrm{L}$ es la longitud total de la cuerda, el cual fue de $3.7 \times 10^{-3} \mathrm{~kg} / \mathrm{m}$. La masa se midió con una incertidumbre de $\pm 0,001 \mathrm{~g}$. y la longitud con $\pm 0,1 \mathrm{~cm}$.

Con estos datos, se calcula la incertidumbre de la densidad de la masa de la siguiente forma.

$$
\begin{gathered}
\Delta \mu=\mu\left(\frac{\Delta m}{m}+\frac{\Delta l}{l}\right) \\
\Delta \mu=\left(3.7 * 10^{-3} \frac{\mathrm{Kg}}{\mathrm{m}}\right)\left(\frac{0,000001 \mathrm{Kg}}{0,0098126 \mathrm{Kg}}+\frac{0,001 \mathrm{~m}}{2,63 \mathrm{~m}}\right) \\
\Delta \mu=0,002 * 10^{-3} \frac{\mathrm{Kg}}{\mathrm{m}} \\
\mu=3,7 * 10^{-3} \frac{\mathrm{kg}}{\mathrm{m}} \pm 1,79 * 10^{-6} \frac{\mathrm{kg}}{\mathrm{m}}
\end{gathered}
$$

Dónde: $\Delta \mu$ es la incertidumbre de la densidad

$\mu=3.7 * 10^{-3} \frac{\mathrm{Kg}}{\mathrm{m}}$ es la densidad de la cuerda

$\Delta m=0,000001 \mathrm{~m} \mathrm{Kg}$ es la incertidumbre de la masa

$m=0,0098126 \mathrm{Kg}$ es la masa

$\Delta l=0,001 \mathrm{~m}$ es la incertidumbre de la longitud de la cuerda

$l=2,63 m$ es la longitud de la cuerda.

Si se considera este valor como teórico y se compara en términos de porcentaje al valor de $\mu$ obtenido en el parte experimental tenemos.

$$
\begin{gathered}
E_{\%}=\frac{V_{\text {teo }}-V_{\text {exp }}}{V_{\text {teo }}} * 100 \\
E_{\%}=\frac{3,7 * 10^{-3}-3,87 * 10^{-3}}{3,7 * 10^{-3}} * 100
\end{gathered}
$$




$$
E_{\%}=4,6 \%
$$

Seguido el procedimiento de toma de datos, los estudiantes cambiaron condiciones en las variables a medir. Para la segunda parte se conserva la longitud $\mathrm{L}=1.26 \mathrm{~m}$ y se varia la tensión, para luego variar la frecuencia del generador hasta encontrar el segundo armónico Ver figura 51. Dicha frecuencia es registrada en la tabla 2. Cada vez que se cambia la tensión se repite el procedimiento para encontrar el armónico deseado y registrar los resultados.

\begin{tabular}{|c|c|}
\hline Tensión(N) & Frecuencia(Hz) \\
\hline 1.4 & 7.1 \\
\hline 1.8 & 9.1 \\
\hline 2.25 & 10.1 \\
\hline 2.63 & 11.1 \\
\hline 2.83 & 12.1 \\
\hline
\end{tabular}

Tabla 2 Registro de los datos suministrados para el cambio de tensión [Autor].

Con los datos arrojados por el equipo, los estudiantes toman los datos que se encuentran registrados en la tabla 2, para construir la gráfica de la figura 52 de frecuencia en función de la raíz cuadrada de la tensión.

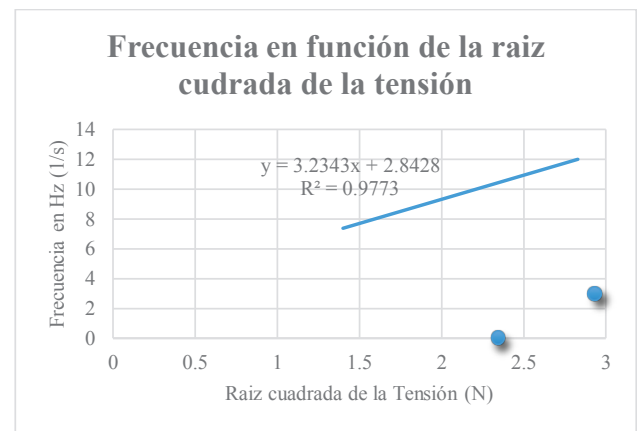

Figura 60 Frecuencia en función de la raiz cuadrada de la tensión [Autor].

Posteriormente, el estudiante refleja el resultado arrojado por la gráfica y da una respuesta de ella donde la gráfica obtenida anteriormente es una línea recta. A partir de este gráfico se obtuvo la ecuación que relaciona la frecuencia con la tensión un nuevo valor para $\mu$ con su respectiva incertidumbre. Para luego compararlo con su dato teórico.

La ecuación que relaciona la frecuencia con la tensión es:

Donde $\mathrm{n}=1, \mathrm{f}=7,1, \mathrm{~L}=1,26 \mathrm{~m}$ y $\mathrm{T}=1,18$

$$
\begin{gathered}
f=9,0704 \sqrt{T}+3,4153 \\
f_{n}=\frac{n}{2 L} \sqrt[2]{\frac{T}{\mu}} \\
\mu=\left(\frac{n T}{2 L(f)}\right)^{2}
\end{gathered}
$$$$
\mu=\left(\frac{1 * 1,18}{2(1,26)(7,1)}\right)^{2}
$$$$
\mu=4,35 * 10^{-3} \frac{\mathrm{kg}}{\mathrm{m}}
$$$$
\Delta \mu=\frac{\partial \mu}{\partial L}=\frac{2 \Delta L}{\left(f^{2}\right) * L^{3}} ;
$$ 
Con $\Delta L=0,001, \mathrm{f}=7,1 \mathrm{~Hz}$ y $\mathrm{L}=1,26 \mathrm{~m}$

$$
\begin{gathered}
\Delta \mu=\frac{\partial \mu}{\partial L}=\frac{2 * 0,001}{\left(7,1^{2}\right) *\left(1,26^{3}\right)} \\
\Delta \mu=9,92 * 10^{-6} \frac{\mathrm{kg}}{\mathrm{m}} \\
\mu=4,35 * 10^{-3} \frac{\mathrm{kg}}{\mathrm{m}} \pm 9,92 * 10^{-6} \frac{\mathrm{kg}}{\mathrm{m}}
\end{gathered}
$$

Ahora el porcentaje de error será:

$$
\begin{gathered}
E_{\%}=\frac{V_{\text {teo }}-V_{\text {exp }}}{V_{\text {teo }}} * 100 \\
E_{\%}=\frac{3,7 * 10^{-3}-4,35 * 10^{-3}}{3,7 * 10^{-3}} * 100 \\
E_{\%}=17,6 \%
\end{gathered}
$$

Teniendo en cuenta los procedimientos realizados por los estudiantes, se comprueba que al variar la tensión el porcentaje de error aumenta, pero se considera un valor considerablemente apropiado ya que se puede tener algún tipo de error en la toma de uno de los datos, sin embargo, aún si se presenta este crecimiento los datos son más cercanos y confiables que los datos arrojados por los equipos y prácticas realizadas con los materiales existentes en el laboratorio.

Como último cambio en la experimentación los estudiantes dejan fija la tensión y varían la longitud de la cuerda como se muestra en la figura 53 con el fin de encontrar las frecuencias del segundo armónico para cada variación y regístralos en la tabla 3.

Con los datos suministrados con el equipo, se registran para luego entrar en el estudio y análisis de los resultados.

\begin{tabular}{|c|c|}
\hline Longitud $(\mathrm{cm})$ & Frecuencia $(\mathrm{Hz})$ \\
\hline 110 & 13.1 \\
\hline 100 & 15,1 \\
\hline 90 & 16,1 \\
\hline 80 & 19,1 \\
\hline 120 & 12,1 \\
\hline
\end{tabular}

Tabla 3 Datos de cambio de longitud y sus respectivas frecuencias [Autor].

Con los datos suministrados por el equipo se realízala la gráfica de la figura 53 la cual muestra el comportamiento de la frecuencia al variar la longitud.

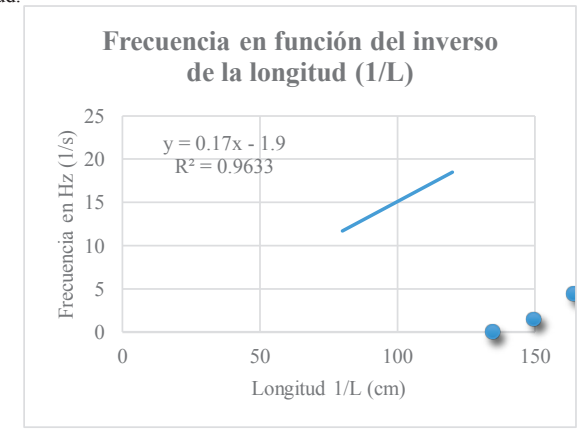

Figura 61 Frecuencia en función del inverso de la longitud [Autor].

Posteriormente, el estudiante refleja el resultado arrojado por la gráfica y da una respuesta de ella donde la gráfica obtenida anteriormente es una línea recta. A partir de este gráfico, se obtuvo la ecuación que relaciona la frecuencia en función del inverso de la longitud donde 


$$
f=1648,8 \frac{1}{L}-1.1729
$$

Con base a los resultados obtenidos el error de la densidad de la masa crece a medida que la longitud varia para este caso el porcentaje de error es muy alto y es un dato que se tiene que tomar de nuevo siguiendo con rigurosidad los pasos de la guía.

Teniendo en cuenta el proceso realizado para el cálculo de la densidad de la masa, se da una comparación con datos arrojados por los equipos existentes en el laboratorio de física 3.

Como primera comparación se muestra las tablas de cada equipo figura 51 Donde los estudiantes sin variar la longitud y tensión varían la frecuencia para encontrar los modos fundamentales.

\begin{tabular}{|c|c|}
\hline \# Armónicos (n) & Frecuencia $(\mathrm{Hz}=1 / \mathrm{s})$ \\
\hline 1 & 9 \\
\hline 2 & 17,8 \\
\hline 3 & 25 \\
\hline 4 & 35 \\
\hline 5 & 45 \\
\hline
\end{tabular}

\begin{tabular}{|c|c|}
\hline \# Armónicos (n) & Frecuencia $(\mathrm{Hz}=1 / \mathrm{s})$ \\
\hline 1 & 10,1 \\
\hline 2 & 20,1 \\
\hline 3 & 29,1 \\
\hline 4 & 35,1 \\
\hline 5 & 48,1 \\
\hline
\end{tabular}

Figura 62 Comparación tablas de datos con longitud y tensión constante [Autor].

Se observa en la figura 54 que en ambas tablas los equipos muestran un comportamiento ascendente en sus datos de frecuencia, conservando la teoría, de que luego de tener el primer modo fundamental, los armónicos siguientes se encontraran cerca de las frecuencias múltiplos de la primera.

Seguido de esta comparación se mostrarán las gráficas obtenidas de cada una de las tablas como se muestra en la figura 55

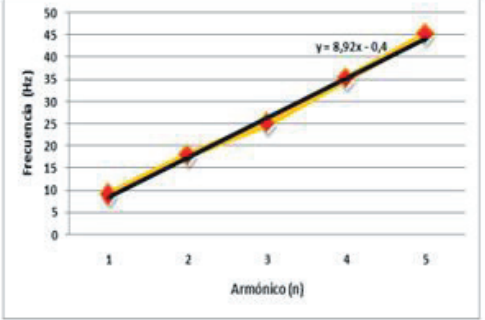

Grafica Equipos de Laboratorio

\section{Frecuencia f en función del número de armónicos $n$}

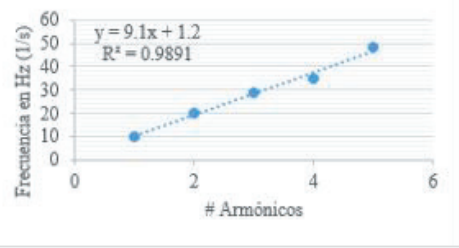

Grafica Equipo Dicoped

Figura 63 Comparación de graficas de los equipos de laboratorio con el equipo de Dicoped [Autor].

Como resultado de la comparación de las gráficas se puede evidenciar que, en ambos casos, se obtiene una recta con su respectiva ecuación.

Teniendo en cuenta el proceso del cálculo de la densidad de masa y su respectiva incertidumbre, se muestra la comparación de los resultados arrojados para cada experimentación.

En la figura 56, se muestran las ecuaciones y sus respectivas densidades. 


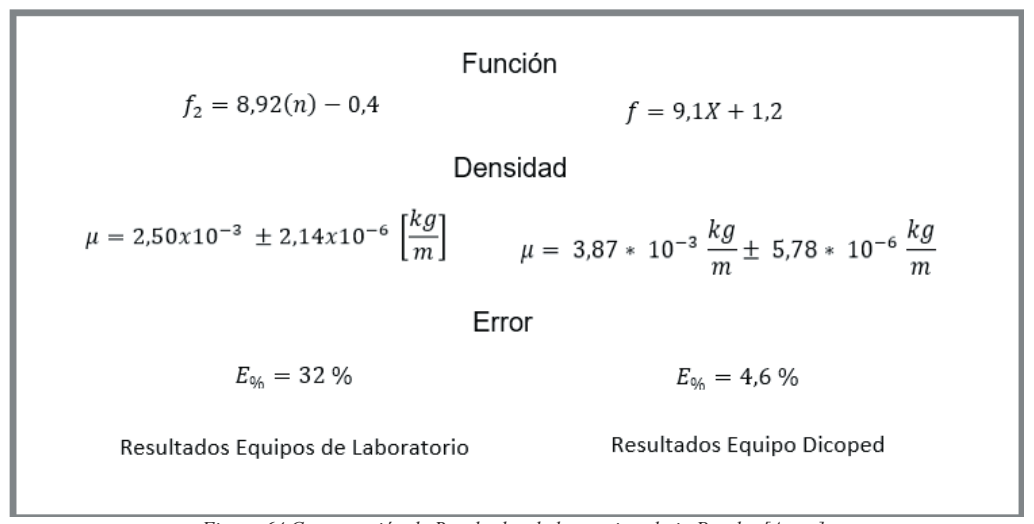

Figura 64 Comparación de Resultados de los equipos bajo Prueba [Autor].

Con base a los resultados comparados, se puede evidenciar que el equipo diseñado presenta un mejor desempeño que los equipos de laboratorio, ya que el error presentado por el equipo diseñado es menor que el presentado por los equipos de laboratorio.

Posteriormente, se realizaron los cálculos y análisis de la densidad de masa $\mu$ para dos variaciones más (longitud, tensión) donde los errores en la densidad de masa para ambos equipos se incrementan. Sin embargo, los cálculos evidencian las mismas diferencias donde el equipo diseñado siempre presenta un menor error en sus resultados.

\subsubsection{Comparación Laboratorio de Metrología de Variables Eléctricas.}

Como segundo resultado importante del proyecto, se tiene la calibración del generador de señales en el laboratorio de metrología en variables eléctricas de la Universidad Tecnológica de Pereira (UTP). Donde se buscó la confiabilidad del generador de señales Gs 2018 el cual fue comparado con el osciloscopio Digital Fluke 123 en el modo medición.

Este proceso se llevó a cabo en las instalaciones del laboratorio de metrología bajo condiciones óptimas y reglamentarias, en este procedimiento se tuvieron en cuenta condiciones como la temperatura y la humedad.

Seguidamente, el generador fue comparado en el modo generación de frecuencia en el rango de 1 a $150 \mathrm{~Hz}$ manejando las tres escalas permitidas por el equipo, $(0,1 \mathrm{~Hz}, 1 \mathrm{~Hz}$ y $10 \mathrm{~Hz})$. El osciloscopio Digital Fluke 123 se colocó en modo medición donde mostró en pantalla la frecuencia emitida por el generador con el fin de demostrar que el generador GS 2018 registra en pantalla una medida confiable.

Se debe tener en cuenta que, en el proceso de calibración, el equipo se encontró siempre en condiciones óptimas, donde el tiempo que duro dicha operación fue de 2 horas.

El proceso de calibración radica en dividir el intervalo de medición en 5 partes, (1Hz, $50 \mathrm{~Hz}, 75 \mathrm{~Hz}, 105 \mathrm{~Hz}, 150 \mathrm{~Hz})$. Para luego generar la frecuencia en cada una de sus escalas permitidas por el generador: colocando la escala de $0,1 \mathrm{~Hz}$ se tomó 10 datos de cada una de las divisiones del rango, luego en la escala de $1 \mathrm{~Hz}$ se repite el procedimiento para cada valor y por último se realiza el proceso con la escala de $10 \mathrm{~Hz}$

Luego de tener los 10 datos por cada frecuencia $(1 \mathrm{~Hz}, 50 \mathrm{~Hz}, 75 \mathrm{~Hz}, 105 \mathrm{~Hz}, 150 \mathrm{~Hz})$ se registra en una tabla de medición que solo posee el laboratorio de metrología, para luego estudiar y analizar los resultados.

Para dar una mejor claridad del proceso realizado se muestra en las figuras 55, 56 y 57 el reporte entregado por el laboratorio de metrología en variables eléctricas. 


\section{MÉTODO DE CALIBRACIÓN:}

Norma Técnica EURAMET cg-15 Guidelines on the Calibration of Digital Multimeters (Versión 3).

\section{CONDICIONES AMBIENTALES:}

Temperatura: $\quad(23,67 \pm 0,36)^{\circ} \mathrm{C}$

Humedad Relativa: $\quad(44,0 \pm 1,7) \%$ HR

\section{EQUIPO UTILIZADO E INFORMACIÓN DE TRAZABILIDAD:}

Equipo: $\quad$ Osciloscopio Digital FLUKE 123

No. de serie: $\quad$ DM9960291

Certificado No: $\quad$ CCEE-368-2018

El Laboratorio establece la trazabilidad de las mediciones del patrón de referencia "Osciloscopio Digital FLUKE 123" con el Sistema Internacional de Unidades (SI) por medio de una cadena ininterrumpida de calibraciones que los vincula a los patrones primarios pertinentes a las unidades de medición del SI.

\section{CONFIGURACIÓN Y OPERACIONES FUNCIONALES DEL EQUIPO BAJO PRUEBA:}

El tiempo de estabilización del equipo bajo prueba con las condiciones ambientales controladas fue de 2 horas antes de iniciar el proceso de calibración y dentro de este tiempo se mantuvo encendido por un periodo de 30 minutos.

Figura 65 Primera Parte del Certificado de Calibración [Autor]. 


\section{OBSERVACIONES:}

- Los puntos de calibración fueron seleccionados de acuerdo a la Solicitud del Cliente.

- El equipo bajo prueba se calibró con sus propios accesorios.

- La incertidumbre expandida es una combinación de componentes de distribución rectangular y componentes de distribución normal.

\section{LABORATORIO DE METROLOGÍA \\ VARIABLES ELÉCTRICAS \\ Carrera 27 No. 10 - 02 - Pereira \\ Teléfono: 3216134}

Certificado No. CCEE-376-2018

- La incertidumbre expandida de la medición reportada se establece como la incertidumbre estándar de medición multiplicada por el factor de cobertura $\mathrm{k}$.

- Los valores de k se calculan para un nivel de confianza del 95\%; si la incertidumbre dominante tiene una distribución rectangular, este factor es de 1,65.

Figura 66 Segunda Parte del Certificado de Calibración [Autor]. 


\section{RESULTADOS DE CALIBRACIÓN}

\section{MODO GENERACIÓN}

\begin{tabular}{|c|c|c|c|c|c|c|c|c|c|}
\hline \multicolumn{10}{|c|}{ Calibración de la función: Frecuencia } \\
\hline Intervalo de Indicación & \multicolumn{2}{|c|}{$\begin{array}{l}\text { Lectura } \\
\text { Promedio } \\
\text { Equipo }\end{array}$} & \multicolumn{2}{|c|}{$\begin{array}{l}\text { Lectura } \\
\text { Patrón }\end{array}$} & \multicolumn{2}{|c|}{ Error } & \multirow{2}{*}{$\begin{array}{c}\mathbf{k} \\
1,65 \\
\end{array}$} & \multicolumn{2}{|c|}{$\begin{array}{l}\text { Incertidumbre } \\
\text { Expandida }\end{array}$} \\
\hline \multirow{5}{*}{$\begin{array}{c}1 \mathrm{~Hz} \text { a } 150 \mathrm{~Hz} \\
\text { Resolución de } 0,10 \mathrm{~Hz}\end{array}$} & 1,000 & $\mathrm{~Hz}$ & 1,041 & $\mathrm{~Hz}$ & $-0,041$ & $\mathrm{~Hz}$ & & $\pm 0,14$ & $\mathrm{~Hz}$ \\
\hline & 50,00 & $\mathrm{~Hz}$ & 50,04 & $\mathrm{~Hz}$ & $-0,04$ & $\mathrm{~Hz}$ & 2,01 & $\pm 0,29$ & $\mathrm{~Hz}$ \\
\hline & 75,00 & $\mathrm{~Hz}$ & 74,92 & $\mathrm{~Hz}$ & 0,08 & $\mathrm{~Hz}$ & 1,96 & $\pm 0,38$ & $\mathrm{~Hz}$ \\
\hline & 105,0 & $\mathrm{~Hz}$ & 104,9 & $\mathrm{~Hz}$ & 0,1 & $\mathrm{~Hz}$ & 1,96 & $\pm 0,51$ & $\mathrm{~Hz}$ \\
\hline & 150,0 & $\mathrm{~Hz}$ & 150,2 & $\mathrm{~Hz}$ & $-0,2$ & $\mathrm{~Hz}$ & 1,65 & $\pm 0,60$ & $\mathrm{~Hz}$ \\
\hline \multirow{5}{*}{$\begin{array}{c}1 \mathrm{~Hz} \text { a } 150 \mathrm{~Hz} \\
\text { Resolución de } 1,00 \mathrm{~Hz}\end{array}$} & 1,000 & $\mathrm{~Hz}$ & 1,039 & $\mathrm{~Hz}$ & $-0,039$ & $\mathrm{~Hz}$ & 1,65 & $\pm 0,14$ & $\mathrm{~Hz}$ \\
\hline & 50,00 & $\mathrm{~Hz}$ & 50,05 & $\mathrm{~Hz}$ & $-0,05$ & $\mathrm{~Hz}$ & 2,01 & $\pm 0,29$ & $\mathrm{~Hz}$ \\
\hline & 75,00 & $\mathrm{~Hz}$ & 74,91 & $\mathrm{~Hz}$ & 0,09 & $\mathrm{~Hz}$ & 1,96 & $\pm 0,38$ & $\mathrm{~Hz}$ \\
\hline & 105,0 & $\mathrm{~Hz}$ & 104,9 & $\mathrm{~Hz}$ & 0,1 & $\mathrm{~Hz}$ & 1,96 & $\pm 0,51$ & $\mathrm{~Hz}$ \\
\hline & 150,0 & $\mathrm{~Hz}$ & 150,2 & $\mathrm{~Hz}$ & $-0,2$ & $\mathrm{~Hz}$ & 1,65 & $\pm 0,60$ & $\mathrm{~Hz}$ \\
\hline \multirow{5}{*}{$\begin{array}{c}1 \mathrm{~Hz} \text { a } 150 \mathrm{~Hz} \\
\text { Resolución de } 10,00 \mathrm{~Hz}\end{array}$} & 1,000 & $\mathrm{~Hz}$ & 1,041 & $\mathrm{~Hz}$ & $-0,041$ & $\mathrm{~Hz}$ & 1,65 & $\pm 0,14$ & $\mathrm{~Hz}$ \\
\hline & 51,00 & $\mathrm{~Hz}$ & 50,97 & $\mathrm{~Hz}$ & 0,03 & $\mathrm{~Hz}$ & 2,01 & $\pm 0,30$ & $\mathrm{~Hz}$ \\
\hline & 81,00 & $\mathrm{~Hz}$ & 80,99 & $\mathrm{~Hz}$ & 0,01 & $\mathrm{~Hz}$ & 1,96 & $\pm 0,41$ & $\mathrm{~Hz}$ \\
\hline & 101,0 & $\mathrm{~Hz}$ & 101,1 & $\mathrm{~Hz}$ & $-0,1$ & $\mathrm{~Hz}$ & 1,96 & $\pm 0,49$ & $\mathrm{~Hz}$ \\
\hline & 150,0 & $\mathrm{~Hz}$ & 150,2 & $\mathrm{~Hz}$ & $-0,2$ & $\mathrm{~Hz}$ & 1,65 & $\pm 0,60$ & $\mathrm{~Hz}$ \\
\hline
\end{tabular}

\section{FINAL DE DATOS}

Figura 67 Tercera Parte del Certificado de Calibración [Autor].

Por otra parte, se realizó la implementación de un segundo generador de frecuencia para mostrar el estudio de las ondas utilizando dos generadores diferentes. Se trata de un estroboscopio el cual también fue diseñado y construido como una mejora del equipo para visualizar de una manera más clara las frecuencias de resonancia.

En la figura 60 se muestra la implementación del estroboscopio en la experimentación de cuerda tensa.

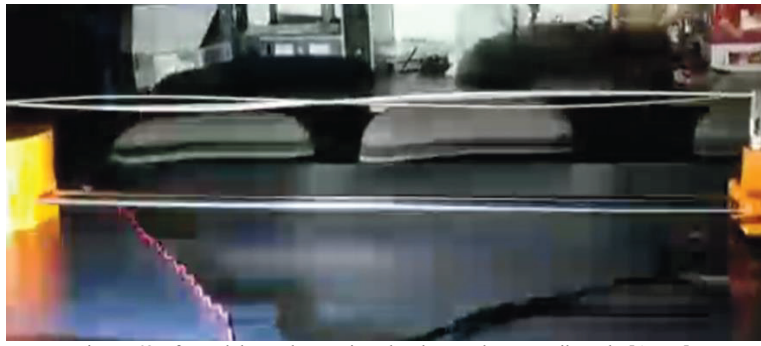

Figura 68 Efecto del estroboscopio sobre la cuerda tensa vibrando [Autor]

Se observa en la figura 60, que el efecto del estroboscopio sobre el prototipo funcional permite una mejor visualización de fenómeno ondulatorio presente sobre la cuerda tensa. Este equipo se implementó de manera adicional al sistema de cuerda tensa, para que facilitara a los estudiantes y docentes la visualización de los modos normales generados sobre la cuerda según cada frecuencia. 
De este modo, los estudiantes en el procedimiento de la experimentación de la cuerda tensa usaron un estroboscopio que al dejar un armónico en la cuerda $(1,2,3,4)$ encienden el generador y observan lo que sucede con la cuerda en el momento en que aumentan la frecuencia del estroboscopio para luego explicar con sus palabras y analizar lo observado en el experimento.
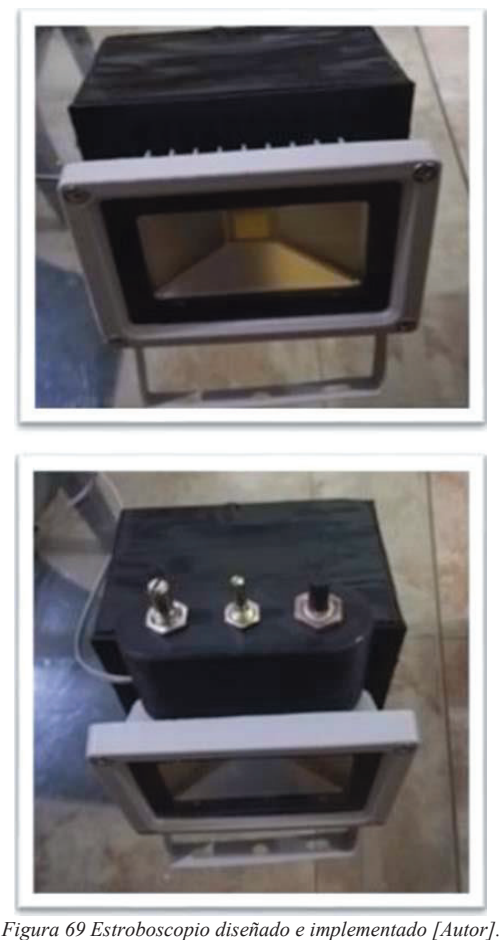

Como se observa, la figura 61 muestra el estroboscopio desde dos ángulos distintos, en la imagen superior se puede ver la parte frontal por donde genera la ráfaga de luz, y en la imagen inferior los controles de calibración de frecuencia del equipo.

\subsection{Conclusiones}

Se diseñó e implementó un prototipo funcional para la práctica experimental de las ondas estacionarias en una cuerda tensa.

Se diseñó e implementó una guía de laboratorio para la materia "Laboratorio de física III", donde se utiliza el equipo implementado para la realización de la práctica.

Se diseñó e implementó un software capaz de manejar el equipo, el cual permite modificar las variables de frecuencia desde una pantalla de control fácil de manejar, con la que, estudiantes y docentes, pueden realizar cambios a la onda generada en la cuerda tensa.

Se diseñaron e implementaron los sistemas electrónicos y mecánicos necesarios para el funcionamiento del equipo bajo las condiciones normales de un laboratorio de física de la Universidad Tecnológica de Pereira. 
Se diseñó un manual de funcionamiento del equipo y el software, donde se recopila la información de cada una de las piezas, forma de instalación, puesta en marcha del equipo, manejo de la interfaz de usuario y características técnicas del equipo.

Se realizó una calibración certificada del equipo, realizada por el Laboratorio de Metrología de la Universidad Tecnológica de Pereira, que permite garantizar la calidad de las medidas tomadas por el equipo y la eficiencia de los elementos utilizados en el mismo.

Se generó trazabilidad del equipo realizado, lo cual le da un aporte de confiabilidad al generador creado que, a su vez, da soporte a la ley física demostrada.

Se puede evidenciar que el equipo diseñado muestra un mejor comportamiento en los datos y una mayor confiabilidad gracias a que su error es menor y la exactitud con la que se encuentran las frecuencias es mayor que la manejada con los equipos existentes en el laboratorio.

Por último, se concluye que, al realizar una comparación de los datos obtenidos por los estudiantes en la realización de la práctica experimental, y su respectivo análisis de resultados, con el prototipo diseñado y los equipos existentes en el laboratorio de física, siempre se obtuvo un resultado más exacto respecto a la literatura con el prototipo, gracias a la mayor resolución presente en este, su capacidad de variar la frecuencia y otros parámetros con precisión por medio del software y la facilidad con la que realiza la toma de datos. 



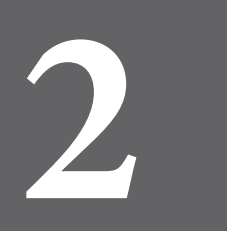

CAPÍTULO

DOS 



\section{Diseño, Construcción e Implementación de una Cubeta de Ondas para el Estudio de la Frecuencia, Velocidad y Longitud de Onda de Ondas Mecánicas mediante Procesamiento Digital de Imágenes}

\subsection{Introducción}

El uso de tecnología en contribución para el aprendizaje, tanto del alumno como del docente, ha venido cobrando fuerza debido a los grandes avances que se han presentado en tecnología para la educación. Una de las asignaturas de mayor complejidad a la hora de concebir por parte de los estudiantes es la física, por lo que es de vital importancia implementar tecnología que facilite la interiorización del conocimiento.

Se propone diseñar y construir un dispositivo tipo cubeta que conste de un generador de ondas donde se pueda apreciar el fenómeno. Logrado lo anterior, se buscará desarrollar un software que permita realizar el procesamiento digital de imágenes para analizar características básicas de la onda como frecuencia, velocidad de propagación y longitud de onda. Donde se pueda además apreciar los fenómenos físicos de reflexión y refracción.

El propósito principal es la obtención de un equipo que permita fortalecer la enseñanza de la física, en este caso de las ondas mecánicas. Razón por la cual deberá ser un equipo dinámico que facilite la pedagogía y que, a través de la interacción con este, se logre una apropiación del conocimiento más sólida y a largo plazo.

Con lo anterior se pretende estimular el trabajo en el campo de la instrumentación, línea que permite innovar, mejorar la productividad e impactar positivamente en diferentes contextos dado los bajos costos del proyecto. Se quiere un equipo propio, de fabricación regional que represente una alternativa económica para la docencia de alta calidad. Así, se promueve también la creación de empresa mostrando alternativas en la producción local de estos equipos.

Finalmente, se tendrá un equipo completo que se utilizará para la enseñanza de la física en los diversos entornos educativos contribuyendo tanto a docentes como estudiantes. Cumpliendo con lo propuesto y resolviendo el problema aquí delimitado se deja la posibilidad a futuro de adicionar otros fenómenos ondulatorios para su estudio, pero con el equipo ya funcionando. 


\subsection{Objetivos}

Diseño, Construcción E Implementación De Una Cubeta De Ondas Para El Estudio De La Frecuencia, Velocidad Y Longitud De Onda De Ondas Mecánicas Mediante Procesamiento Digital De Imágenes

\subsubsection{Objetivo General}

- Diseñar, construir e implementar una cubeta de ondas para el estudio de la frecuencia, velocidad de propagación y longitud de onda mediante el uso adecuado del Sistema Arduino.

\subsubsection{Objetivos Específicos}

- Diseñar y construir el sistema electrónico y mecánico para la generación de ondas.

- Diseñar y construir el sistema mecánico de cubeta de ondas.

- Integrar el sistema mecánico y electrónico del generador de ondas con el sistema de la cubeta de ondas.

- Desarrollar e implementar un software para el funcionamiento de la cubeta de ondas.

- Realizar una guía de laboratorio para la corroboración del fenómeno y la utilización de las propiedades estudiadas.

\subsection{Antecedentes}

El uso de herramientas tecnológicas para mejorar la comprensión de conocimientos teóricos, principalmente en la física, son cada día más necesarias en el ámbito académico y científico, tener la posibilidad de estudiar fenómenos o probar teorías mediante el uso de prototipos tecnológicos permite tanto al docente como al estudiante mejorar su capacidad de comprensión y realizar estudios más profundos de manera ágil y práctica.

En el trabajo de Yun-Ta Wu et al (Wu \& Hsiao, 2018) se observa como utilizan el modelado y experimentación de una onda solitaria viajera en el tanque de ondas, lo que les permitió definir cuál de las teorías sobre propagación de ondas solitarias es la más acertada, para esto utilizan un cálculo numérico con cada una de las teorías y comparan los resultados con los obtenidos en el proceso experimental de la onda viajera dentro del tanque de ondas. Este trabajo demuestra la importancia del tanque de ondas para el análisis de teorías basados en los resultados experimentales donde el centro de estudio es la propagación de una onda en un medio viscoso.

Del mismo modo, el trabajo de My Ha Dao et al (Dao, Chew, \& Zhang, 2018) presenta una aplicación del tanque o cubeta de ondas para el estudio de las olas y como se absorben en el terreno poroso de la arena, presentan una construcción de un modelo numérico de tanques de olas físicas generadas con palas colgantes que se dirigen a un sistema poroso que simula la arena en la playa. El modelo numérico está construido con base al solucionador de Navier-Stokes y el método de Volumen de fluidos en el software de código abierto operación y manipulación de campo abierto (OpenFOAM).

My Hu Dao et al (Dao et al., 2018) realizaron la construcción de un equipo que permite generar ondas en agua salada contenida en un tanque, dirigiéndolas al extremo opuesto del equipo donde se encontraba una placa con un sistema de poros ubicada de diagonal en un ángulo premeditado, de este modo logran simular el movimiento de las olas del mar acercándose a la arena. Este trabajo muestra la importancia del estudio de la longitud de onda aplicado al movimiento de las olas en el mar, debido a que en sus conclusiones encontraron que, tanto para el modelo numérico de estudio como para el modelo experimental, la longitud de onda con la que venían las olas a la placa era determinante para la absorción de las olas. Ratificando para nuestro proyecto la importancia del estudio y la comprensión más clara de la longitud de onda como característica básica de las ondas mecánicas.

Igualmente, M. Oliva en su trabajo sobre el estudio de ondas superficiales en un fluido confinado en un recipiente elíptico (Oliva, 2011) muestra que al variar la geometría se puede modular la forma de oscilación de cada uno de los modos normales de oscilación de un fluido no viscoso. El estudio numérico lo realizó en términos de las funciones de Mathieu demostrando la dependencia de las frecuencias naturales en función de las propiedades del fluido y la excentricidad de la sección transversal del tanque. Así mismo encontró que sus resultados se convierten en una base versátil para el estudio y la simulación dinámica de ondas superficiales bajo el confinamiento elíptico. Debido a sus resultados encontró que utilizando una ecuación típica de ondas podría describir el comportamiento de estas en un fluido con viscosidades bajas.

Finalmente, el trabajo de I. Sergievskaya, (Sergievskaya, Ermakov, \& Kapustin, 2010) titulado "Radar Probing of Steep Gravity Waves. Weve Tank Experiment", permite realzar la importancia de la realización de experimentos ondulatorio en tanques o cubetas de ondas, debido a su variedad de aplicaciones en el ámbito científico, en este trabajo realizaron experimentos ondulatorios en el tanque de ondas que permitieron el estudio de la ruptura suave y fuerte de la superficie de las ondas en la señal del "Ka-Radar" en diferentes ángulos de observación. Observaron que la ruptura suave para las ondas de gravedad-capilar de centímetro a decímetro $(\mathrm{GCW})$ en una inclinación alta puede generar las llamadas ondas capilares parásitas (ondas de escala milimétrica). Concluyeron, entre otras cosas, que el radar de banda Ka que se dispersa a partir de ondas superficiales empinadas en los ángulos de incidencia moderada están determinados por las ondulaciones de Bragg.

Estos trabajos muestran la importancia del uso de tanques de ondas para estudio de las ondas mecánicas, donde es posible observar su comportamiento y buscar formas de modelar interacciones naturales de las ondas con otros medios. Para el presente 
proyecto toma mucha más fuerza la intensión de generar un prototipo que permita apropiarse del conocimiento sobre las características fundamentales de las ondas, permitiendo que docentes y estudiantes se embarquen en proyectos sobre fenómenos ondulatorios con mayor propiedad.

\subsection{Marco Teórico}

El movimiento repetitivo de un objeto donde éste pasa de una posición conocida a otra y regresa a la posición inicial en un tiempo fijo se le conoce como movimiento periódico, un caso especial es el movimiento armónico simple que nos permite formar la base de la comprensión de las ondas, donde centraremos la atención.

Un ejemplo de este fenómeno es cuando gotas de agua caen de una hoja a un estanque, la perturbación provocada por el agua que cae hace que la superficie del agua oscile, dichas oscilaciones se asocian con ondas que se mueven alejándose del punto donde cayó la gota de agua.

\subsubsection{Movimiento Ondulatorio y Ondas}

Si se considera un objeto sobre la superficie del agua en un estanque, al dejar caer una gota en el estanque se vería mover el objeto de manera vertical y horizontal en torno a su posición original, así como todos los elementos del agua. La onda del agua se mueve, pero lleva el agua consigo, es decir el movimiento ondulatorio transporta energía, pero no materia.

En general el fenómeno ondulatorio implica la propagación de energía desde una región de un sistema a otro y se dividen en dos tipos las ondas mecánicas y las ondas electromagnéticas, adicionalmente cada tipo de ondas tienen sus características y propiedades que deben ser identificadas (Serway \& Jawett, 2008a)

La característica principal de las ondas mecánicas es que necesitan un medio mecánico para viajar. Las ondas electromagnéticas como la luz, ondas de radio, infrarrojas, radiación ultravioleta, rayos x y rayos gamma no necesitan un medio para propagarse, es decir, pueden viajar en el espacio vacío. Otra clase de fenómeno ondulatorio se encuentra en el comportamiento de las partículas atómicas y subatómicas, fenómeno estudiado por la mecánica cuántica.

\subsubsection{Ondas mecánicas}

Como se mencionó anteriormente, las ondas mecánicas son aquellas perturbaciones que requieren de un medio material para transportarse. Todas las ondas mecánicas requieren 1) alguna fuente de perturbación, 2) un medio que contenga elementos que sean factibles de perturbación y 3) algún mecanismo físico a partir del cual los elementos del medio puedan influirse mutuamente. Una forma de demostrar el movimiento ondulatorio es agitando el extremo de una larga cuerda tensada y fija en el extremo opuesto a donde se produce la agitación, se verá entonces recorrer un "chichón" con velocidad fija, desde la perturbación hasta el extremo fijo.

Otro ejemplo de ondas mecánicas son las olas del mar que consisten en el largo abultamiento de agua que se ve llegar a la playa o las pequeñas ondas de agua que consisten en ondas de tensión superficial. Estas últimas serán las que se generarán en la cubeta para su posterior estudio pues, capturando una fotografía de las ondas se podrá analizar la relación entre frecuencia, velocidad de propagación y longitud de onda haciendo uso de la herramienta de procesamiento digital de imágenes explicada posteriormente (Feynman, Leighton, \& Sands, 1977).

\subsubsection{Tipos de desplazamiento de las ondas mecánicas}

Sabiendo que una onda mecánica es la perturbación que viaja por algún material o sustancia llamada medio y que son las partículas las que producen el desplazamiento de energía a través de este medio, según la naturaleza de la onda se presenta el tipo de desplazamiento.

Cuando el movimiento del medio es perpendicular o transverso a la dirección en la que viaja la onda a través del medio, se le llama onda transversal. Cuando el movimiento de las partículas del medio es hacia atrás y adelante sobre la misma dirección en la que viaja la onda, se le llama onda longitudinal (Young \& Freedman, 2000). 
Supóngase el movimiento de una partícula en el extremo izquierdo de una cuerda $(\mathrm{x}=0)$ en el que se origina la onda, está dado por:

$$
y(x=0, t)=A \operatorname{sen}(\omega t)=A \operatorname{sen}(2 \pi f t)
$$

Lo que significa que las partículas oscilan en un movimiento armónico simple con amplitud A, frecuencia $f$ y frecuencia angular $\omega=2 \pi f$.

La perturbación viaja desde $x=0$ a algún punto $\mathrm{x}$ a la derecha desde el origen en una cantidad de tiempo dada por $\frac{x}{v}$ donde $v$ es la velocidad de onda. Así, el movimiento desde un punto $\mathrm{x}$ a un tiempo dado es igual al movimiento desde $x=0$ en el momento $t-\frac{x}{v}$. Con lo anterior se tiene:

$$
y(x, t)=A \operatorname{sen} \omega\left(t-\frac{x}{v}\right)=A \operatorname{sen} 2 \pi f\left(t-\frac{x}{v}\right)
$$

Si expresamos la función en términos del periodo $T=\frac{1}{f} \mathrm{y}$ de $\lambda=\frac{v}{f}$ :

$$
y(x, t)=A \operatorname{sen} 2 \pi\left(\frac{t}{T}-\frac{x}{\lambda}\right)
$$

Si además se define la cantidad $k$ llamada número de onda:

$$
k=\frac{2 \pi}{\lambda}
$$

Se substituye $\lambda=\frac{2 \pi}{k}$ y $f=\frac{\omega}{2 \pi}$ en la relación longitud de onda - frecuencia $v=\lambda f$ para una onda periódica:

$$
\omega=v k
$$

Se puede reescribir la ecuación (1) y se tiene la función de onda:

$$
y(x, t)=A \operatorname{sen}(\omega t-k x)
$$

De este modo se obtiene la ecuación de onda para una onda periódica.

\subsubsection{Aceleración y velocidad de una partícula en una onda sinusoidal}

De la función de onda se pude obtener una expresión para la velocidad transversal de cualquier partícula en una onda transversal. A esto se le llama $v_{y}$ para diferenciarlo de la velocidad de propagación de la onda $v$. Para encontrar esa velocidad transversal en un punto $x$ tomamos la derivada de la función $y(x, t)$ con respecto de $t$. Si la función de onda es:

Entonces:

$$
y(x, t)=A \operatorname{sen}(\omega t-k x)
$$

$$
v_{y}(x, t)=\frac{\partial y(x, t)}{\partial t}=\omega A \cos (\omega t-k x)
$$

El símbolo $\partial$ es una expresión modificada de $d$ usada para referenciar que $y(x, t)$ aunque es una función en dos variables, sólo se toma por variable a $t$. La otra variable $x$ queda como constante porque se busca en un punto particular de la cuerda. Esta derivada se conoce como derivada parcial.

La ecuación anterior muestra la velocidad transversal de una partícula que varía con el tiempo como se espera en el movimiento armónico simple. La velocidad máxima de la partícula es $\omega A$; la cual puede ser mayor, menor o igual a la velocidad $v$ según la amplitud y la frecuencia de la onda.

La aceleración de cualquier partícula es la segunda derivada parcial de $y(x, t)$ con respecto a $t$ :

$$
a_{y}(x, t)=\frac{\partial^{2} y(x, t)}{\partial t^{2}}=-\omega^{2} A \operatorname{sen}(\omega t-k x)=-\omega^{2} y(x, t)
$$


La aceleración de una partícula es $-\omega^{2}$ veces el desplazamiento.

También se pueden computar derivadas parciales de $y(x, t)$ con respecto a $x$ mantiendo $t$ constante. Esto corresponde al estudio de la forma de la cuerda en un instante de tiempo. La primera derivada es la pendiente de la cuerda en cualquier punto. La segunda derivada es la curvatura de la cuerda:

$$
\frac{\partial^{2} y}{\partial x^{2}}=-k^{2} A \operatorname{sen}(\omega t-k x)=-k^{2} y(x, t)
$$

De la aceleración de la partícula, la curvatura de la cuerda y la relación $\omega=v k$ se tiene:

$$
\begin{gathered}
\frac{\frac{\partial^{2} y(x, t)}{\partial t^{2}}}{\frac{\partial^{2} y(x, t)}{\partial x^{2}}}=\frac{\omega^{2}}{k^{2}}=v^{2}, \\
\frac{\partial^{2} y(x, t)}{\partial x^{2}}=\frac{1}{v^{2}} \frac{\partial^{2} y(x, t)}{\partial t^{2}}(\text { ecuación de onda) }(3)
\end{gathered}
$$

La ecuación de onda es una de las ecuaciones más importante de toda la física. En el momento que ocurra, se sabe que la perturbación puede propagarse como una onda a lo largo del eje $x$ a una velocidad $v$. La perturbación no debe ser necesariamente como onda sinusoidal, todas las formas válidas como función de onda satisfacen la ecuación de ondas. El concepto de función de onda es igual de útil con ondas longitudinales y todo lo mencionado con funciones de onda puede ser adaptado en este caso. La cantidad $y$ sigue midiendo el desplazamiento de una partícula en el medio desde su posición de equilibrio, la diferencia es que, en una onda longitudinal, el desplazamiento es paralelo al eje $x$ en lugar de perpendicular (Young \& Freedman, 2000).

\subsubsection{Imágenes digitales}

Para entrar en el campo del procesamiento digital de imágenes es necesario entender que una imagen es una función de dos dimensiones $\mathrm{f}(\mathrm{x}, \mathrm{y})$, donde $\mathrm{x}$, $\mathrm{y}$ son coordenadas espaciales, $\mathrm{y}$ la amplitud de $\mathrm{f}$ en cualquier par de $\mathrm{x}$, $\mathrm{y}$ es llama intensidad o nivel de gris de la imagen en ese punto. Cuanto todos estos valores son finitos en cantidades discretas, se habla de imagen digital, $\mathrm{y}$ a cada punto o valor mínimo se le conoce como píxel (ver figura 63).

Se consideran tres tipos de procesamiento digital de imágenes, de nivel bajo, medio y alto. El proceso de nivel bajo se refiere a caracterizar por el hecho de que entradas y salidas son imágenes. El proceso de imágenes en nivel medio involucra la segmentación, la clasificación y la descripción de objetos. Por último, el nivel alto involucra las funciones cognitivas normalmente asociadas a la visión (Serway \& Jawett, 2008b).

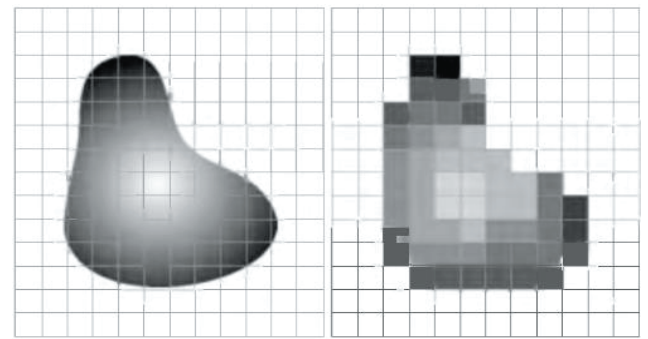

Figura 71 Imagen proyectada en el arreglo de un sensor e imagen muestreada y cuantificada (Gonzalez \& Woods, 2002).

Respecto del nivel de procesamiento de interés para este proyecto se habla de segmentación en lo que se refiere a la detección de puntos y al reconocimiento de objetos. La detección de puntos en una imagen obedece al resultado de aplicar una máscara y donde esta se centre, localizar el punto si se cumple que:

$$
R \geq T
$$

Donde T es el umbral no negativo y R está dado por: 


$$
R=\sum_{i=0}^{n} W_{i} Z_{i}
$$

Donde $\mathrm{Z}$ es el nivel de gris de la máscara asociado al coeficiente $\mathrm{W}$ y n el tamaño de la máscara.

Para la detección de objetos en imágenes, desde el punto de vista de la segmentación, se utiliza la detección de bordes encontrando discontinuidades en niveles de gris.

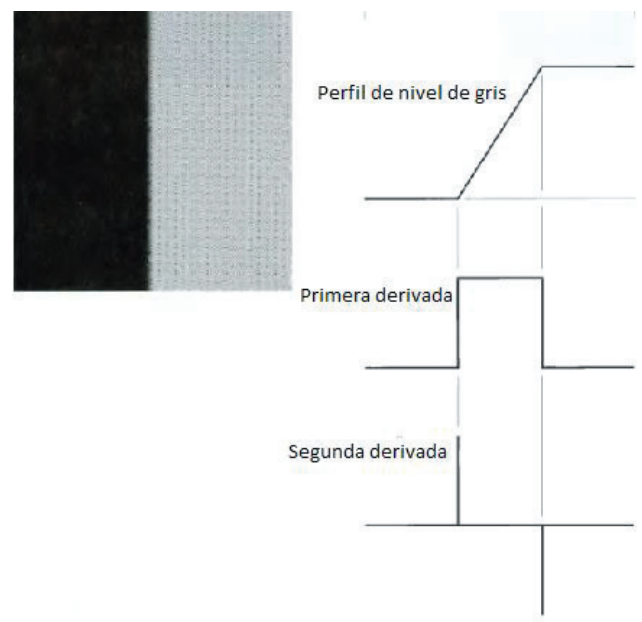

Figura 72 Dos regiones separadas por un borde vertical. Perfil del nivel de gris y primer y segunda derivada (Gonzalez \& Woods, 2002).

Como se muestra en la figura 64, el grosor del borde es determinado por la longitud de la rampa. La primera derivada puede usarse para detectar el borde en un punto de la imagen. De forma similar, el signo de la segunda derivada puede utilizarse para determinar si un pixel borde se encuentra la parte más oscura o más clara del borde (Gonzalez \& Woods, 2002).

\subsubsection{Propuesta para el desarrollo}

El equipo propuesto puede clasificarse como un instrumento que permite estudiar la frecuencia, velocidad de propagación y longitud de onda. Además, podría permitir la visualización de fenómenos físicos como la reflexión, refracción y el efecto Doppler. Lo anterior haciendo uso de la herramienta de procesamiento digital de imágenes que busca favorecer la enseñanza por permitir una interacción dinámica con el equipo.

Teniendo en cuenta lo anterior se debe instrumentar un generador y un equipo mecánico que definan la viabilidad y confiabilidad del equipo. La propuesta a realizar se resume de la siguiente manera:

- El generador: se debe implementar un generador que permita transmitir la perturbación a un medio líquido para la propagación de la onda, que es la base del proyecto. Se espera generar ondas que oscilen entre $0 \mathrm{~Hz}$ y $50 \mathrm{~Hz}$ para una visualización adecuada en la imagen que se pretende capturar y procesar.

- $\quad$ El sistema mecánico: se propone fabricar una cubeta que satisfaga las necesidades de un docente para la enseñanza de la física y que además sea fácil de usar por el alumno autodidacta que desea aprender. Para el uso de todo el sistema se desarrollará una guía de usuario que facilite la enseñanza y el aprendizaje. El tamaño de la cubeta será el adecuado para 
su manipulación, con una superficie que servirá de pantalla para la visualización de las ondas generadas y la captura de las imágenes de esta. Se espera que el equipo sea más económico en comparación a los importados para tener la posibilidad de acceder a este fácilmente. Adicionalmente, se desarrollarán los obstáculos pertinentes para ubicarlos en el medio líquido y estudiar los fenómenos de reflexión y refracción. Por último, para el estudio del efecto Doppler es necesario un sistema que permita el desplazamiento de la fuente o generador y así visualizar este fenómeno.

- El procesamiento digital de imágenes: Las últimas salidas del equipo serán las realizadas con esta herramienta.

- Los valores de las características de la onda: velocidad, frecuencia y longitud.

A continuación, se presenta el esquema del sistema propuesto:

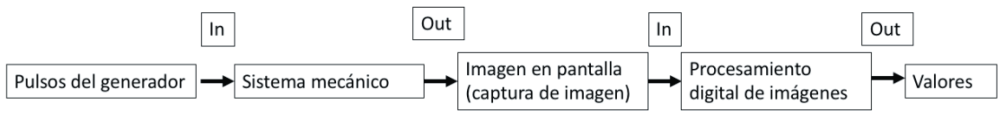

Figura 73 Esquema general del sistema propuesto [Autor].

\subsection{Diseño Metodológico}

\subsubsection{Unidad de análisis}

La base del proyecto presentado es la medición de las características de una onda generada en un medio líquido mediante la transmisión de pulsos. Con la imagen capturada de la perturbación y su propagación se realizará el respectivo procesamiento.

\subsubsection{Variables}

Las variables que se determinaron en el proyecto corresponden a las características de velocidad de propagación, frecuencia y longitud de onda. Con el generador implementado y acoplado en el sistema mecánico se pueden generar pulsos en el medio líquido a una frecuencia deseada. Una vez capturada la imagen de la onda generada es posible con la información de la frecuencia y la longitud de onda medida, determinar su velocidad de propagación.

Por otro lado, con la implementación de obstáculos en el medio y una fuente móvil es posible estudiar los fenómenos físicos correspondientes a reflexión y refracción. Lo anterior con la posibilidad de variar la posición del obstáculo o la velocidad a la que se desplaza la fuente.

A continuación, en el siguiente apartado se enumeran las actividades en orden de acuerdo con la forma en que se desarrolló el proyecto propuesto:

1. Diseño e implementación de un generador que permita transmitir impulsos a un medio líquido para la propagación de esta perturbación. Se dispone de un generador que permite generar perturbaciones entre los 0 y $50 \mathrm{~Hz}$

Los pasos fueron los siguientes:

- Realizar el levantamiento de requerimientos para la implementación del generador de ondas.

- Definir los valores mínimos y máximos de frecuencia a la que el generador produce la onda para su estudio

- Diseñar el generador de ondas basado en los requerimientos y con las condiciones de máximo y mínimo valor de frecuencias definidas.

- Instrumentar (construir) el generador de ondas basado en el diseño.

2. Desarrollar un plan de pruebas que permitió comparar el generador ondas con otros equipos similares.

- Realizar los ajustes necesarios para lograr el óptimo funcionamiento del generador de ondas.

- Implementar (instrumentar) y puesta en marcha del generador de ondas teniendo en cuenta los ajustes y elementos encontrados en el plan de pruebas.

3. Con las anteriores actividades se recolectó la información que se presenta a continuación:

- Los instrumentos electrónicos y mecánicos que fueron utilizados. 
- El rango de frecuencia a la que debía trabaja el generador.

- La capacidad que tiene el generador de lograr lo requerido en comparación a las simulaciones.

- Diseñar e implementar un equipo mecánico tipo cubeta que satisfaga las necesidades del proyecto.

- Realizar el levantamiento de requerimientos mecánicos y técnicos para el diseño de la cubeta de ondas.

- Diseño e implementación de un sistema que permitiera la movilización del generador de ondas mientras produce las perturbaciones.

- Diseño e implementación de un sistema de obstáculos móvil y de fácil uso para el posible estudio de otros fenómenos ondulatorios.

- Diseñar e implementar una pantalla para la visualización de las ondas y la toma de imágenes digitales.

\subsection{Implementación Experimental}

Para el correcto funcionamiento del prototipo de cubeta de ondas, se diseñaron y construyeron subsistemas, que se acoplaron para obtener el resultado esperado, cumpliendo con los parámetros establecidos para este proyecto de funcionalidad y fácil manejo.

De esta forma, se diseñó un esquema guía que permitió identificar cada una de partes involucradas en el funcionamiento del prototipo, en la figura a continuación se observa cada una de las partes que componen el prototipo de cubeta de ondas, además el esquema muestra por medio de líneas de colores, las conexiones entre cada uno de los subsistemas y cómo deben comunicarse entre sí.

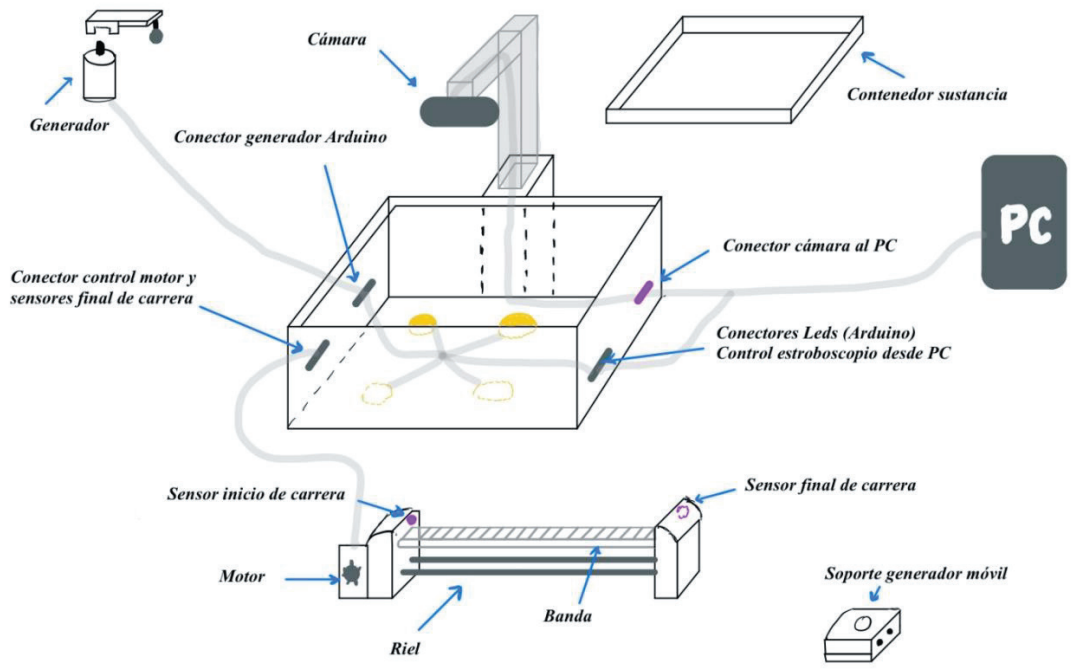

Figura 74 Esquema del Prototipo de Cubeta de Ondas [Autor].

El esquema de la figura 66 permitió contemplar la forma estructural que tomaría el prototipo, y se constituyó en el eje central para realizar los diseños de los subsistemas, permitiendo diseñar pieza por pieza teniendo en cuenta su ubicación final y cual función adicional, de existir una, cumpliría dentro del prototipo, así como a cuáles otros subsistemas deberían de acoplarse entre sí. Se observa el generador en la parte superior izquierda, la cámara en la parte superior del tanque, el tanque central donde se ubica el contenedor de sustancias y los sensores electrónicos, igualmente se observa las conexiones entre los equipos y el computador.

Se dividió la implementación del prototipo en partes: diseño e implementación del generador de ondas, diseño e implementación de la cubeta de ondas, diseño e implementación del software de control y manejo del equipo, y por último realización de la guía del equipo y software, cada uno de estos pasos se describen a continuación. 
Todas las piezas mecánicas que fue necesario diseñarlas para imprimirlas en la impresora 3D, fueron diseñadas en el software SolidWorks, que brinda al usuario la posibilidad de crear piezas a la medida en un marco profesional, del mismo modo el software es compatible a la impresora 3D Wanhao en la cual se imprimieron todas estas piezas del prototipo.

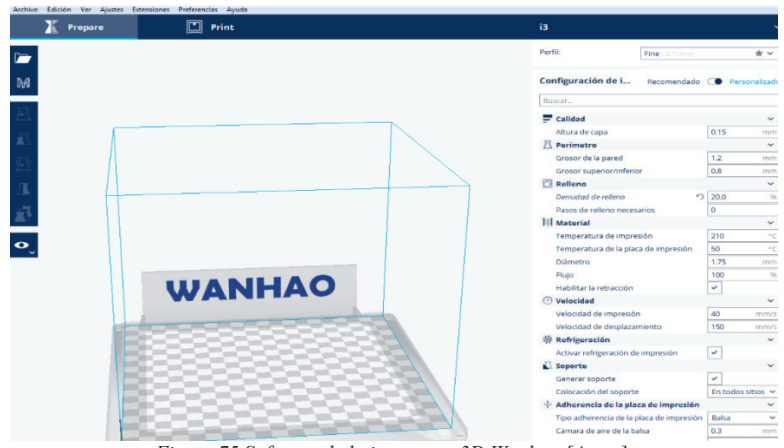

Figura 75 Software de la impresora 3D Wanhao [Autor].

En la figura 67 se observa un recorte de pantalla del módulo de diseño de piezas del software de la impresora 3D Wanhao utilizado para la impresión de las piezas mecánicas del prototipo.

\subsubsection{Diseño e Implementación de un generador de ondas.}

Se inició el proceso de diseño con el levantamiento u obtención de requerimientos mínimos del equipo, donde se estableció el rango de trabajo para el generador, el tamaño del equipo, el material que se utilizó, entre otros parámetros básicos, requeridos, en el espacio de un aula de clase o un laboratorio real, usando como referencia el laboratorio de Maestría en Instrumentación Física de la Universidad Tecnológica de Pereira, además, se estableció un tamaño para el equipo y se determinó el rango de funcionamiento que sería entre $0 \mathrm{~Hz}$ y $50 \mathrm{~Hz}$ con una precisión de $\pm 0,1$ en unidades de Hertz.

El generador de ondas es un circuito integrado del tipo AD9823, es decir, es un oscilador controlado por voltaje (VCO) que genera señales de salida sinodales, cuadradas y triangulares, posee además la opción de controlar la frecuencia de salida (Electronica, 2018), entre otros parámetros, como se muestra en la siguiente imagen:

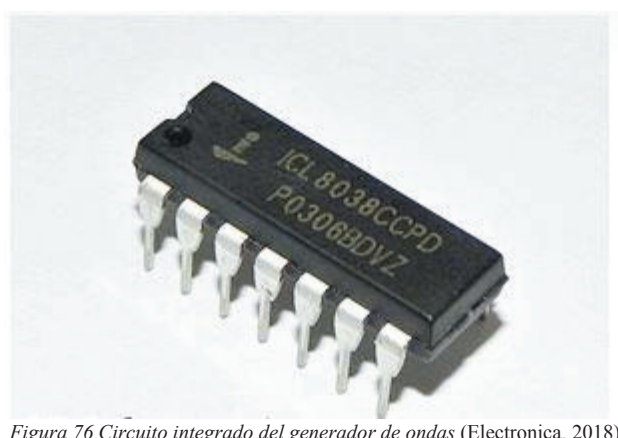

Se observa en la figura 68, el circuito integrado que actúa al recibir una señal de voltaje controlada desde el Arduino, convirtiéndola en una onda con frecuencia ajustable, que se transmite al fluido para su estudio por medio del sistema de transmisión de la onda. 
De este modo, fue necesario acoplar este circuito integrado con sistema de transmisión de onda, que consiste en dos elementos principales con algunas partes diseñadas e impresas en la impresora 3D, que permiten la transferencia de la onda con frecuencia ajustable entregada por el circuito integrado al fluido, donde puede ser visualizada la onda y estudiada.

El primer elemento es el cuerpo o sistema central que posee una bobina que genera un movimiento vertical y horizontal de cabezal o punta, con base en el principio de un electroimán, el movimiento se da en la frecuencia indicada por el circuito integrado, que, a su vez, transmite la frecuencia a través del cabezal al fluido para el estudio de las ondas generadas.

El sistema de transmisión de onda entrega la señal generada por circuito integrado al fluido por medio de dos actuadores VCM (Voice Coil Motor) que consisten en una bobina redonda, concéntrica ubicada en un espacio donde hay un campo magnético radial. Este campo generalmente se obtiene mediante un imán permanente ubicado dentro de la estructura (Magnetic, Duras, 2018).

La interacción entre el campo magnético de la bobina y el campo magnético en el gap es lo que da lugar a la fuerza lineal (vertical, en este caso) que actúa sobre la bobina. El campo magnético de la bobina se debe a la corriente que fluye en la bobina, esta corriente de salida necesaria para el correcto funcionamiento del embobinado fue calculada previamente. Así mismo, la posición del imán dentro de la unidad, el tipo de imán, la estructura circundante, etc., influye en el valor de esta fuerza (Magnetic, Duras, 2018) como se observa en la figura 69.

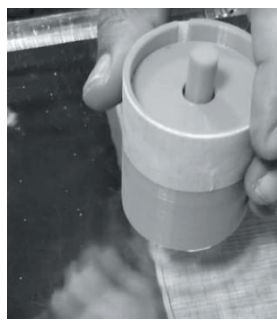

Figura 77 Sistema de transmisión de onda VCM (Voice Coil Motor) [Autor].

En la figura 69. se observa uno de actuadores diseñados para el generar el movimiento vertical oscilatorio de la punta y transmitir de manera controlada la onda en la frecuencia esperada al fluido.

Por otra parte, el segundo elemento es el cabezal o punta, que consiste en un elemento base y elementos removibles o intercambiables que se acoplan al sistema de transmisión de ondas, lo que permite estudiar el fenómeno ondulatorio con diferentes frentes de ondas. Ambos elementos se muestran a continuación en la figura 70.

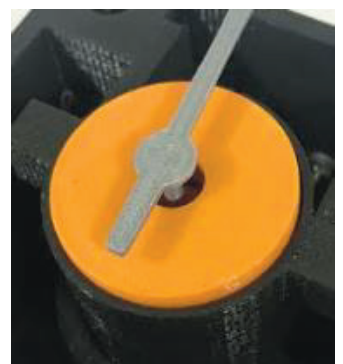

Figura 78 Elementos de transmisión de Onda al Fluido [Autor].

En la figura 70, se observa las piezas para el sistema de transmisión de onda y el cabezal que va en contacto con el fluido, este es el que finalmente transmite la onda con la frecuencia deseada. Igualmente, puntas intercambiables del cabezal fueron diseñadas e impresas en la impresora 3D, una de estas se muestra a continuación en la figura 71. 


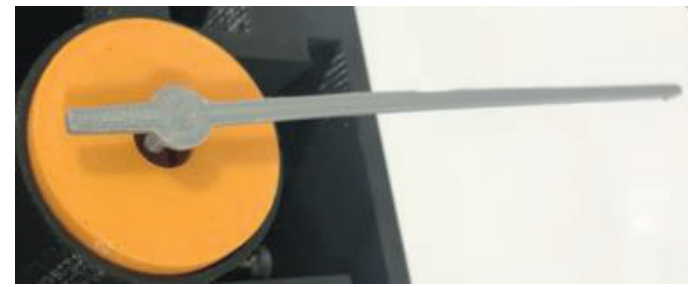

Figura 79 Cabezales intercambiables para estudio de diferentes tipos de frente de onda [Autor].

En la figura 71, se observa el cabezal que puede ser intercambiado por otro para el estudio de diferentes fenómenos ondulatorios, como fue mencionado anteriormente, estos fenómenos implican frentes de onda distintos sobre el fluido, los cabezales permiten generar diferentes frentes de ondas con frecuencias determinadas por el generador de ondas.

De este modo, todas las piezas se diseñaron en el programa SolidWorks y todas las piezas del prototipo en una impresora 3D marca Wanhao, como fue mencionado antes, disponible en el laboratorio del grupo de investigación DICOPED.

Finalmente, se diseñó un plan de pruebas que consistió básicamente en realizar órdenes básicas desde el panel de usuario diseñado específicamente para el equipo, como generar ondas en una frecuencia determinada y luego aumentar dicha frecuencia También se utilizó el riel de movimiento mientras el generador estaba encendido, así como otras pruebas funcionales y de resistencia.

Al finalizar este periodo de prueba, se realizaron los ajustes pertinentes tanto en la parte hardware como de software del equipo, realizando la puesta a punto de la primera etapa del sistema.

\subsubsection{Diseño e Implementación de la estructura de cubeta de ondas}

Para un uso óptimo de espacio se diseñaron dos cubetas, una que contiene el fluido donde se realizará el estudio de las ondas generadas, y otro que sirve de soporte tanto para la cubeta anteriormente mencionada como para los circuitos y los sistemas secundarios necesarios para el funcionamiento del equipo.

La cubeta secundaria se diseñó con medidas de $220 \mathrm{~mm}$ de ancho por $430 \mathrm{~mm}$ de largo, fue cortada y ensamblada en acrílico, y está contemplada para el uso de sustancias de viscosidad variable como agua, aceite, entre otras. En la figura 24 . se observa el esquema inicial y la pieza terminada.
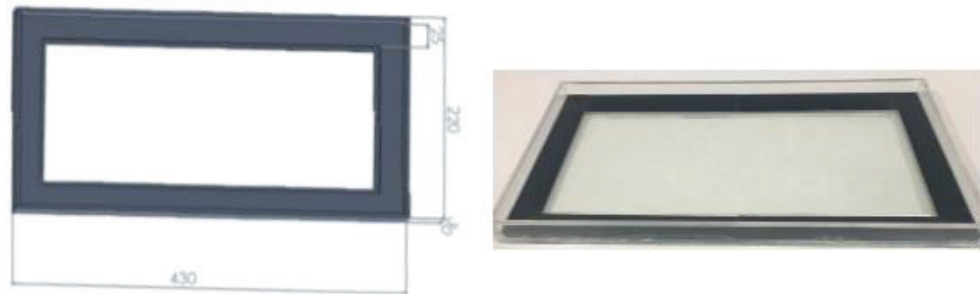

Figura 80 Esquema de cubeta secundaria (izquierda) y pieza finalizada (derecha) [Autor].

En la figura 72, se observa el diseño de la cubeta secundaria a la izquierda de la figura con sus respectivas dimensiones, y en la parte derecha de la imagen se observa la pieza terminada y lista para su integración al sistema.

Por otra parte, la cubeta primaria (ver figura 73), como ya fue mencionado, se diseñó con el objetivo de contener, no solo la cubeta secundaria, sino también los elementos electrónicos necesarios para el estudio de las ondas generadas en la cubeta secundaria, es decir, los componentes electrónicos que permiten realizar la generación de las ondas y la toma de imágenes de estas. 
Estos elementos se distribuyeron de tal forma que permitiera el uso eficiente del espacio de la cubeta primaria, respetando el espacio para la cubeta secundaria. Los elementos principales contenidos en esta cubeta primaria es el circuito electrónico para controlar los componentes del sistema, y los leds que al encenderse permiten una visualización clara de las ondas en el fluido.
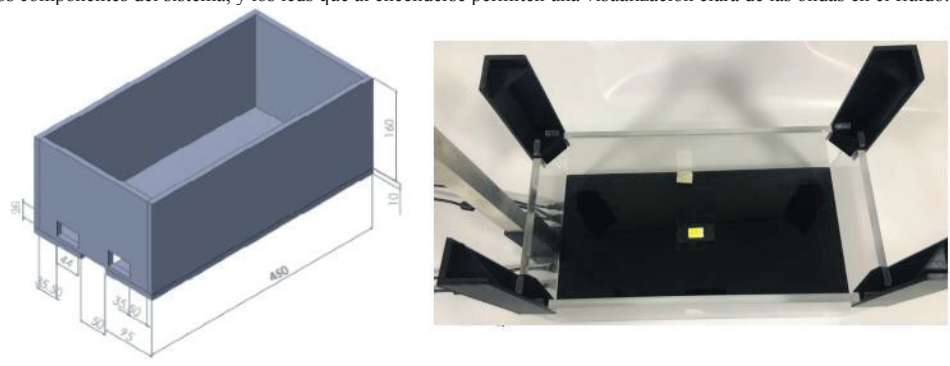

Figura 81 Esquema de cubeta primaria (izquierda) y pieza finalizada (derecha) [Autor].

Los elementos electrónicos contenidos en la cubeta principal se diseñaron con base al microcontrolador ATMEGA 328, fue necesario utilizar dos microcontroladores de este tipo. Se realizó la programación de estos en la plataforma Arduino con las instrucciones necesarias para el control de los elementos electrónicos periféricos que rodean el microcontrolador. Fue necesario también, diseñar e implementar una Shield para el sistema electrónico, que son placas de circuitos modulares que se montan unas encima de otras para dar funcionalidad extra a un microcontrolador o un Arduino, esto permitió integrar los sistemas electrónicos periféricos.

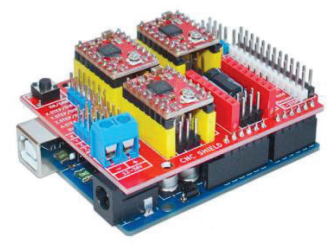

Figura 82 Muestra de una Shield instalada en un microcontrolador Arduino (Arduino, 2018)

En la figura 74 se observa el dispositivo electrónico conformado por la Shield y el microcontrolador con el software de control de los sistemas del equipo. El elemento Shield diseñado para el presente trabajo consta de cuatro Driver A4988, los cuales permiten controlar los motores paso a paso, 2 actuadores VCM que se encargan de generar las frecuencias qué necesita el tanque, y por último el control de la luz led, es importante resaltar que se realizó la calibración de estos drivers para su correcto funcionamiento y evitar errores en la ejecución del programa quemado en el microcontrolador.

El dispositivo electrónico controla la iluminación del tanque de ondas, esto se realiza a través de un driver A4988, el cual limita la corriente que fluye a través de leds de potencia 3 watts de luz blanca generando un efecto Strober, al controlar digitalmente su encendido y apagado, esto permite un efecto de visualización en cámara lenta del movimiento de los objetos, en este caso de las ondas en el fluido (Wikipedia The Free Enciclopedy, 2009).

Igualmente, el dispositivo electrónico controla el giro y velocidad del motor paso a paso que permite mover el riel en dirección adelante y atrás, así mismo, permite leer los interruptores del inicio y fin de carrera (Switch), cabe aclarar que el riel es paralelo al tanque de ondas, lo cual permite visualizar el efecto Doppler generado por el movimiento de la fuente de ondas.

\subsubsection{Diseño e implementación adicional sistema de riel horizontal}

Como un adicional, se diseñó e implementó un sistema de riel para el movimiento en una dimensión del generador de ondas, que permite el movimiento de este en forma horizontal mientras este se encuentra en funcionamiento. Esto permitió el estudio de 
otros fenómenos ondulatorio como el efecto Doppler, y abrió la posibilidad de aumentar la capacidad de estudio de otros fenómenos ondulatorios utilizando el equipo diseñado.

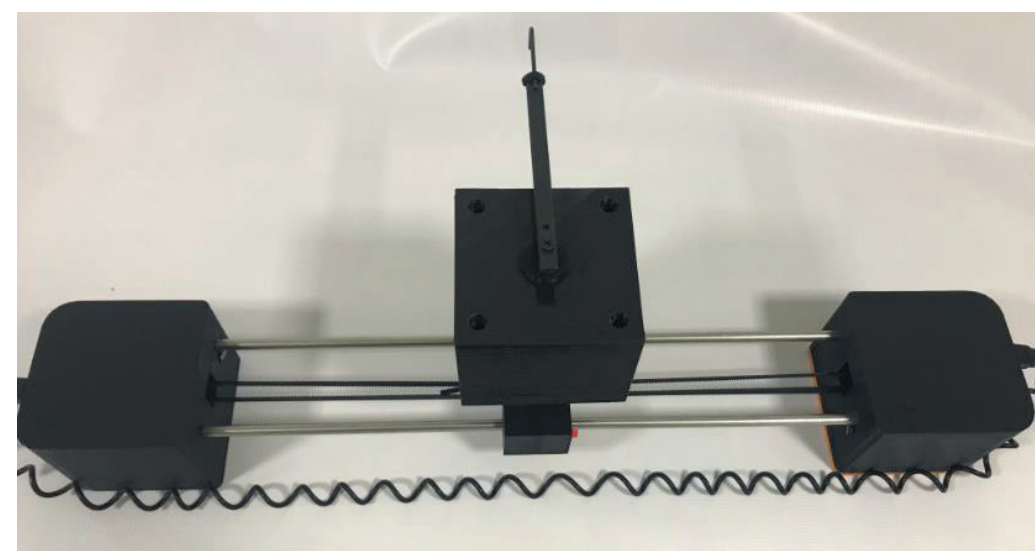

Figura 83 Riel, pieza terminada [Autor].

En la figura 75, se puede observar el riel para el movimiento horizontal del generador de ondas, todas las piezas fueron diseñadas en la impresora 3D. Se utilizó un motor paso a paso para el movimiento, que es controlado desde la plataforma, donde se puede variar la velocidad de movimiento del generador y se puede mover mientras este está generando ondas para el estudio de diferentes fenómenos ondulatorios.

\subsubsection{Diseño e implementación de una plataforma virtual para el control del equipo}

Para el diseño y desarrollo de la plataforma digital se utilizó el entorno de desarrollo Visual Studio de Microsoft versión 2010, codificado en lenguaje de programación C\#, para realizar la interfaz de usuario y el panel de control debido, entre otras cosas, a que tiene una licencia gratuita para libre uso, es muy utilizado en la maestría en Instrumentación Física de la Universidad Tecnológica de Pereira, y permite la manipulación y análisis de imágenes.

Consta de una interfaz gráfica del tipo Formulario de Windows que se compone de 5 pantallas, las cuales se describen a continuación:

- Pantalla principal: es una pantalla que contiene un menú superior con las siguientes opciones.

- Archivo, permite al usuario cerrar la aplicación en la opción "Salir".

- Ayuda, brinda la posibilidad de acceder al "manual de usuario" en PDF o de verificar la información básica de la aplicación en "Acerca de" 


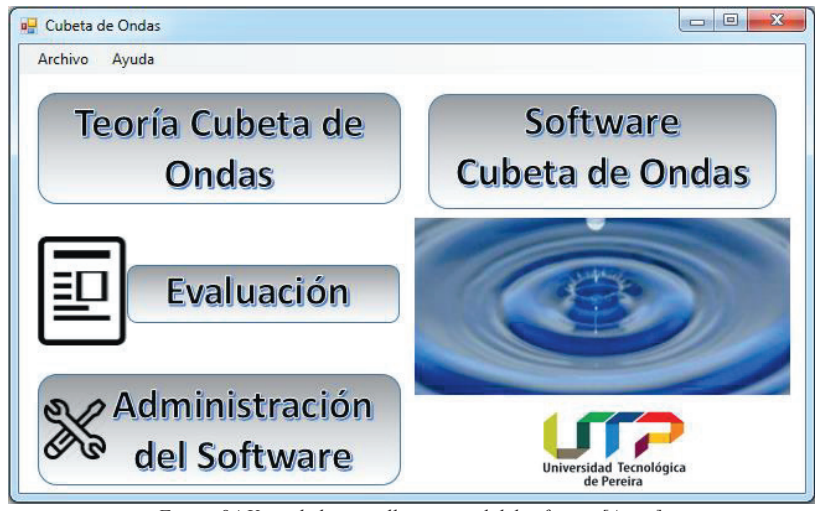

Figura 84 Vista de la pantalla principal del software [Autor].

En la figura 76, se observa la pantalla principal del software diseñado para el control del prototipo y todas sus configuraciones.

Así mismo, se dispone de un contenedor principal donde se muestran las diferentes opciones o módulos a las cuales puede acceder el usuario, presionando clic en el icono definido para cada una de ellas, las opciones que se dispone son las siguientes:

- Teoría movimiento ondulatorio: en esta sección se puede revisar conceptos básicos referente a los fenómenos ondulatorios vistos desde el área de la física, allí se dispone de una lista de selección múltiple que cuenta con conceptos predeterminados para la aplicación, esto permite al estudiante, disponer de las herramientas necesarias para entender los fenómenos que se trabajaran en la práctica asociada al experimento de cubeta de ondas, para ello se cuenta con una descripción textual de cada uno de los conceptos, acompañados, de ser necesario, de una imagen para aclarar o reforzar los mismo, además de la descripción de la fuente de donde fue tomada la definición. De igual forma es importante aclarar que el administrador del software tendrá la posibilidad de ingresar nuevas definiciones para complementar la aplicación.

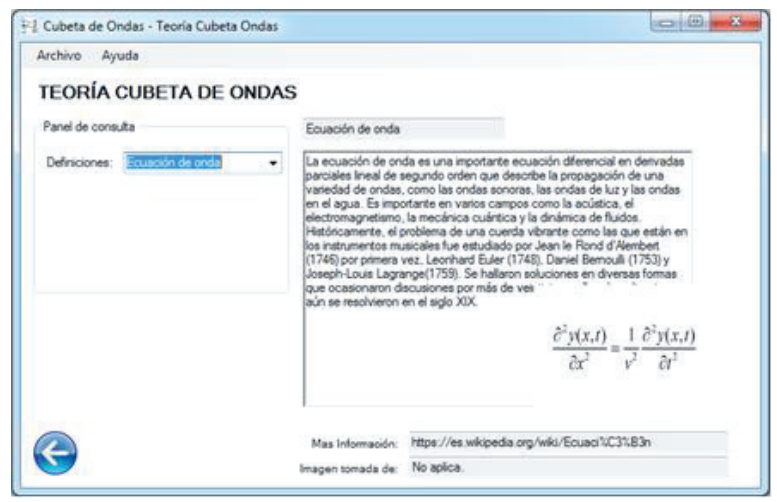

Figura 85 Vista del módulo de Teoría del Movimiento Ondulatorio [Autor].

- Evaluación: en este módulo se plantearon preguntas relacionadas con el tema de movimiento ondulatorio y específicamente de cubeta de ondas, donde el docente tendrá la posibilidad de evaluar el avance y el aprendizaje de los 
conceptos por parte del estudiante. Para ello se dispone de una base de datos de preguntas de selección única y además se brinda la posibilidad desde la pantalla de administración del software para complementar, es decir, adicionar, modificar o eliminar las preguntas según el docente lo considere pertinente.

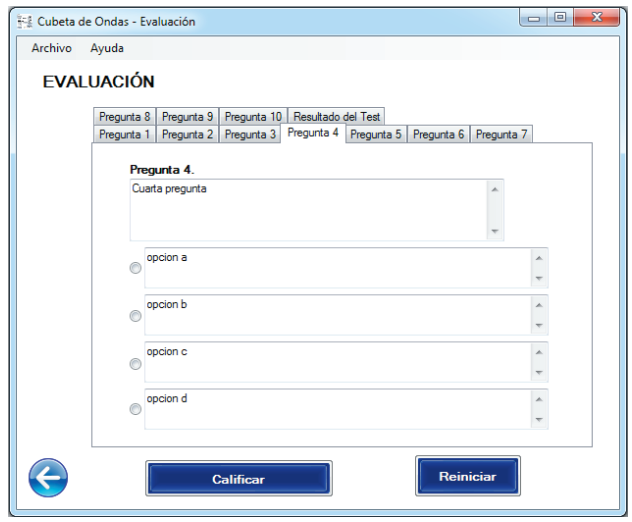

Figura 86 Vista del módulo de Evaluación [Autor].

- Software de control de Cubeta de Ondas: en este módulo se desarrolló la parte funcional del software en conjunto con el prototipo de experimentación, dentro de la pantalla se podrá controlar el funcionamiento de cada uno de los periféricos (elementos del sistema), tales como, cámara, generadores de señales, riel para desplazamiento de las fuentes de ondas, sensores y leds. En pantalla (software en ejecución) se observa un módulo donde se realiza la visualización, captura y estudio de las características de las ondas generadas en la cubeta. Para ello se dispone de una cantidad de botones funcionales (objetos) que le permiten al usuario interactuar con la aplicación.

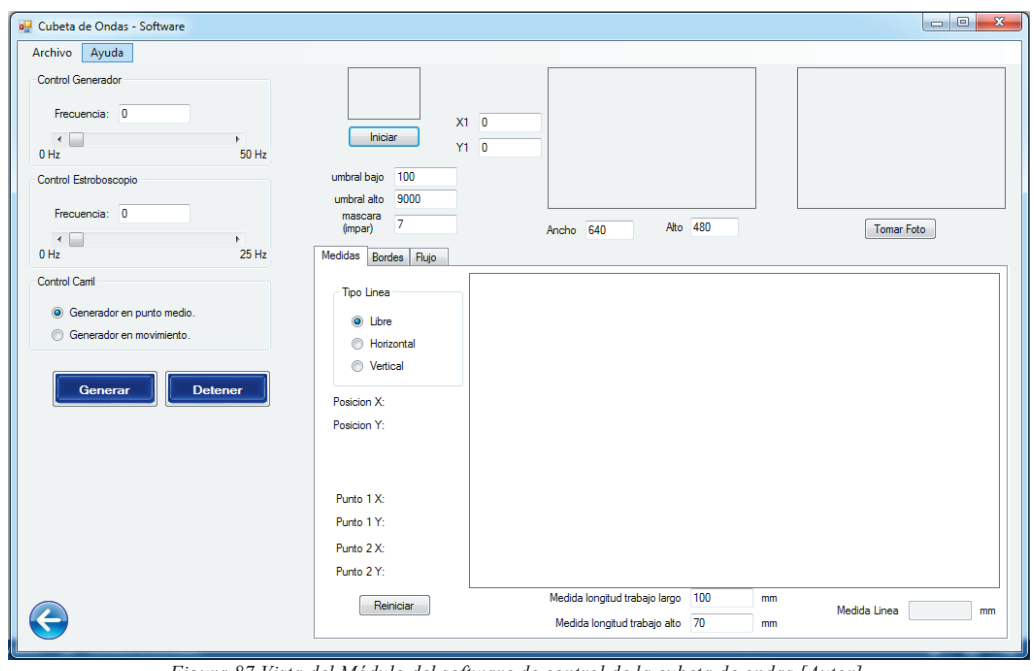

Figura 87 Vista del Módulo del software de control de la cubeta de ondas [Autor]. 
- Administración del Software: en este módulo el administrador, tiene la posibilidad de manipular la información relacionada con las definiciones de conceptos teóricos para el módulo de teoría de movimiento ondulatorio, así mismo, está en la capacidad de definir nuevas preguntas de selección única para el módulo de evaluación y finalmente podrá gestionar un cambio de clave para el acceso al presente modulo.

\begin{tabular}{|c|c|c|c|c|c|}
\hline \multicolumn{3}{|c|}{ If Cubeta de Ondas - Administración Software } & \multicolumn{3}{|c|}{\begin{tabular}{|l|l|l|}
$口$ & 回 & $x$ \\
\end{tabular}} \\
\hline Archivo & \multicolumn{5}{|l|}{ Ayuda } \\
\hline \multirow{2}{*}{\multicolumn{6}{|c|}{ ADMINISTRACIÓN SOFTWARE }} \\
\hline & & & & & \\
\hline & Acciones & \multirow[b]{2}{*}{ Lista de definiciones } & \multicolumn{3}{|c|}{ Definición (titulo): } \\
\hline & Crear definición & & \multicolumn{3}{|c|}{ Onda mecánica } \\
\hline & Modficar/Eliminar & \begin{tabular}{|l|} 
Onda \\
Onda mecánica
\end{tabular} & \multicolumn{3}{|l|}{ Descripción: } \\
\hline & definición & $\begin{array}{l}\text { Onda rransversaal } \\
\text { Onda longitudinal } \\
\text { Ecuación de onda } \\
\text { Amplitud de onda } \\
\text { Cresta } \\
\text { Valle } \\
\text { Nodo } \\
\text { Longitud de onda } \\
\text { Ciclo } \\
\text { Frecuencia } \\
\text { Imagen digital }\end{array}$ & \multicolumn{3}{|c|}{ 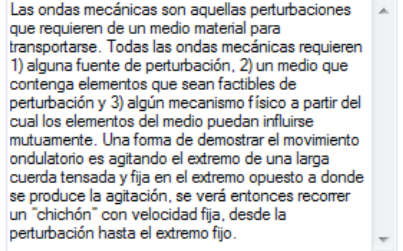 } \\
\hline & & & \multicolumn{3}{|c|}{ Link infomación (opcional): } \\
\hline & & & \multicolumn{3}{|c|}{ R. Serway. J. Jawett, Serway Fisica para Ciencias e Inge } \\
\hline & & & \multicolumn{3}{|c|}{ Link imagen (opcional): } \\
\hline & & & \multicolumn{3}{|c|}{ No aplica. } \\
\hline & & & Eliminar & Modificar & \\
\hline
\end{tabular}

Figura 88 Vista del módulo de Administración del software [Autor].

- Manual de usuario: Descripción de cada una de las pantallas, usos de los botones, como se refleja en el prototipo y el prototipo que variables puede tener y como modificarlas.

\subsection{Análisis de Resultados}

El resultado principal del presente trabajo es el prototipo funcional con todos los sistemas integrados y operando, igualmente integrado con cada uno de los sistemas y software para su correcto funcionamiento y control. A continuación, se enumeran los resultados obtenidos en orden de pertinencia.

\subsubsection{Prototipo Funcional}

El prototipo consiste en diferentes sistemas integrados y controlados por un software diseñado con este fin, en la siguiente imagen se puede observar el prototipo integrado. 


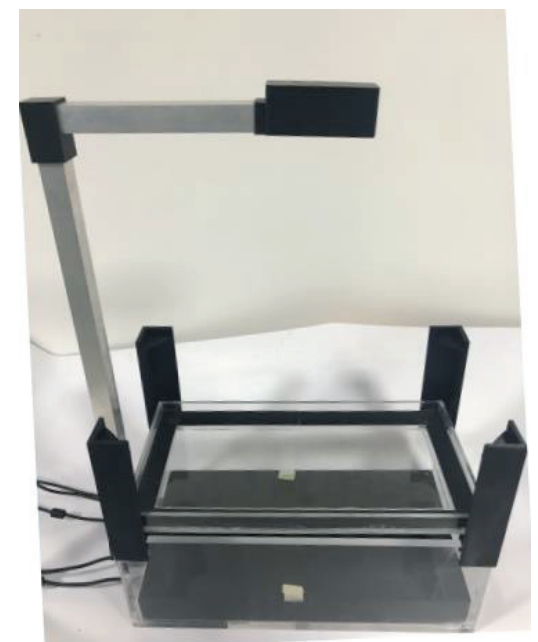

Figura 89 Prototipo de cubeta de ondas [Autor].

En la figura 81 se observa el prototipo funcional de cubeta de ondas con todos los sistemas integrados. Adicional al módulo mostrado se incluye el riel que fue mostrado en imágenes previas, dicho riel permite realizar prácticas adicionales para el análisis de las ondas cuando la fuente que las genera se encuentra en movimiento.

Como parte del protocolo de puesta en marcha del equipo, se realizó un plan de pruebas que permitiera resaltar las posibles fallas del equipo, con el cual fue posible realizar ajustes y dejar el equipo de cubeta de ondas totalmente funcional y ajustado para su correcto funcionamiento. El plan de pruebas se describe a continuación:

\subsubsection{Plan de Pruebas}

El plan de pruebas fue diseñado con la idea de buscar posibles errores y encontrar la forma óptima de manejarlos. Se realizó una vez el equipo se encontraba integrado y consistió una serie de pasos ordenados, que tenían como objetivo definir si se encontraba un problema, de haberlo se procedía a realizar los ajustes necesarios para solucionar el problema, sino se continuaba con el siguiente paso hasta terminar todas las etapas de prueba.

Este plan de pruebas se manejó con un protocolo tipo encuesta donde se puede escribir la solución dada al problema encontrado, con el fin de tener trazabilidad del trabajo realizado y evitar futuros problemas en nuevos desarrollos a realizarse; el protocolo de plan de pruebas fue el siguiente:

Plan de Pruebas de funcionalidad del equipo de cubetas de ondas:

1. Conectar todos los sistemas electrónicos del equipo y realizar la conexión con el computador. Conectar el equipo a la fuente de poder y encenderlo. Inicial la detección y comunicación del equipo desde el software de control. ¿El software detectó el equipo? Si_. No__. Solución:

2. Con el equipo encendido y conectado al computador, dar la orden por medio del software de encender los leds. ¿Encienden? Si_. No_. Solución:

3. Con el equipo encendido y conectado al computador, dar la orden por medio del software de encender y apagar los leds en intervalos cortos, es decir, que proporcionen luz de forma intermitente. Mientras lo hacen desconectar la fuente de poder. Encender de nuevo el equipo y realizar la misma orden. ¿Encienden de forma intermitente? Si_. No_. Solución: 
4. Con el equipo encendido y conectado al computador, dar la orden por medio del software de realizar el movimiento horizontal del riel que sostiene el generador de ondas. ¿Funciona? Si_. No_. Solución:

5. Con el quipo encendido y conectado al computador, dar la misma orden de mover el riel, mientras lo mueve desconectar la fuente de poder. Encender de nuevo el equipo y realizar la misma orden. ¿funciona? Si_. No _. Solución:

6. Con el equipo encendido y conectado al computador, dar la orden de visualizar la cámara, tomar una foto y visualizarla en el software de análisis de imágenes. ¿Funciona? Si_. No__. Solución:

7. Con el equipo encendido y conectado al computador, depositar agua sobre la cubeta secundaria. Ubicarla en el lugar correcto dentro de la cubeta primaria. Dar la orden de generar ondas de frecuencia $5 \mathrm{~Hz}$. ¿Funciona? Si_. No__. Solución:

8. Con el equipo encendido y conectado al computador, dar la orden de generar ondas con frecuencia de $5 \mathrm{~Hz}$ y variar la frecuencia hasta llegar a los $20 \mathrm{~Hz}$. ¿Funciona? Si_. No__. Solución:

9. Con el equipo encendido y conectado al computador, dar la orden de generar ondas con frecuencia de $5 \mathrm{~Hz}$ y variar hasta llegar a los $20 \mathrm{~Hz}$, mientras se realiza esta variación, desconectar la fuente de poder. Encenderla de nuevo y realizar la misma orden. ¿Funciona? Si_. No_. Solución:

10. Con el equipo encendido y conectado al computador, revisar en el software el contenido teórico y los exámenes de conocimientos. Entrar en modo administrador y escribir una pregunta nueva en el examen y agregar un tema corto a la base teórica. Guardar y apagar el equipo. Nuevamente encenderlo y revisar que la pregunta agregada se encuentra dentro de las preguntas estándar del módulo de evaluación. ¿Guardó la información? Si_. No__. Solución:

Prueba realizada en la fecha: DD/MM/AAAA. Realizada por:

Una vez realizada el plan de pruebas y realizados los ajustes necesarios, de haberlos, se procede con los últimos detalles estéticos del equipo, evitando que queden cables por fuera de los contenedores de circuitos y las cajas establecidas para esta función.

\subsubsection{Software de Control del Equipo}

El diseño e implementación del software de control hace parte fundamental del equipo y permite la funcionalidad y control de los diferentes sistemas que componen el prototipo de cubeta de ondas. Permite realizar las variaciones de diferentes variables del equipo como la frecuencia de las ondas generadas y la toma de las imágenes de estas, además tiene a disposición un módulo de análisis de imágenes para estudio de las ondas.

En las características del software sobresale la posibilidad de realizar cambios en distintas variables para realizar estudios de diferentes fenómenos ondulatorios, entre los cuales se da la posibilidad de variar la velocidad de movimiento del riel donde está soportado el generador de ondas, esto posibilita el estudio del efecto Doppler a diferentes frecuencias y con diferentes frentes de onda.

Por otra parte, las imágenes tomadas pueden ser visualizadas en el módulo de análisis de imágenes, que contiene herramientas que permiten realizar la parametrización de la medición las condiciones bajo las cuales se definió la ubicación de la cámara antes de tomar la imagen para realizar el procesamiento.

Para el procesamiento de imágenes el software permite definir dos puntos dentro de las imágenes y medir a cuánto corresponde la distancia entre los puntos en unidades de milímetros, para esto la imagen se pasa a escala de grises y se binariza, de esto se hablará en detalle dentro del "manual de Usuario del prototipo cubeta de ondas" (anexo 1), que hace parte integral del proyecto.

\subsubsection{Manual de usuario}

En el manual de usuario del equipo se encuentran las especificaciones técnicas de cada uno de los sistemas que integran el prototipo de cubeta de ondas, como armar el equipo, soluciones a posibles problemas, configuraciones iniciales y manejo del software de control. 
En las especificaciones técnicas aparecen detalles como el voltaje y corriente con la que funciona el equipo, el espacio necesario para lograr una instalación efectiva, las dimensiones de cada una de las piezas, cantidad de piezas y donde deben ir ubicadas para el correcto funcionamiento del equipo.

De igual modo, cuenta con un paso a paso de como armar el equipo para una configuración inicial, y una guía de posibles problemas encontrados durante el primer ensamble del prototipo, por ejemplo, qué hacer si no detecta la cámara, que hacer si no encienden los leds, entre otras.

Por otra parte, contiene una guía de usuario para el software de control donde muestra las configuraciones iniciales para la puesta en marcha del prototipo, además de explicaciones detalladas de cada uno de los módulos y sus funciones en modo usuario y modo administrador.

Finalmente, el manual de usuario contiene el protocolo del plan de pruebas realizado al equipo, esto con la finalidad de que pueda ser realizado por el usuario, y verificar por sí mismo el correcto funcionamiento del prototipo de cubeta de ondas.

Cabe resaltar que el manual contiene ilustraciones de las piezas, las pantallas de los módulos del software y descripciones de estos para facilitar el uso del equipo tanto a docentes como alumnos.

\subsection{Conclusiones}

Se construyó un equipo funcional y fácil de usar para el estudio de las ondas mecánicas sobre un fluido, con la capacidad de medir las variables de frecuencia, velocidad de propagación y longitud de onda por medio del análisis digital de imágenes.

Se diseñó el equipo de cubeta de onda con la capacidad realizar movimiento horizontal y vertical mientras genera las ondas a una frecuencia controlada, lo que permite el estudio de diferentes fenómenos ondulatorios.

El equipo de cubeta de onda tiene la capacidad de intercambiar la punta del generador de ondas para cambiar el frente de onda generado en el fluido, permitiendo el estudio de otros fenómenos ondulatorios basados en el tipo de frente de onda.

El software implementado para el control del equipo de cubeta de onda tiene la capacidad de ser programado para el estudio de otros fenómenos ondulatorios, por lo que tiene un gran potencial de mejora. 



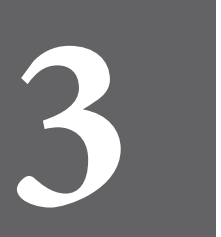

CAPÍTULO TRES 



\section{Diseño, Construcción e Implementación de un Equipo Experimental para el Efecto Doppler}

\subsection{Introducción}

En el estudio de las ondas mecánicas y electromagnéticas, aparecen diferentes fenómenos que merecen un acercamiento más detallado para su comprensión y aplicación de forma práctica. Tal es el caso del efecto Doppler, conocido en la física porque es la base que permite generar diferentes dispositivos que miden distancias y velocidades de los objetos solo por medio de ondas.

En el grupo DICOPED nace la necesidad de desarrollar un proyecto para comprobar el efecto Doppler mediante el sonido, planteando la idea de construir el dispositivo capaz de aplicar la teoría del efecto Doppler. Inicialmente se planteó realizarlo con ultrasonido, pero en la práctica se definió que cumplía una mejor función el sonido audible, principalmente el que se encuentra en los rangos de entre $5.000 \mathrm{~Hz}$ y $10.000 \mathrm{~Hz}$. Esto se debe a que las características del ultrasonido y el sonido audible son las mismas a excepción de su frecuencia (donde se clasifican) y además con el sonido audible el experimentador puede percibir el sonido y del mismo modo percibir el efecto Doppler, lo cual no es posible con ultrasonido.

El prototipo diseñado consta de un micrófono que funciona entre estas frecuencias, un parlante, sensores especializados y un computador; se desarrolló un software que analiza el sonido recibido y computa los cálculos necesarios para obtener la velocidad con la que el objeto que emite el sonido se encuentra cuando pasa frente al micrófono.

Como resultados se obtuvo un software capaz de realizar los cálculos con el sonido recibido por el micrófono, se generó una guía de laboratorio para el prototipo. De esta forma se puede medir la velocidad del sonido en el medio y la velocidad de un auto (objeto de prueba), comprobada con la velocidad promedio utilizando leyes de la cinemática por un medio independiente para su calibración.

\subsection{Marco Teórico}

El efecto Doppler es el cambio de frecuencia percibido de una fuente de frecuencia constante, como efecto resultante del cambio en el estado cinético, ya sea de la fuente misma, el receptor o el cambio en el estado de movimiento de los dos, receptor y fuente.

Como es conclusión obvia de lo descrito en el párrafo anterior, al centrar la atención en la frecuencia, este efecto se aplica tanto a las ondas mecánicas como a las ondas electromagnéticas.

Para facilitar la comprensión del modelamiento matemático y mantener la coherencia con el alcance de este trabajo, la explicación y desarrollo del efecto Doppler se centrará en el resultado sobre el sonido como onda mecánica principal. 
Como fenómeno físico, el efecto Doppler puede ser percibido cuando, por ejemplo:

- Se está viajando a alta velocidad en un auto que pasa por un lugar donde hay un sonido fuerte de alarma. En este caso, el que viaja en el vehículo percibirá un sonido que cambiará justo cuando cruza el vehículo la fuente del sonido.

- Si se está parado en un andén y un vehículo, antes de cruzar, hace sonar el claxon o pito indicando su afán. Mientras el vehículo cruza por nuestra posición, se percibe un cambio en el sonido del claxon.

Cualquiera sea el caso, y por facilidad en el análisis previo, la velocidad con que se cruza sea constante, se puede notar lo siguiente:

- Aunque el sonido emitido no tiene cambios (ni en amplitud, ni en la frecuencia), el sonido percibido presenta cambios en la amplitud y en el tono (frecuencia)

- $\quad$ La amplitud del sonido percibido es directamente proporcional a la distancia de la fuente y las características físicas del medio en que se transmite el sonido (amortiguación del aire).

- Aunque la frecuencia del sonido emitido no tenga cambios, el sonido percibido será diferente al emitido en su tono (frecuencia), y su diferencia más notable será en el instante en que se cruza la fuente de sonido (el emisor) con el que percibe (receptor) el sonido.

Por lo tanto, la frecuencia del sonido percibido es siempre determinado, por la velocidad relativa con que se mueve el receptor con respecto a la fuente.

\subsubsection{Modelamiento Matemático}

Se deben considerar las características del sonido similares a las características de las ondas que se ven en el agua cuando se perturba la superficie en reposo, ya que ambas son ondas mecánicas que se expanden o transmiten a través de un medio, en este caso, una en el aire (gas) y la otra en el agua (liquido).

De similar manera a las ondulaciones del agua, en el aire, las perturbaciones del sonido provocan frentes de onda las cuales se representan en la figura, como círculos concéntricos, donde el círculo mayor es el primer frente de onda o la primera cresta generada, ya que es posible considerar, a todas las ondas viajeras desplazándose simétricamente, desde la fuente hacia el exterior y a velocidad constante (velocidad del sonido).

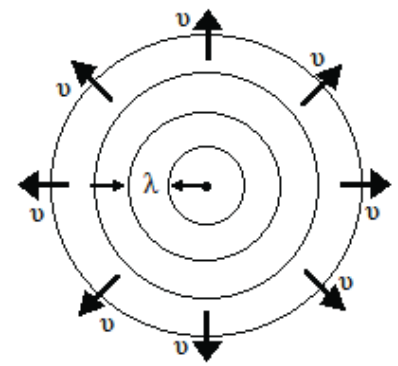

Figura 90 Frente de Onda (Young \& Freedman, 2013)

Por lo tanto, cada frente de onda se expandirá a una rapidez constante $v$ y con una longitud de onda $\lambda$, indicada en la gráfica (Figura 82) como la distancia entre dos frentes de onda. Cabe recordar, en las ondas viajeras, la rapidez de la onda $v$ es proporcional a la longitud de onda $\lambda$ y a la frecuencia $f$, esto es:

$$
v=\lambda f
$$

Así, el sonido será el mismo para cualquier observador ubicado en las inmediaciones de la fuente, siempre y cuando ni la fuente (emisor) ni el observador (receptor) estén en movimiento. 
Nota: Por simplificación en el análisis, se considerará el caso especial en que el movimiento del observador y/o la fuente se realiza en un solo sentido, es decir, o se acercan o se alejan entre sí.

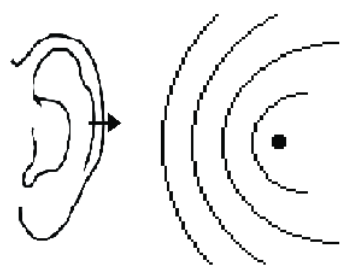

Figura 91 Expansión de frentes de onda (Young \& Freedman, 2013).

3.2.1.1 Caso 1: Fuente estática y receptor en movimiento.

Cuando el receptor se mueve, el tono recibido no es el mismo que el tono emitido, esto es en términos físicos, los frentes de onda recibidos no tienen la misma frecuencia de onda $f$ de la fuente original, ya que están siendo afectados por la velocidad del receptor (Ver figura). En términos de magnitudes, se distinguen tres tipos de velocidad (rapidez):

$v$ : Velocidad del sonido (sólo depende del medio de transmisión)

$v_{0}$ : Velocidad del observador/receptor

$v^{\prime}$ : Velocidad relativa entre el Observador-emisor (fuente)

Hay que tener claro que esta última velocidad determina las características del sonido recibida por el observador, esto es $f, T, v, \lambda, \omega$, etc.

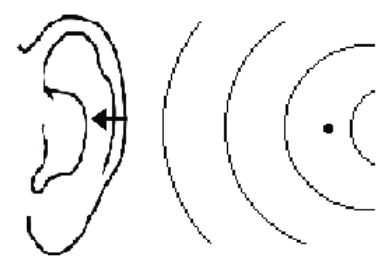

Figura 92 Distancia entre frentes de onda cuando el observador está (Young \& Freedman, 2013).

$$
v^{\prime}=\lambda^{\prime} . f^{\prime} \text { despejando la frecuencia } f^{\prime}=\frac{v^{\prime}}{\lambda \prime}
$$

Recordando para este caso, que es el receptor el que se mueve, queda claro que las características mecánicas de la onda no cambian, esto es $\lambda^{\prime}=\lambda=\frac{v}{f}$

Pero, la velocidad de la onda percibida (velocidad relativa $v^{\prime}$ ) entre el receptor y la velocidad del sonido, cambia debido al movimiento del observador, así:

- Cuando el Receptor se acerca a la fuente, la velocidad de la onda percibida $\left(v^{\prime}\right)$ es la suma de la velocidad del sonido con la velocidad del observador, esto es:

$$
v^{\prime}=v+v_{0}
$$

- Cuando el receptor se aleja de la fuente, la velocidad de la onda percibida $\left(v^{\prime}\right)$ es la resta de la velocidad del sonido con la velocidad del observador, esto es:

$$
v^{\prime}=v-v_{0} .
$$

Por lo tanto, es la velocidad relativa $v^{\prime}$ la que se afecta con el movimiento del observador, por lo tanto:

$$
f^{\prime}=\frac{v^{\prime}}{\lambda^{\prime}}
$$


donde es "+" si se acerca; o "-"se aleja de la fuente.

$$
\begin{aligned}
f^{\prime} & =\frac{v}{\lambda \mp \Delta \lambda} \\
f^{\prime} & =\frac{v}{\frac{v}{f} \mp \frac{v_{s}}{f}} \\
f^{\prime} & =\frac{1}{1 \mp \frac{v_{s}}{v}} f
\end{aligned}
$$

\subsubsection{Caso 2: Fuente en movimiento y receptor estático.}

Con proceso analítico similar al anterior caso, se puede afirmar:

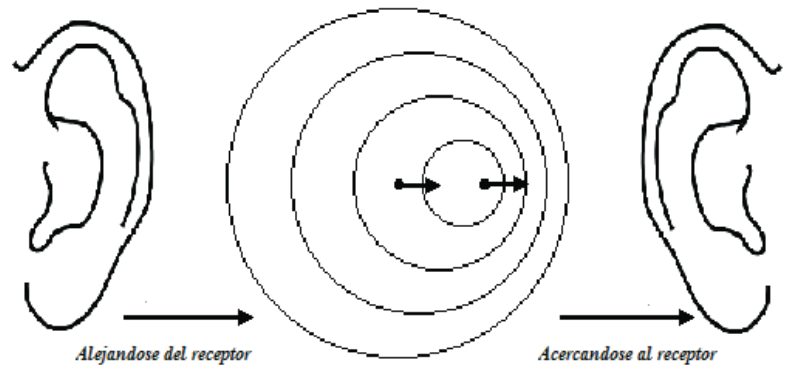

Figura 93 Cuando la fuente se mueve en el medio de transmisión (Young \& Freedman, 2013)

Cuando la fuente se mueve con respecto al receptor, las características mecánicas de la onda emitida cambian, ya que la longitud de onda estará aumentando o disminuyendo, dependiendo de la posición del receptor, es decir, los frentes de onda aumentaran o disminuirán su longitud de onda dependiendo de la dirección que tome la fuente de sonido.

En términos de magnitudes, se distinguen tres tipos de velocidad (rapidez):

$v$ : Velocidad del sonido (sólo depende del medio de transmisión)

$v_{s}$ : Velocidad de la fuente de sonido.

$v^{\prime}$ : Velocidad relativa entre el Observador-emisor (fuente)

Teniendo claro que cuando la fuente se mueve, es el receptor el que percibe el cambio de la onda emitida, la mejor forma de representar cuantitativamente este cambio es la longitud de onda con un $\Delta \lambda$, así:

- Cuando la fuente se acerca al receptor la onda emitida cambia ya que la longitud de onda se hace más pequeña con el paso del tiempo y por tanto la longitud de onda percibida será $\lambda^{\prime}=\lambda-\Delta \lambda$

- Cuando la fuente se aleja del receptor, la onda emitida se hace más grande en su longitud de onda con el paso del tiempo, $\lambda^{\prime}=\lambda+\Delta \lambda$

Como ya se indicó tal cambio en la longitud de onda $(\Delta \lambda)$ está determinada por la velocidad de desplazamiento de la fuente $\left(v_{s}\right)$ y el tiempo en que otro frente de onda vuelve a surgir ( $T$-Periodo), esto es:

$\Delta \lambda=v_{s} T=v_{s} / f$ donde $f$ es la frecuencia original del sonido

En consecuencia, la frecuencia percibida por el receptor estará dada como: $f^{\prime}=\frac{v^{\prime}}{\lambda \prime}=\frac{v}{\lambda \mp \Delta \lambda}=\frac{v}{\frac{v^{v}}{f} \frac{v_{s}}{f}}=\frac{1}{1 \mp \frac{v_{s}}{v}} f:$ donde es "- "si se acerca al receptor o "+" si se aleja

\subsubsection{Caso 3: Fuente en movimiento y receptor en movimiento.}

En términos de magnitudes, se distinguen cuatro tipos de velocidad (rapidez): 


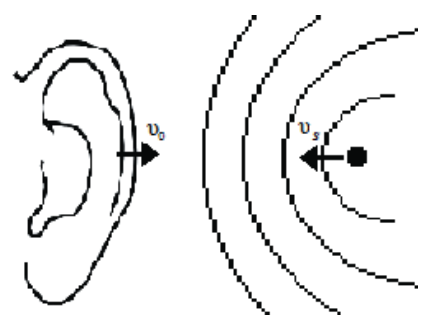

Figura 94 Receptor y fuente acercándose (Young \& Freedman, 2013).

$v$ : Velocidad del sonido (Solo depende del medio de transmisión)

$v_{s}$ : Velocidad de la fuente de sonido.

$v_{0}$ : Velocidad del observador/receptor

$v^{\prime}$ : Velocidad relativa entre el Observador-emisor (fuente)

Se aprovechará el análisis realizado en los dos casos anteriores para determinar las relaciones cuantitativas que caracterizan este caso.

La frecuencia del sonido que percibe el observador es determinada por la velocidad relativa entre el observador y la fuente, esto es:

$$
v^{\prime}=\lambda^{\prime} . f^{\prime} \text { O dado en frecuencia } f^{\prime}=\frac{v^{\prime}}{\lambda^{\prime}}
$$

Así estos dos valores $\left(v^{\prime}, \lambda^{\prime}\right)$ deben ser determinados para cada situación física;

Cuando El receptor y la fuente de sonido se acercan, las magnitudes $\left(v^{\prime}, \lambda^{\prime}\right)$ toman los siguientes valores:

La velocidad relativa es:

$$
v^{\prime}=v+v_{0}
$$

Y la longitud de onda recibida es:

$\lambda^{\prime}=\lambda-\Delta \lambda$

Resolviendo en $f^{\prime}=\frac{v^{\prime}}{\lambda^{\prime}}$ se obtiene

$$
f^{\prime}=\left(\frac{v+v_{0}}{v-v_{s}}\right) f
$$

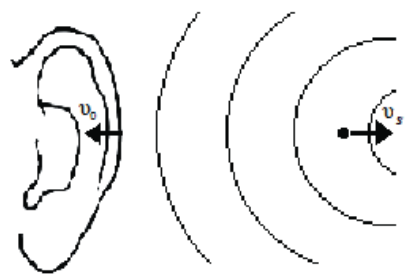

Figura 95 Receptor y fuente alejándose (Young \& Freedman, 2013).

Cuando el receptor y la fuente de sonido se alejan, las magnitudes $\left(v^{\prime}, \lambda^{\prime}\right)$ toman los siguientes valores:
La velocidad relativa es:
$v^{\prime}=v-v_{0}$
Y la longitud de onda recibida es:
$\lambda^{\prime}=\lambda+\Delta \lambda$
Resolviendo en $f^{\prime}=\frac{v^{\prime}}{\lambda^{\prime}}$ se obtiene
$f^{\prime}=\left(\frac{v-v_{0}}{v+v_{s}}\right) f$ 
Por lo tanto, en forma general, esta relación es representada como $f^{\prime}=\left(\frac{v \mp v_{0}}{v \pm v_{s}}\right) f$ en los casos que el receptor-fuente, estando en movimiento ambos, se acerquen o se alejen.

Esta relación es de altísima importancia para este proyecto, ya que de allí se puede despejar la relación de velocidades en función de las frecuencias medidas, quedando de la siguiente manera:

$$
v_{0}=\left(1 \pm \frac{f^{\prime}}{f}\right) v \pm\left(\frac{f^{\prime}}{f}\right) v_{s}
$$

Para el caso en que sea de interés la velocidad de la fuente de sonido:

$$
v_{s}=\left(\frac{f}{f^{\prime}}-1\right) v-\left(\frac{f}{f^{\prime}}\right) v_{0}
$$

\subsection{Metodología y Desarrollo}

El equipo de laboratorio se ha desarrollado para emitir un rango de frecuencias determinadas por una fuente de ondas sonoras y un receptor de estas, las cuales se perciben por medio de un micrófono.

En este equipo se busca registrar un cambio de frecuencia debido al Efecto Doppler explicado anteriormente, con esta información podremos calcular la velocidad de la fuente y la velocidad del sonido, los datos de frecuencia se observarán en el software desarrollado como interfaz del equipo.

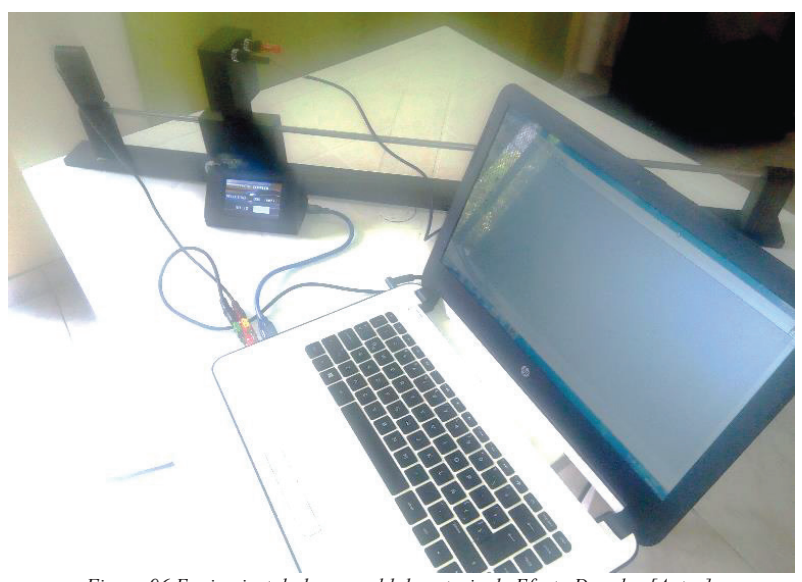

Figura 96 Equipo instalado para el laboratorio de Efecto Doppler [Autor].

El equipo consta:

- De un carro móvil en donde se instala la fuente de sonido, y el cual consta de un cable que se debe conectar a una fuente DC y un interruptor que permite controlar la dirección de giro, permitiendo acercar o alejar la fuente de sonido. 


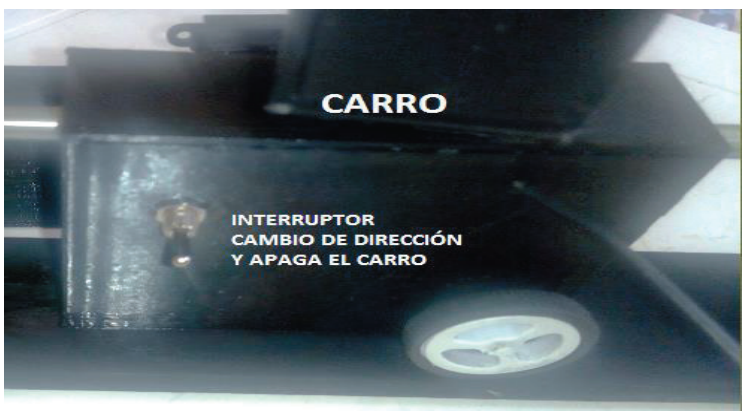

Figura 97 Carro del sistema [Autor].

- Un sistema microcontrolado que se comunica con una pantalla HMI que muestra la velocidad del carro: Es de notar que la velocidad del carro se mide con un sensor óptico, el cual, al detectar el carro móvil pasar por el frente de este, envía una señal a la interfaz y activa un temporizador hasta que el vehículo pasa. En el momento que el vehículo pasa, se calcula la velocidad con el tiempo que se demora, teniendo en cuenta que la longitud del carro es un valor fijo.

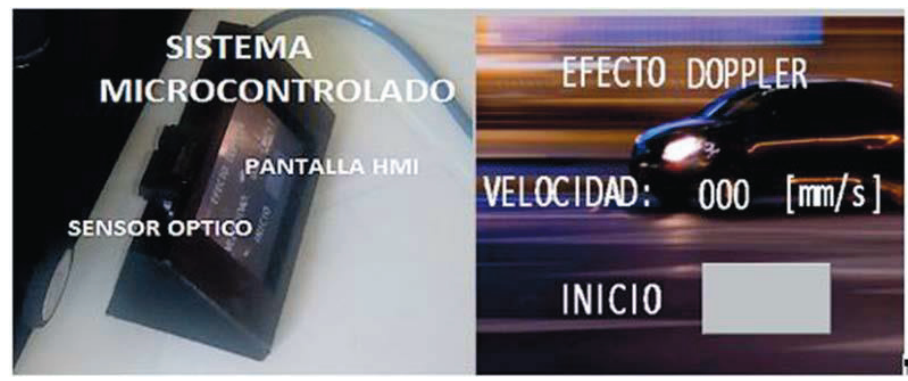

Figura 98 Sistema microcontrolado [Autor].

- Posee un micrófono el cual capta las señales sonoras generadas por el parlante, esta señal se digitaliza y se lleva al software del laboratorio. 


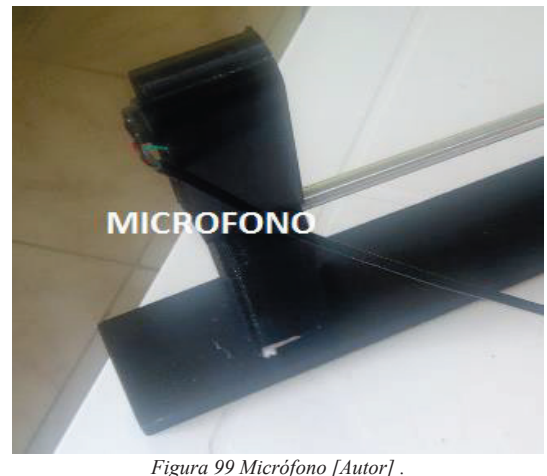

- Un parlante que generara sonidos con frecuencias entre 100 y $10000 \mathrm{~Hz}$, las cuales nos permite desarrollar la práctica de laboratorio.

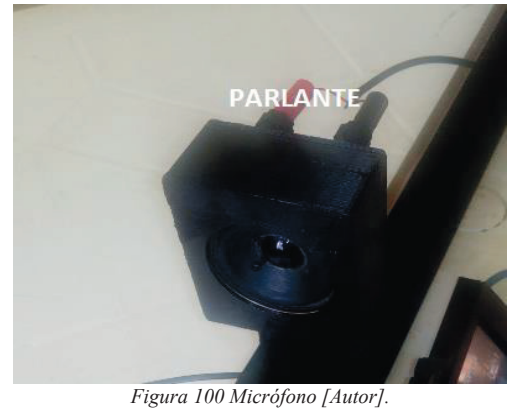

\subsubsection{Desarrollo Del Software}

La interfaz del usuario consta de dos controles los cuales permiten cambiar frecuencia emitida por el parlante y la intensidad generada.

También consta de dos gráficas en tiempo real, que nos permiten observar la señal senoidal emitida y la señal recibida por el observador.

Por último, el software nos permite tomar datos a través de dos indicadores registrando la diferencia de frecuencia entre lo emitido y lo recibido y la frecuencia del observador. A continuación, se describe de manera general este procedimiento (Laraja Vizcaíno \& Pelegrí Sebastiá, 2011).

\subsubsection{Programa desarrollado para el laboratorio del Efecto Doppler.}

El programa se desarrolló en LABVIEW, este software se basa en programación basada en orientación de objetos (Travis \& Kring, 2006)

Cada programa desarrollado en esta plataforma cuenta con un panel frontal y un panel de diagramación, el panel de diagramación es donde se visualiza indicadores y controles para que el usuario pueda interactuar con estos indicadores y controles los cuales son variables dentro del programa. 
Sebastián Martínez García - Diego Fernando Salazar - Andrés Felipe Osorio Ramírez Leonardo Bohórquez Santiago - Hugo Armando Gallego Becerra

En el panel de diagramación podemos observar la programación utilizada y sus funciones propias del software, las cuales se llaman subvis.

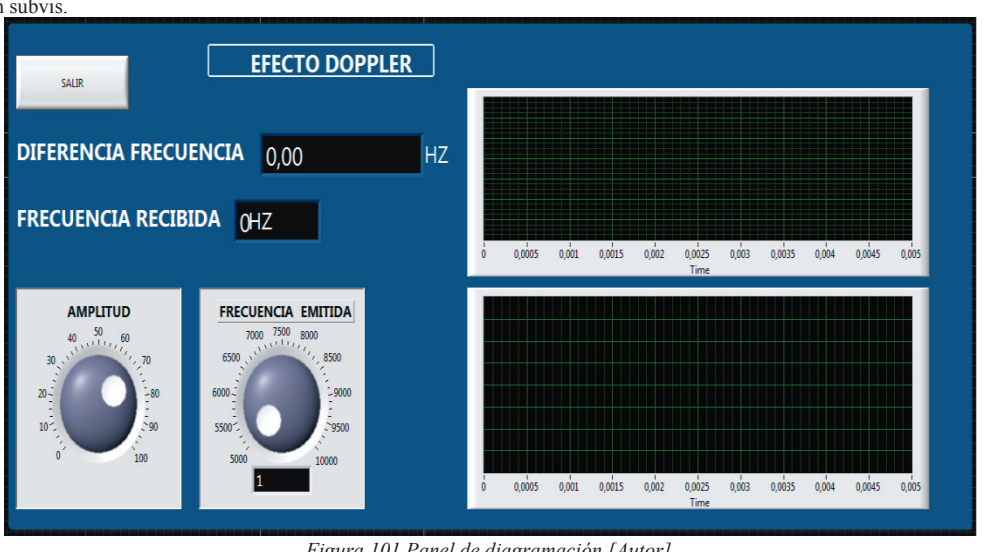

Figura 101 Panel de diagramación [Autor].

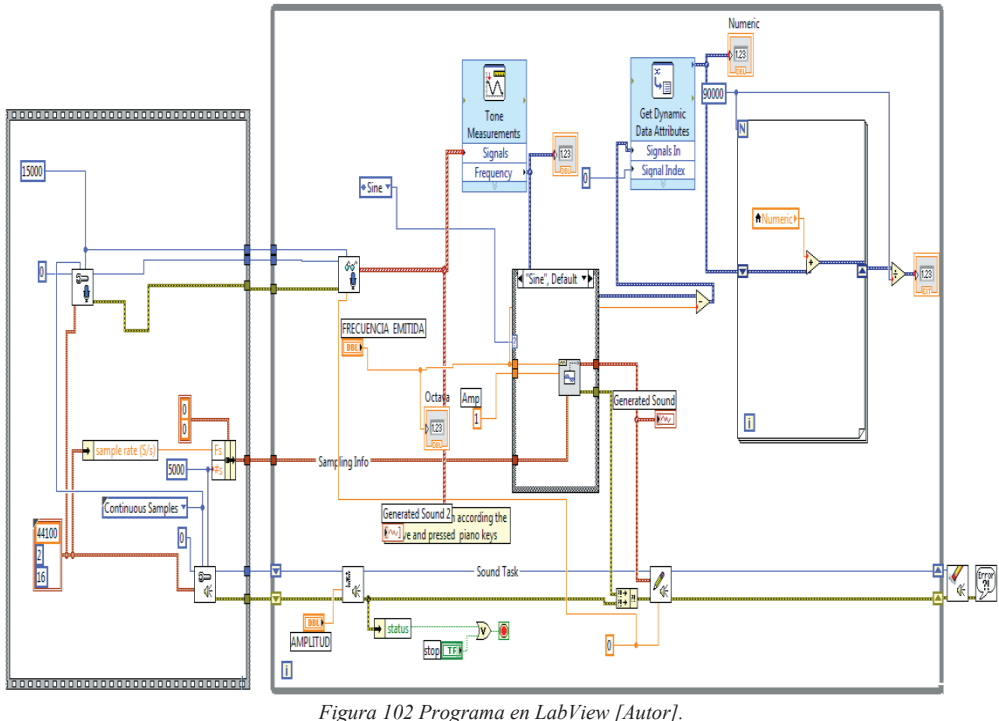

Para desarrollar la práctica de laboratorio del Efecto Doppler, se identificaron las variables más importantes como: 
- Frecuencia de la onda sonora.

- Intensidad de la onda sonora.

El primer subvi utilizado, son los de configuración, por ellos se configura el micrófono de una tarjeta de sonido auxiliar y el tamaño del buffer de memoria donde se almacenará la información adquirida por el micrófono, además de tener en cuenta el formato de sonido.

\section{Sound Input Configure.vi}

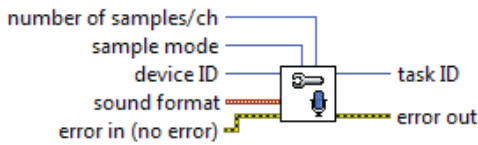

Figura 103 Subvi de configuración Input [Autor].

El segundo Subvi utilizado es el que configura la salida de audio a través de una tarjeta de sonido auxiliar, conectada al puerto USB, dentro de la configuración de este dispositivo está el número de muestras generadas y el formato de sonido.

\section{Sound Output Configure.vi}

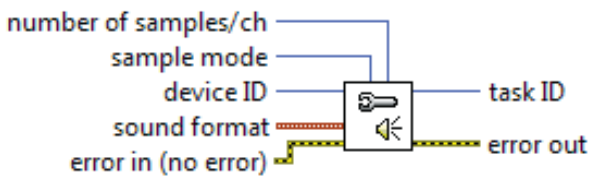

Figura 104 Subvi de configuración Output [Autor].

En la siguiente figura se puede observar los dos subvis de configuración de entrada y salida de audio dentro del programa desarrollado.

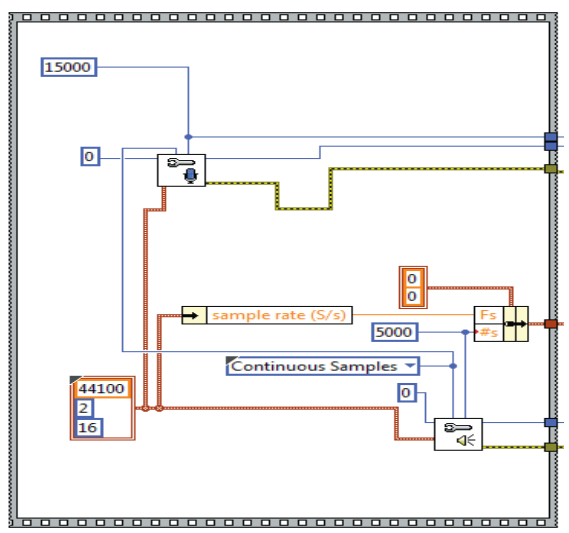

Figura 105 Subvi de configuración samples [Autor].

Una de las variables más importantes para desarrollar la práctica del laboratorio es manejar la intensidad sonora, para ello se utilizó el siguiente subvi, el cual aumenta o disminuye la amplitud de la onda generada por la salida de audio, en el panel frontal se tiene un control llamado amplitud: 


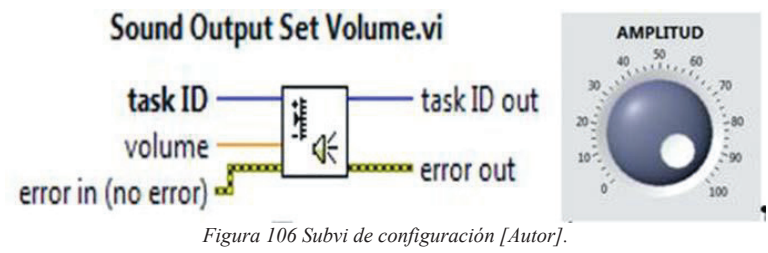

Dentro del laboratorio desarrollado se deberían generar señales de diferentes frecuencias, para ello se utilizó un subvi llamado Sine Waveform, el cual genera diferentes señales a la salida de audio, de esta manera, se puede manejar ángulo de fase, frecuencia y amplitud.

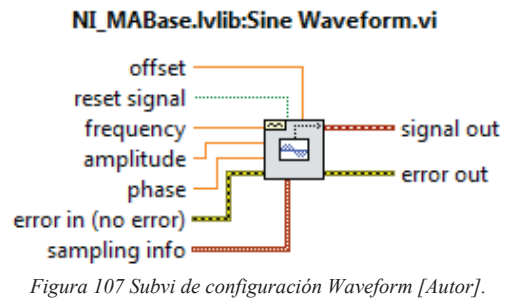

Por último, la onda generada debe ser escrita a la tarjeta de sonido auxiliar, para ello se utilizó el siguiente subvi:

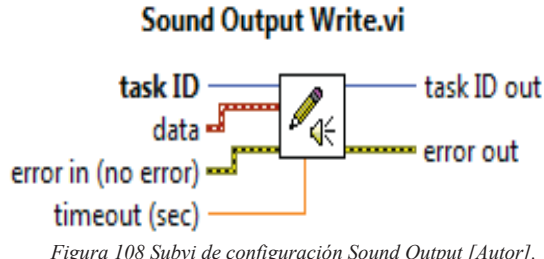

Posteriormente, se extrae una parte del panel de diagramación para observar la programación utilizada en la generación de las ondas y los subvis antes mencionados. 


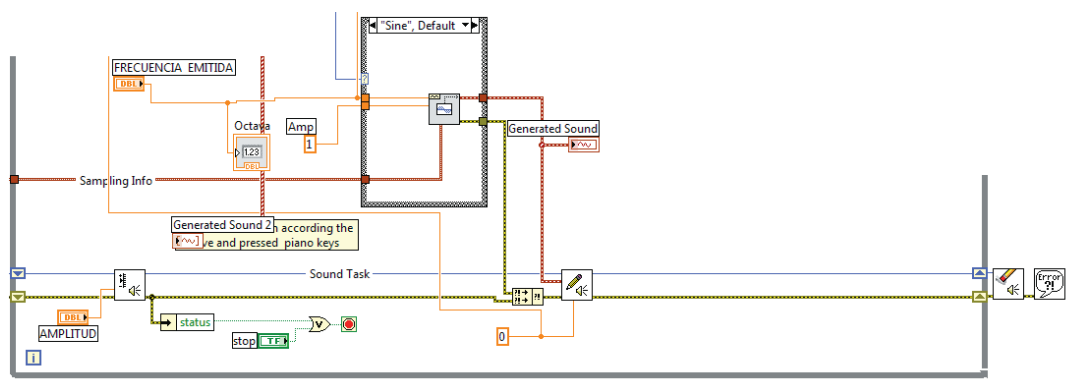

Figura 109 Subvi de configuración Generación de Onda [Autor].

Después de generar señales con diferentes frecuencias e intensidades, se debe capturar las señales de audio por el micrófono, que en el caso de la práctica de laboratorio representa al observador, por tanto, se describirá continuación los subvis utilizados y se extraerá el código desarrollado.

Por lo anterior, se utiliza el subvi Sound Input Read.vi, donde se debe indicar las muestras adquiridas y la identificación del dispositivo de audio a utilizar, este vi nos debe entregar los datos adquiridos de una forma ordenada.

\section{Sound Input Read.vi}

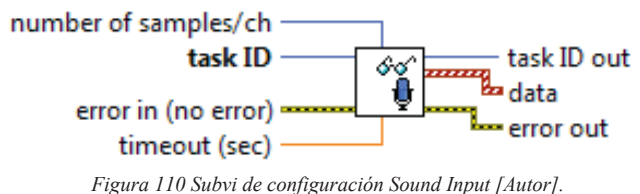

Para detectar la frecuencia recibida por el observador utilizamos un Express vi, el cual tiene como función encontrar la señal con mayor amplitud y darnos la frecuencia de la señal adquirida en el micrófono.

\section{Tone Measurements}

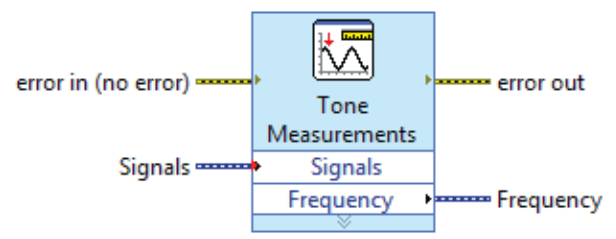

Figura 111 Subvi de configuración Tone Measurements [Autor].

Dentro del código se realizó un promedio de las frecuencias adquiridas y la frecuencia generada para poder encontrar la diferencia de frecuencia que es la utilizada para realizar la práctica de laboratorio. Finalmente se adiciona un recorte del código donde se usan la vis y la forma de encontrar la diferencia de frecuencia entre la emitida por el emisor y la recibida por el observador. 


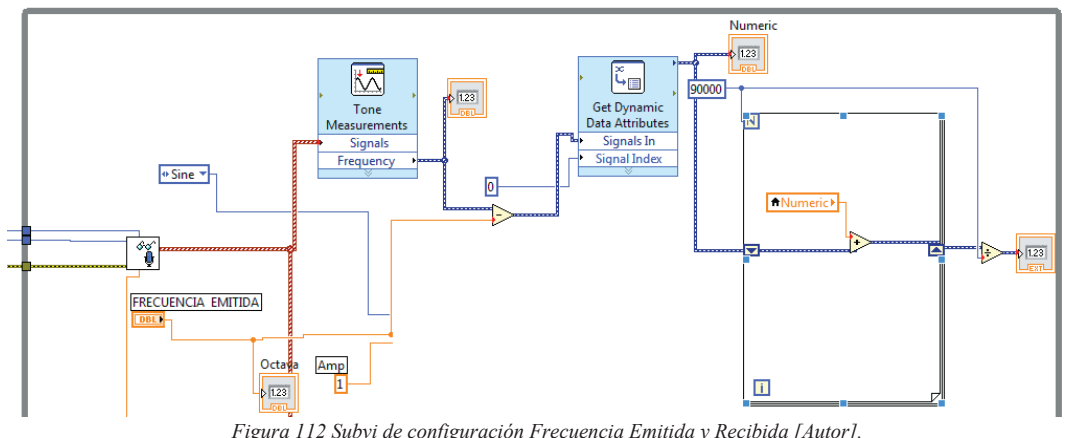

Figura 112 Subvi de configuración Frecuencia Emitida y Recibida [Autor].

Una vez estructurado el programa y acoplado el sistema podemos mostrar cómo quedó el prototipo para la experimentación del efecto Doppler. Ver figura.

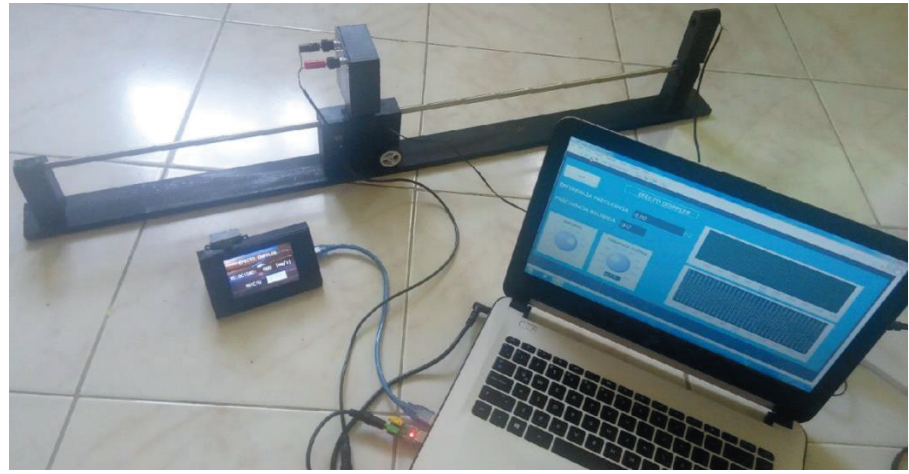

Figura 113 Prototipo Final Funcional [Autor].

\subsection{Conclusiones}

Se obtuvo un prototipo experimental capaz de probar el efecto Doppler por medio de sonido audible entre las frecuencias de $5.000 \mathrm{~Hz}$ y $10.000 \mathrm{~Hz}$, y se realizó una prueba en la que se demuestra la funcionalidad del prototipo y la su capacidad para medir la velocidad del objeto que emite el sonido.

Se desarrolló un software con la herramienta de LabView, con la capacidad de recibir las señales de sonido y procesarlas para obtener la velocidad del objeto que la emite y la velocidad del sonido en el aire.

Se desarrolló una guía para una práctica experimental con el prototipo para demostrar el efecto Doppler por medio de sonido, lo que permite que sea implementada dentro de las prácticas del curso de física III en el capítulo de ondas. 



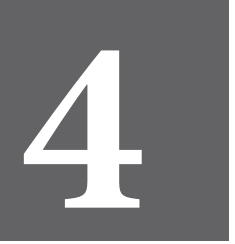

CAPÍTULO

CUATRO 



\section{Guías de Laboratorio para los Prototipos Experimentales Desarrollados por el Grupo DICOPED}

\subsection{Introducción}

En este capítulo se pondrá a disposición las guías de laboratorio diseñadas para cada uno de los equipos construidos por el grupo de investigación DICOPED, las cuales consta de una parte teórica referente al tema tratado en el laboratorio experimental, una parte de puesta a punto del equipo experimental y preparativos antes de iniciar la práctica, y por último una serie de instrucciones que el estudiante deberá seguir para lograr responder las preguntas propuestas en cada una de las guías.

La implementación de estas guías prácticas para cada uno de los equipos diseñados permite que cualquier alumno o docente utilice los equipos DICOPED para mejorar su entendimiento de los conceptos básicos de la física, para el presente caso, el concepto de onda.

\subsection{Guía Física III: Ondas Estacionarias en una Cuerda Tensa.}

Teniendo en cuenta los conceptos vistos y estudiados en la teoría de ondas, esta práctica busca que el estudiante interactúe con un equipo experimental que muestra como es el comportamiento de una onda en una cuerda, de igual forma se busca encontrar la relación entre la frecuencia y lo que se llama armónico, nodo fundamental, nodo, antinodo y amplitud.

\subsubsection{Objetivos}

1. Encontrar la relación entre la frecuencia y los modos de oscilación de una cuerda tensa

2. Determinar la densidad de la cuerda

3. Encontrar las variaciones de la frecuencia del modo fundamental con relación al peso y la longitud.

4. Encontrar la relación que existe en la frecuencia cuando se utiliza un generador de luz estroboscópica en una cuerda tensa

5. Encontrar los armónicos normales de oscilación en una cuerda tensa y su relación con el modo fundamental. 


\subsubsection{Marco Conceptual}

Onda: es un movimiento o alteración que se produce y se propaga a través de los diferentes medios donde se pueda generar, como el agua, aire, cuerda, entre otras; dichas ondas se clasifican según el medio donde se produce las cuales se pueden distinguir como ondas mecánicas y ondas electromagnéticas. Además, hay diferentes formas de ondas, onda senoidal, onda cuadrada.

En la onda no hay nada material que se esté propagando, se trata del movimiento coordinado de muchos elementos como por ejemplo cuando se acoplan muelles unos con otros, cuando varias capas de aire se mueven unas a otras, también sucede cuando un campo eléctrico induce uno magnético y viceversa.

Se debe tener en cuenta que el punto de una onda cambia en cada lugar del espacio y del tiempo de esta forma se crea una ecuación matemática que cumpla con esas condiciones.

Onda Mecánica: se llama onda mecánica a la perturbación que viaja a través de un medio elástico, transportando energía. Se consideran dos tipos de ondas:

- Ondas Transversales: Las partículas que conforman el medio se mueven perpendicular a la dirección de la propagación.

- Ondas Longitudinales: Las partículas que conforman el medio se mueven en un va y viene en la misma dirección de la propagación.

Una onda trasversal es periódica, es decir, que tenemos un movimiento armónico simple donde su ecuación la función general de la onda se puede describir de la siguiente manera:

Donde

$$
y(x, t)=A \cdot \operatorname{sen}(k x \pm \omega t+\emptyset)
$$

A amplitud de la onda

$\mathrm{k}$ el número de veces que se encuentra la onda de 0 a $2 \pi$ dado por la ecuación

$$
K=\frac{2 \pi}{\lambda}
$$

$\omega$ frecuencia angular dada por la formula

$$
\omega=k \cdot v=2 \pi f=\frac{2 \pi}{T}
$$

Teniendo en cuenta que en una onda están presentes la longitud $\lambda$, la frecuencia $f$ y la velocidad $v$, se puede apreciar una relación entre ellas de la siguiente manera:

$$
\begin{aligned}
& \lambda=v / f \\
& f=v / \lambda \\
& v=\lambda . f
\end{aligned}
$$

Si se considera una cuerda de longitud $\mathrm{L}$ y densidad de masa $\mu$ sujeta por sus extremos donde su posición inicial es $\mathrm{X}=0 \mathrm{y}$ Su posición Final es $\mathrm{X}=\mathrm{L}$, la cuerda se le integra una alteración llamada vibración por medio de un generador mecánico, conectado a un generador de ondas sinodales, las cuales al ir variando su frecuencia mostrara una serie de vientres o armónicos donde dos señales se superponen, dejando ver así los nodos y puntos máximos de oscilación.

Cuando la cuerda perturbada entra en resonancia con el generador mecánico que produce el movimiento, se presentan los distintos modos propios de oscilación y los desplazamientos transversales tendrán su máxima amplitud.

Para encontrar las frecuencias $f_{n}$ que corresponden a cada modo propio de oscilación se deben tener en cuenta las siguientes condiciones de frontera.

$$
\begin{aligned}
& y(0, t)=0 \\
& y(L, t)=0
\end{aligned}
$$

Si tenemos que $K L=n \pi \operatorname{con} n=1,2,3 \ldots$ y consideramos las ecuaciones (2) y (6) obtenemos la ecuación de las frecuencias correspondientes a los modos propios de oscilación de la cuerda.

$$
f_{n}=\frac{n v}{2 L}
$$

De las ondas transversales en una cuerda podemos tener que la velocidad de propagación a lo largo de la cuerda es:

$$
v=\sqrt{\frac{T}{\mu}}
$$

Siendo T la tensión de la cuerda, a expresión para las frecuencias de los modos de vibración quedaran definidas por: 


$$
f_{n}=\frac{n}{2 L} \sqrt{\frac{T}{\mu}}
$$

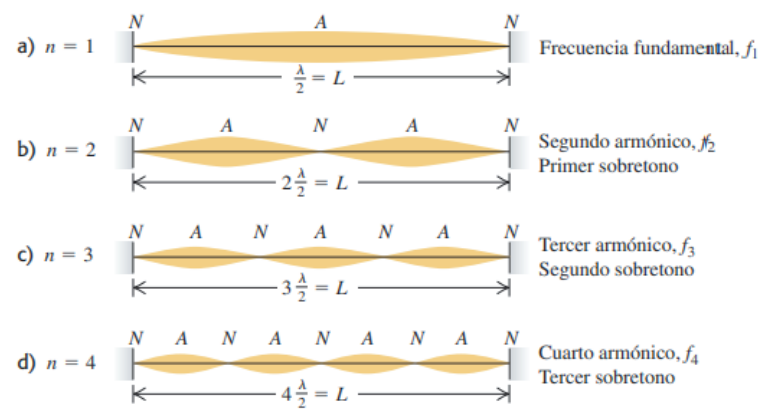

Figura 114 Modos de oscilación en una cuerda tensa (Young \& Freedman, 2009).

Onda estacionaria: se llama así porque tiene la presencia de puntos que son inmóviles los cuales son llamados nodos, consiste en una onda que viaja ya sea, a través de una cuerda tensa, tubo de aire, entre otros, donde interfieren dos ondas con la misma amplitud y frecuencia, pero en sentido contrario (Young \& Freedman, 2013).

Frecuencia: es cuando un suceso se repite bajo las mismas condiciones en un periodo determinado de tiempo. La unidad de medida para la frecuencia es en Hertz $(\mathrm{Hz})$ y respectiva formula es:

$$
\begin{aligned}
& \quad f=\frac{1}{T} \\
& \mathbf{f}=\text { frecuencia } \\
& \mathbf{T}=\text { periodo }
\end{aligned}
$$

Ciclo: suceso que se repite en cierto periodo de tiempo, son fenómenos periódicos que siempre vuelven a su configuración inicial.

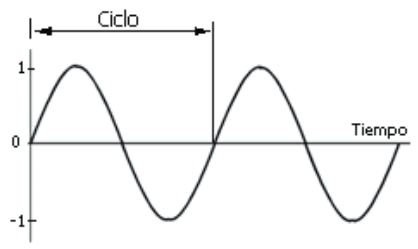

Figura 115 Ciclo de una Onda [Autor]

Amplitud: es una medida que está presente en una onda debido a su oscilación, y de acuerdo con esta oscilación se genera una variación a lo largo de la onda: la amplitud me ayuda a determinar dicha variación. 


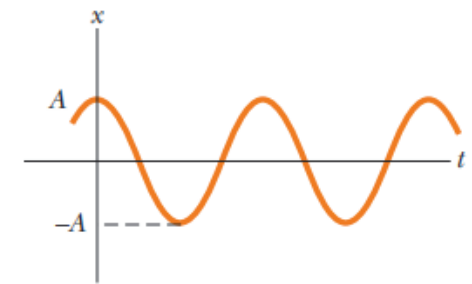

Figura 116 Amplitud de unä Onda (Serway \& Jawett, 2008b)

Longitud de Onda: teniendo en cuenta que en una onda se puede formar una función seno o una función coseno, en las cuales se generan picos. la distancia que hay entre pico y pico se le denomina longitud de onda.

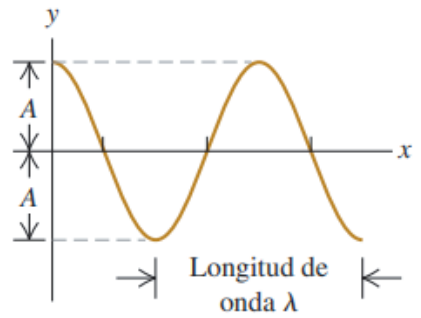

Figura 117 Longitud de Onda (Young \& Freedman, 2009)

Periodo: es el tiempo que transcurre a lo largo de un fenómeno hasta que este nuevamente se repite.

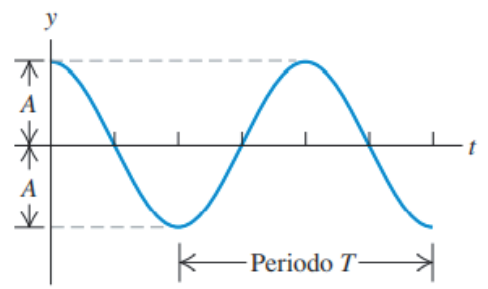

Figura 118 Periodo de una Onda (Young \& Freedman, 2009)

Velocidad: es el ritmo con el cual la onda viaja. Esta velocidad está dada por

$$
V=\frac{\lambda}{T}=f \cdot \lambda
$$




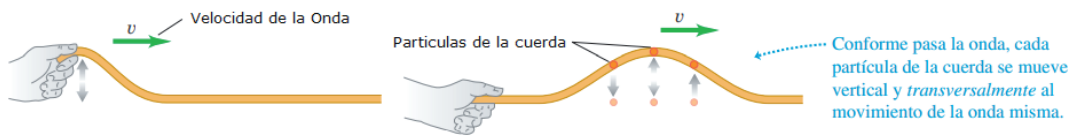

Figura 119 Velocidad de una Onda (Young \& Freedman, 2009)

Oscilación: es el movimiento de un lado a otro partiendo de su punto o eje central que se presenta cuando ocurre una perturbación o variación de un sistema.
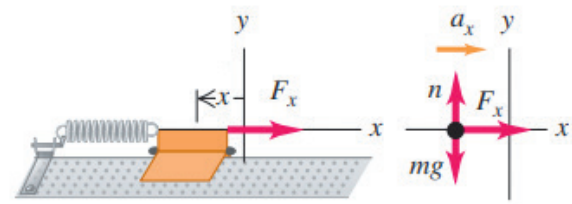

Figura 120 Oscilación (Young \& Freedman, 2009)

Nodos: son los puntos inmóviles a lo largo de la onda estacionaria

Antinodos: en una cuerda tensa se puede producir un antinodo o también llamados vientres, los cuales al ir variando la frecuencia de oscilación producen puntos donde tienen una máxima amplitud.

Armónicos: los armónicos de una cuerda tensa son cuando se generan frecuencias de resonancia, donde las dos ondas que se encuentran están vibrando a la misma frecuencia, pero en sentido contrario

\section{Materiales que utilizar}

- Generador de señales GS 2018

- Cuerda

- Masas y soporte de masas

- Varillas de soporte de equipo

- Generador mecánico

- Estroboscopio

- Galga

- Cables de conexión

- Soporte de base

- Polea. 


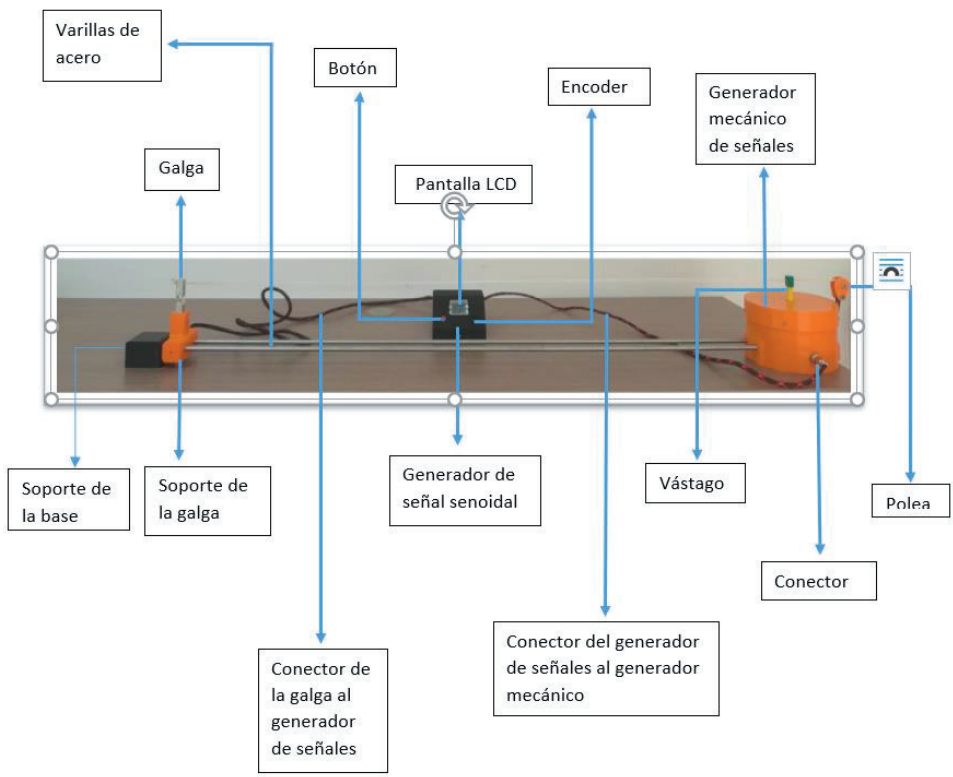

Figura 121 Prototipo ensamblado con todas sus partes [Autor].

Monte el equipo que se muestra en la figura 107 siguiendo las siguientes instrucciones:

4.2.3 Procedimiento.

Para iniciar con el montaje del equipo, se debe tener a la mano las dos varillas de acero, el generador mecánico de ondas, la galga y el soporte de las varillas de acero.

Luego de tener presente dichos materiales, se procede con el montaje del equipo. Primero se debe tomar una de las varillas de acero, e introducirla por uno de los orificios del generador mecánico de ondas y la punta opuesta de la varilla se introduce al soporte de la galga y al soporte de las varillas. Seguidamente, se repite el mismo procedimiento con la segunda varilla.

A continuación, se puede observar las figuras 108,109 y 110, donde se aprecia dicho procedimiento. 
Sebastián Martínez García - Diego Fernando Salazar - Andrés Felipe Osorio Ramírez Leonardo Bohórquez Santiago - Hugo Armando Gallego Becerra

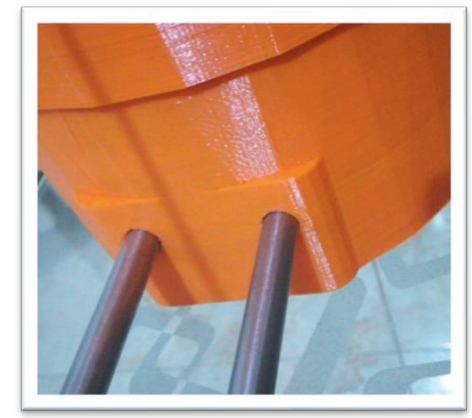

Figura 122 Varillas de acero en el generador mecánico de ondas [Autor].

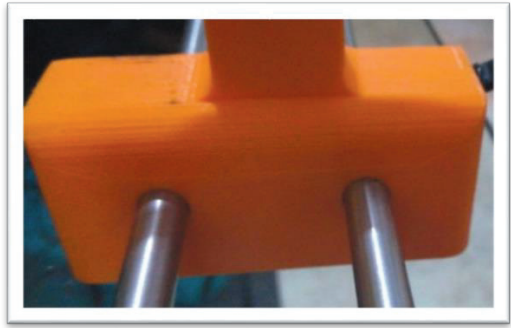

Figura 123 Varillas de acero en el soporte de la galga [Autor].

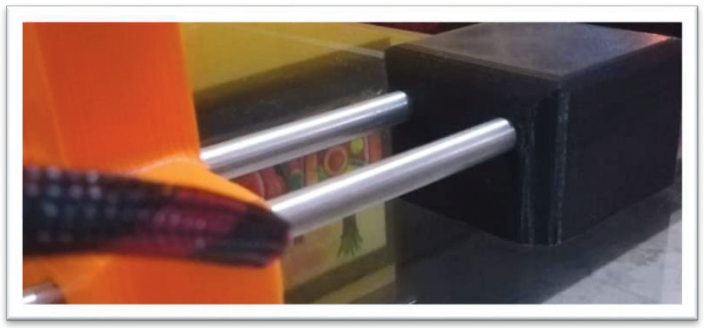

Figura 124 Varillas en su respectivo soporte [Autor].

Luego de montar las piezas anteriormente mencionadas, se procede con las demás partes faltantes, para esto se debe tomar los siguientes materiales; el generador de señales, la polea, la cuerda, las masas, los cables y el cargador del generador de señales.

Como segunda parte del montaje, se continúa insertando la polea en la abertura que se encuentra en la parte trasera del generador mecánico. Como se muestra a continuación en las figuras 111 y 112. 
Diseño y Construcción de Prácticas para el Estudio de Movimiento Ondulatorio

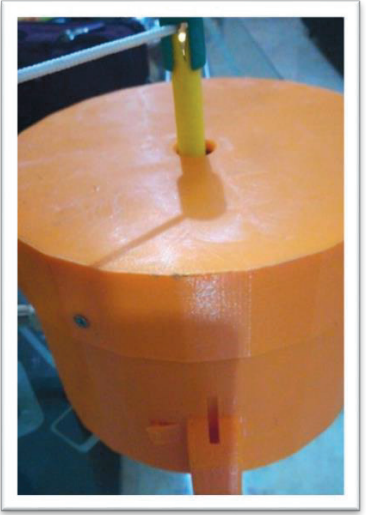

Figura 125 Figura 6. Ranura en la parte trasera del generador [Autor].

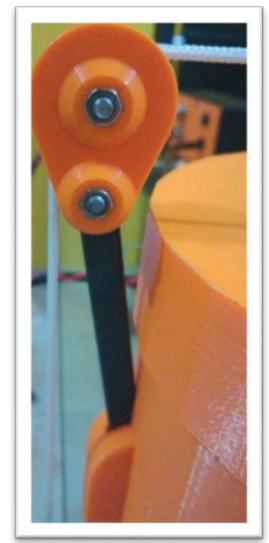

Figura 126 Polea insertada en el generador mecánico de ondas [Autor].

Después de introducir la Polea en el generador mecánico de ondas, se debe ingresar la cuerda (la cual debe ser de $0.5 \mathrm{~m}$ mínimo y $1.30 \mathrm{~m}$ máximo), por el orificio superior de la galga, como se aprecia en la figura 113 . 


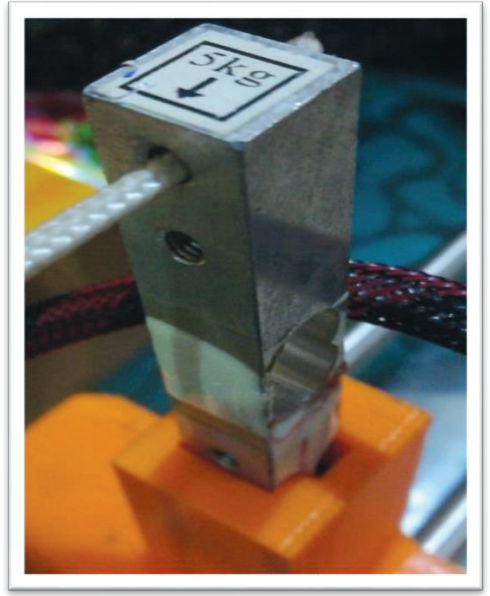

Figura 127 Galga con cuerda [Autor].

Recuerde que la longitud de la cuerda puede variar, debido a que el prototipo permite la movilidad del soporte de la galga y el soporte de las varillas de acero.

Una vez ingrese la cuerda por el orificio superior de la galga, se deberá hacer un nudo al otro lado de la galga para asegurar que la cuerda no se salga.

NOTA: el nudo debe quedar para la parte donde se encuentra el soporte de las varillas, para así asegurar que la cuerda por el lado contrario pase por el vástago del generador mecánico de ondas.

Ahora se debe coger la cuerda y estirarla hasta que pase por el vástago que se encuentra en el generador mecánico de ondas. Ver figuras 114 y 115 .

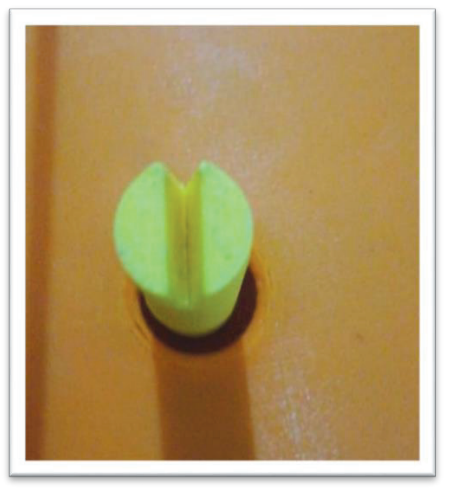

Figura 128 Vástago vista superior [Autor]. 


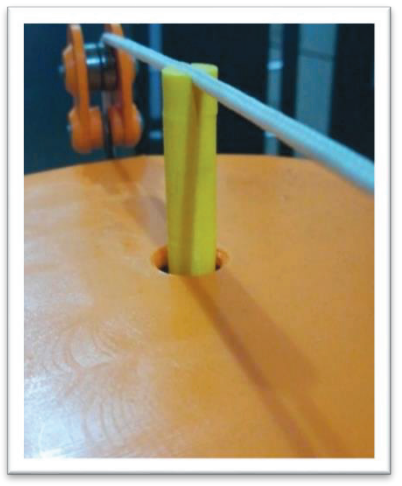

Figura 129 Vástago Vista lateral [Autor].

Para asegurar que la cuerda no se salga del vástago debido a las vibraciones, se le debe colocar la tapa del respectivo vástago. Ver figura 116.

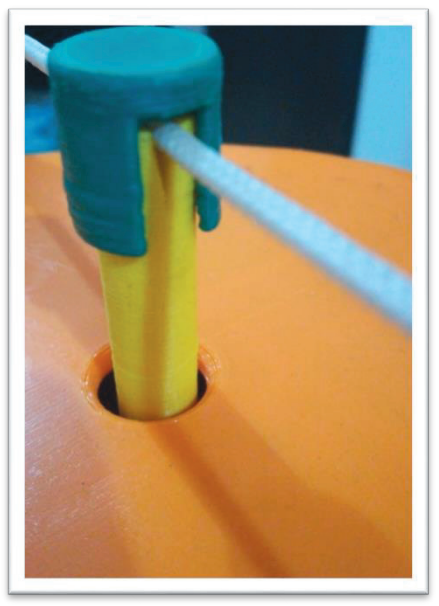

Figura 130 Tapa del vástago [Autor].

Luego de colocar la tapa del vástago, la cuerda debe pasar seguidamente por la polea, la cual le brindará soporte. Ver figuras 117 y 118 . 
Sebastián Martínez García - Diego Fernando Salazar - Andrés Felipe Osorio Ramírez Leonardo Bohórquez Santiago - Hugo Armando Gallego Becerra

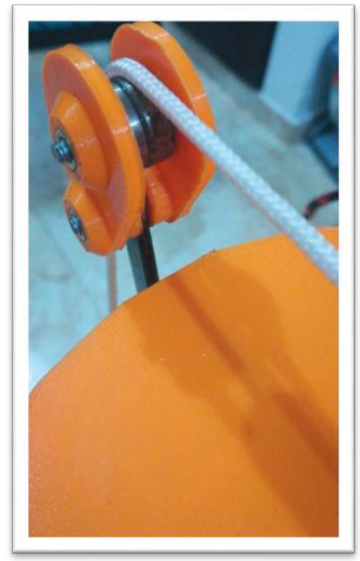

Figura 131 Polea vista superior [Autor].

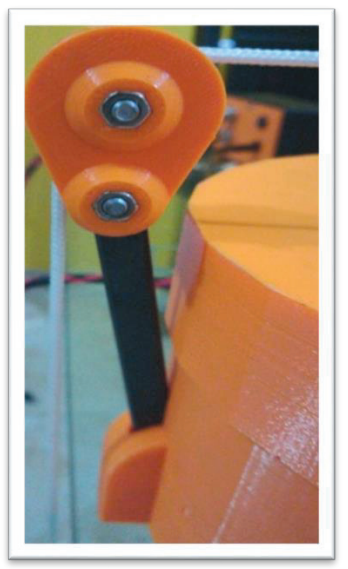

Figura 132 Polea vista lateral [Autor].

Posteriormente, se debe sujetar las masas de la cuerda que cuelga de la polea, para generar una tensión en específico, para esto debe poner el número de masas que usted considere apropiadas para producir la fuerza que necesita. Ver figura 119. 
Diseño y Construcción de Prácticas para el Estudio de Movimiento Ondulatorio

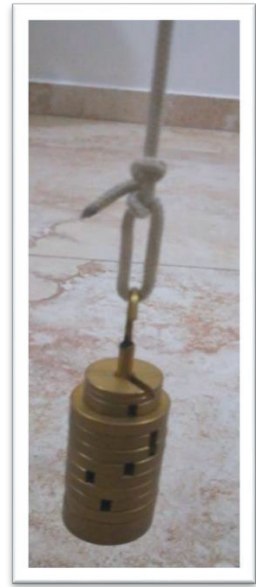

Figura 133 Masas colgando de la cuerda [Autor].

Después de montar la cuerda, la polea y las masas, se procede a conectar el generador de señales al generador mecánico y a la galga. Para ello se debe tomar el cable que tiene un conector de tres patas en ambos lados, y se conecta al generador de señales (en el respectivo conector), y luego al generador mecánico de ondas. Ver figura 120, figura 121, figura 122 y figura 123.

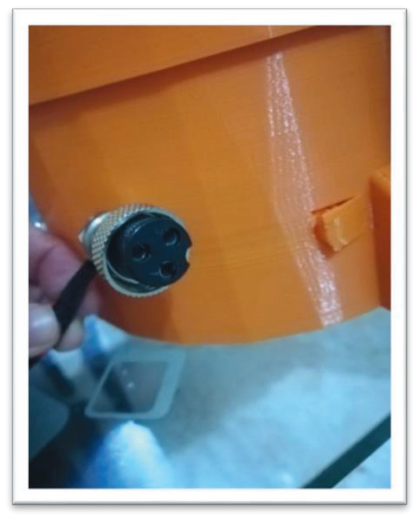

Figura 134 Cable conector de tres patas [Autor]. 
Sebastián Martínez García - Diego Fernando Salazar - Andrés Felipe Osorio Ramírez Leonardo Bohórquez Santiago - Hugo Armando Gallego Becerra

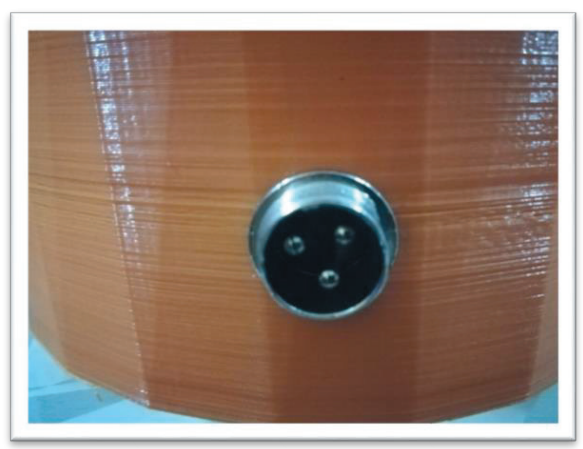

Figura 135 Conector del generador mecánico de ondas, donde irá uno de los conectores del cable [Autor].

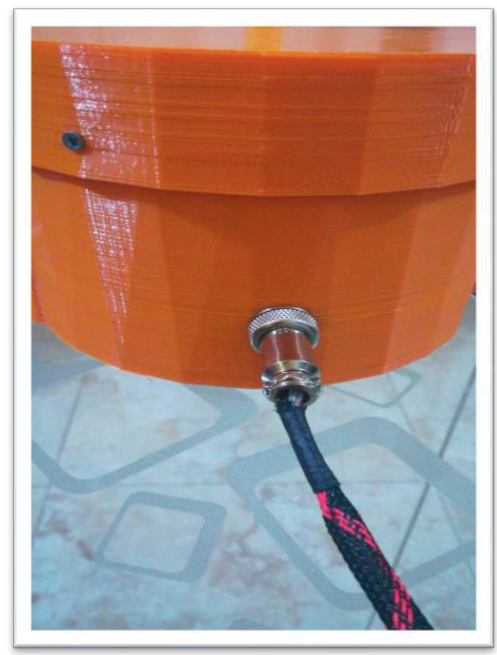

Figura 136 Forma correcta de conectar el cable [Autor]. 


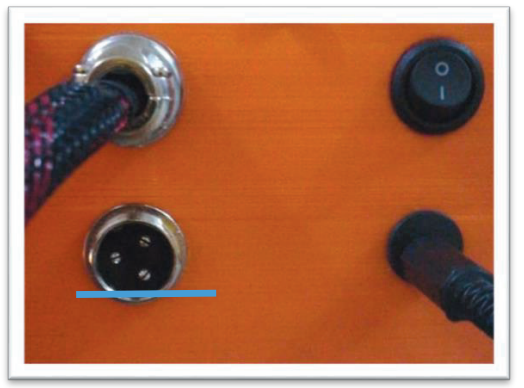

Figura 137 Conector de 3 patas en el generador de señales [Autor].

Con este cable se ha generado la conectividad entre los dos generadores (mecánico y de señales), el cual permite la generación de la onda.

Seguidamente, se debe unir el generador de señales y la galga para mostrar en pantalla la tensión de la cuerda, a través del cable conector de 4 patas, que está conectado por defecto al soporte de la galga y al generador de señales, por tanto, debe ser conectado en su respectivo conector. Ver figuras 124 y 125 .

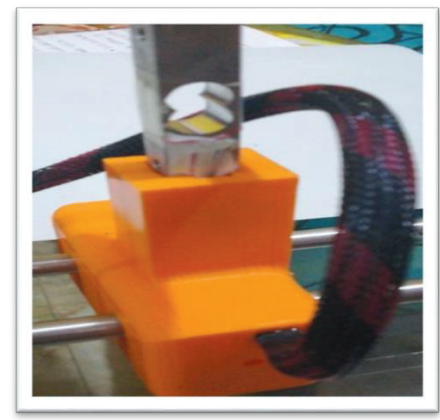

Figura 138 Cable que viene por defecto para soporte de la galga [Autor]. 


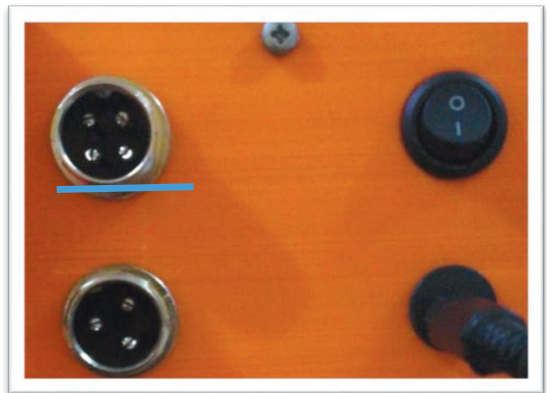

Figura 139 Conector en la parte trasera del generador de señales [Autor].

Y para finalizar con el montaje del prototipo, se debe conectar el cargador al generador de señales en el orificio respectivo. Ver figura 126.

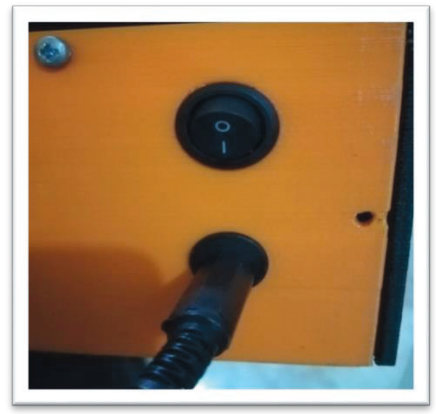

Figura 140 Cargado conectado al generador de señales [Autor].

Luego realizar los pasos anteriores el quipo debe tener la distribución que se ilustra en la figura 107.

\subsubsection{Toma de datos}

Para la toma de datos realice los siguientes procedimientos.

1. Para medir la tensión de la cuerda debe tener en cuenta ajustar el cero de la galga: para este procedimiento antes de encender el generador de señales GS 2018 cerciórese que la cuerda no se encuentre tensionada y que en la pantalla del generador en el modo de tensión muestre 0.0 .

2. Luego de este procedimiento coloque las masas y suspéndalas para generarle tensión a la cuerda y de nuevo visualice en pantalla para verificar si esta, muestra la tensión de la cuerda, modo fundamental y armónicos variando la frecuencia

3. Tome todas las masas disponibles y el soporte, colóquelos sobre la cuerda y suspéndalos.

4. Encienda el generador de señales y suba la frecuencia en la resolución que desee $(0.1 \mathrm{~Hz}, 1.0 \mathrm{~Hz}, 10.0 \mathrm{~Hz})$ hasta que observe que la cuerda muestra un modo fundamental de resonancia.

5. Tenga en cuenta que debe buscar el modo fundamental con la mayor amplitud posible, luego anote su frecuencia en la tabla 1.

Antes de registrar los datos, pese la cuerda y registre este dato e identifíquela como $\mathrm{M}$ 


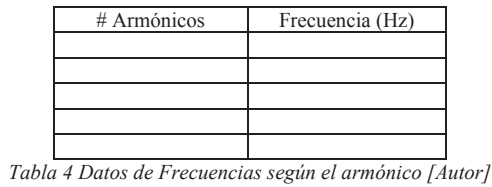

M: es la masa total de la cuerda.

T: tensión de la cuerda

L: longitud de la cuerda

Luego de encontrar el modo fundamental aumente gradualmente la frecuencia para encontrar los armónicos y frecuencias de resonancia múltiplos del primer modo fundamental, 2,3,4,5 hasta 6 armónicos y anote sus frecuencias en la tabla 4 .

6. Relación de frecuencia en relación con la variación de longitud.

Para la segunda parte del experimento, divida la varilla en 5 partes iguales tomando como primera medida la máxima longitud 1.2 $\mathrm{m}$ aproximadamente. Varié la frecuencia hasta encontrar el modo fundamental, luego encuentre el segundo armónico de ese modo fundamental y registre la frecuencia del segundo armónico en la tabla 5.

\begin{tabular}{|c|c|}
\hline Longitud (cm) & Frecuencia (Hz) \\
\hline & \\
\hline & \\
\hline & \\
\hline & \\
\hline \\
\multicolumn{1}{|l|}{ Tabla 5 Datos de longitud y frecuencia [Autor] }
\end{tabular}

Varié la longitud 4 veces y repita el procedimiento anterior encontrando la frecuencia del segundo armónico. Luego registre sus datos en la tabla 5 .

7. Relación entre frecuencia y masa.

Para la tercera parte de este experimento, tome 5 masas diferentes, sin variar la longitud de $1.2 \mathrm{~m}$ encuentre para cada masa el modo fundamental y luego encuentre el segundo armónico. Registre su frecuencia en la tabla 6. Para medir las masas use la gramera dada por el profesor. Para cada dato de masa mida 5 veces la masa y tome un promedio regístrela en la tabla 7.
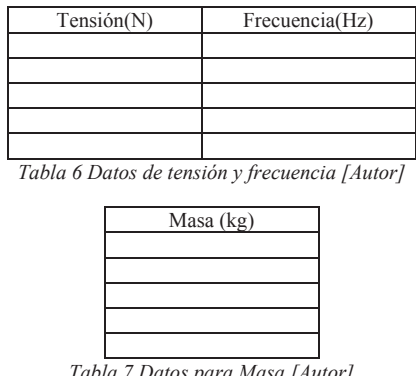

8. Relación de frecuencia usando luz estroboscópica.

Para esta experimentación el estudiante debe seleccionar los armónicos $(2,3,4,5)$ del modo fundamental de la primera experimentación, luego encienda el estroboscopio y empiece a subir la frecuencia hasta que observe que la cuerda se queda quieta y muestra los vientres definidos como si se encontraran estáticos. Ver figura. Luego anote en la tabla 4 la frecuencia del generador de señales y del estroboscopio. 


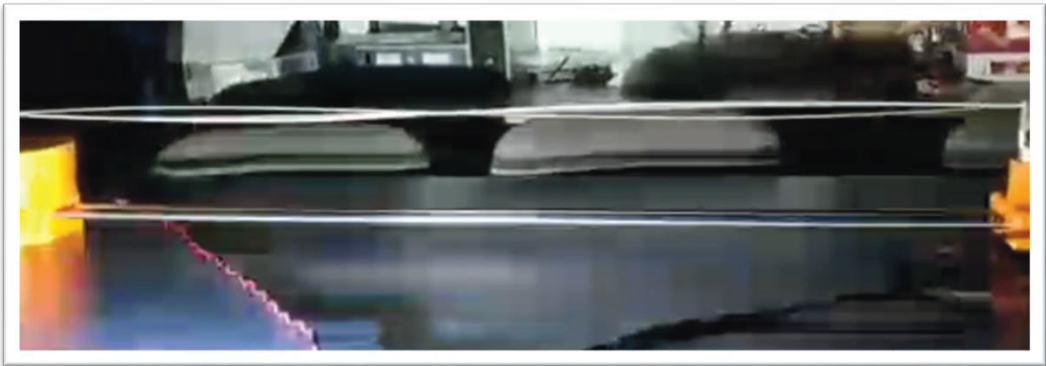

Figura 141 Armónico \# 2 expuesto a luz estroboscópica [Autor].

Nota: Tenga en cuenta que para que la cuerda muestre el vientre bien definido la frecuencia del estroboscopio debe rodear el doble de la frecuencia en la que oscila la cuerda.

Para una nueva experimentación tome uno de los armónicos 2 o 3 y empiece a subir la frecuencia del estroboscopio hasta su punto máximo. De una breve descripción de lo observado y diga qué relación encuentra entre la frecuencia de oscilación de la cuerda y la frecuencia del estroboscopio.

\subsubsection{Análisis.}

1. Con los datos suministrados en la tabla 1 construya una un gráfico de frecuencia en función del número de armónicos ¿qué tipo de grafica obtiene? ¿cómo es la relación entre la frecuencia y el número de armónicos?

De acuerdo con los resultados obtenidos realice el siguiente análisis.

- Si la gráfica encontrada es una recta encuentre la ecuación de relación entre la frecuencia y el número de armónicos.

- Con la expresión teórica que relaciona la frecuencia de las oscilaciones en una cuerda tensa, en función de las variables que afectan dicho comportamiento, la cual está dada por:

$$
f_{n}=\frac{n}{2 L} \sqrt{\frac{T}{\mu}}
$$

n: Es el número de armónico

L: Es la longitud de la cuerda

T: Es la tensión en la cuerda

$\mu$ : Es la densidad de la cuerda

- Determine, el valor de la densidad de masa $\mu$ (Valor experimental) con su correspondiente incertidumbre. Teniendo en cuenta la ecuación de la gráfica obtenida (Young \& Freedman, 2013).

- Determinar el dato teórico de la densidad de la cuerda calculada a partir de su masa y longitud, mediante la expresión $\mu$ $=\mathrm{m} / \mathrm{L}$, donde $\mathrm{m}$ es la masa de la cuerda $\mathrm{y} \mathrm{L}$ es la longitud total de la cuerda.

Nota: solicitar al profesor las especificaciones de la balanza y metro.

- Con los datos experimentales y teóricos encuentre el error porcentual de la densidad de masa $\mu$

2. Con los datos de la tabla 2 de longitud y frecuencia, Tome los datos y realice un gráfico frecuencia f en función de $\frac{1}{L} \dot{ }$ qué tipo de gráfica es y por qué? 
A partir de la gráfica obtenida en el inciso anterior encuentre una ecuación que muestre la relación entre la frecuencia y la longitud de la cuerda. De igual forma repita los procedimientos para calcular la densidad de la masa y su respectiva incertidumbre a partir de sus datos experimentales.

3. Con los datos suministrados en la tabla 3 encuentre un gráfico entre la frecuencia y la raíz cuadrada de la tensión, luego describa que tipo de grafica obtiene y explique el porqué.

De acuerdo con la gráfica anterior encuentre una ecuación que exprese la relación entre la frecuencia y la tensión. De igual forma repita los procedimientos para calcular la densidad de la masa y su respectiva incertidumbre a partir de sus datos experimentales.

4. Describa con sus propias palabras que conclusiones saca de los resultados obtenidos.

\subsection{Guía Experimental Física III: Cubeta de Ondas}

\subsubsection{Introducción}

El movimiento repetitivo de un objeto donde éste pasa de una posición conocida a otra y regresa a la posición inicial en un tiempo fijo se le conoce como movimiento periódico, un caso especial es el movimiento armónico simple que nos permite formar la base de la comprensión de las ondas, donde centraremos la atención.

Un ejemplo de este fenómeno es cuando gotas de agua caen de una hoja a un estanque. La perturbación provocada por el agua que cae hace que la superficie del agua oscile. Dichas oscilaciones se asocian con ondas que se mueven alejándose del punto donde cayó la gota de agua.

\subsubsection{Objetivos}

i. Mostrar como una perturbación en un medio, puede desencadenar una transmisión de energía con características periódicas dependientes de los elementos del sistema.

ii. Determinar experimentalmente la velocidad de propagación de una onda mecánica, en función de las ecuaciones asociadas a un movimiento ondulatorio.

iii. Determinar experimentalmente propiedades de sustancias como el agua a partir del estudio de la propagación de una onda.

iv. Analizar y describir el comportamiento de un sistema a partir de la variación de los parámetros que infieren en el movimiento.

v. Dar sustento experimental a la expresión que determina el comportamiento de las ondas mecánicas en un medio dado.

\subsubsection{Marco Conceptual}

4.3.3.1 Movimiento ondulatorio.

Si se considera un objeto sobre la superficie del agua en un estanque, al dejar caer una gota en el estanque se vería mover el objeto de manera vertical y horizontal en torno a su posición original, así como todos los elementos del agua. La onda del agua se mueve, pero lleva el agua consigo, es decir el movimiento ondulatorio transporta energía, pero no materia.

En general el fenómeno ondulatorio implica la propagación de energía desde una región de un sistema a otro y se dividen en dos tipos las ondas mecánicas y las ondas electromagnéticas, adicionalmente cada tipo de onda tiene sus características y propiedades que pueden ser identificadas.

La característica principal de las ondas mecánicas es que necesitan un medio mecánico para viajar. Las ondas electromagnéticas como la luz, ondas de radio, infrarrojas, radiación ultravioleta, rayos x y rayos gamma no necesitan un medio para propagarse, es decir, pueden viajar en el espacio vacío. Otra clase de fenómeno ondulatorio se encuentra en el comportamiento de las partículas atómicas y subatómicas, fenómeno estudiado por la mecánica cuántica.

\subsubsection{Ondas mecánicas}

Como se mencionó anteriormente, las ondas mecánicas son aquellas perturbaciones que requieren de un medio material para transportarse. Todas las ondas mecánicas requieren 1) alguna fuente de perturbación, 2) un medio que contenga elementos que sean factibles de perturbación y 3) algún mecanismo físico a partir del cual los elementos del medio puedan influirse mutuamente. 
Otro ejemplo de ondas mecánicas son las olas del mar que consisten en el largo abultamiento de agua que se ve llegar a la playa o las pequeñas ondas de agua que consisten en ondas de tensión superficial. Estas últimas serán las que se generarán en la cubeta para su posterior estudio pues capturando una fotografía de las ondas se podrá analizar la relación entre frecuencia, velocidad de propagación y longitud de onda haciendo uso de la herramienta de procesamiento digital de imágenes explicada posteriormente

Sabiendo que una onda mecánica es la perturbación que viaja por algún material o sustancia llamada medio y que son las partículas las que producen el desplazamiento de energía a través de este medio, según la naturaleza de la onda se presenta el tipo de desplazamiento.

Cuando el movimiento del medio es perpendicular o transverso a la dirección en la que viaja la onda a través del medio, se le llama onda transversal. Cuando el movimiento de las partículas del medio es hacia atrás y adelante sobre la misma dirección en la que viaja la onda, se le llama onda longitudinal (Young \& Freedman, 2000).

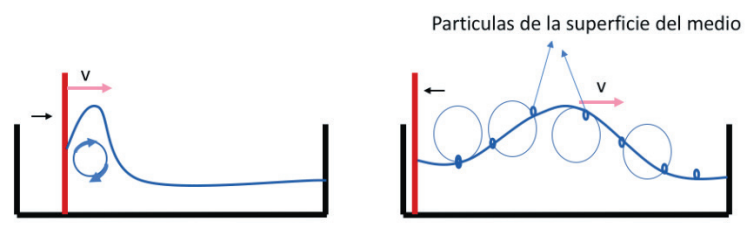

Figura 142 Propagación de onda (Young \& Freedman, 2000).

En la Figura 128 el medio es agua. La barra roja se mueve inicialmente hacia adelante y luego hacia atrás. La perturbación viaja por la cubeta. En este caso el desplazamiento tiene ambos componentes transversal y longitudinal. El estado de equilibrio de este sistema es cuando el agua se encuentra en un solo nivel sobre la superficie. El movimiento ondulatorio es la perturbación de este estado de equilibrio que viaja de una región del medio a otra.

Tres son las características que pueden observarse de lo anterior. La primera es que la perturbación viaja o se propaga a cierta velocidad por el medio. Esta velocidad es llamada de propagación o simplemente velocidad de onda y está determinada por las propiedades mecánicas del medio. No debe confundirse con la velocidad de cada partícula del medio cuando esta es perturbada. La segunda es que el medio no es el que viaja por el espacio; cada partícula individual se mueve hacia adelante y atrás o arriba y abajo desde su posición de equilibrio. El patrón general de la perturbación es el que viaja. Por último, para poner el sistema en movimiento hay que aplicar energía mediante trabajo mecánico. El movimiento ondulatorio transporta esta energía desde una región del medio a otro (Young \& Freedman, 2000).

\subsubsection{Onda Periódica}

Cuando una serie de gotas caen verticalmente en el agua producen una onda periódica que se extiende radialmente desde la fuente. Las crestas y valles de la onda son círculos concéntricos. La distancia entre un valle y otro o una cresta y otra es conocido como la longitud de onda denotada por $\lambda$. En el patrón de onda que viaja a una velocidad constante $v$ y avanza una distancia $\lambda$ en un intervalo de tiempo de un periodo $\mathrm{T}$, se tiene:

$$
v=\lambda f
$$

Porque $f=\frac{1}{T}$. La frecuencia es una propiedad de toda la onda periódica porque todos los puntos del medio oscilan la misma frecuencia $f$.

Para el caso puntual de esta práctica experimental, la velocidad de onda está determinada únicamente por las propiedades mecánicas del medio. En este caso, incrementos en $f$ provocan la disminución de $\lambda$ de manera que el producto $v=\lambda f$ permanecerá igual y las ondas de todas las frecuencias se propagaran con la misma velocidad de onda.

\subsubsection{Descripción matemática de una onda}

Muchas características de las ondas periódicas se pueden describir usando los conceptos de velocidad de onda, periodo, frecuencia y longitud de onda. Sin embargo, se necesitan más detalles para la descripción de la posición y el movimiento de las partículas individuales en el medio durante la propagación de la onda. Para esta descripción es necesario el concepto de función de onda. Una función que describa la posición de cualquier partícula en el medio en cualquier momento. Para este caso la onda satisface una relación sinusoidal, en el que la partícula sigue un movimiento armónico simple a partir de la posición de equilibrio. 


\subsubsection{Función de onda para una onda sinusoidal}

Supóngase el movimiento de una partícula, en el extremo izquierdo de una cuerda $(\mathrm{x}=0)$ en el que se origina la onda, está dado por:

$$
y(x=0, t)=A \operatorname{sen}(\omega t)=A \operatorname{sen}(2 \pi f t)
$$

Lo que significa que las partículas oscilan en un movimiento armónico simple con amplitud $\mathrm{A}$, frecuencia $f$ y frecuencia angular $\omega=2 \pi f$.

La perturbación viaja desde $x=0$ a algún punto $\mathrm{x}$ a la derecha desde el origen en una cantidad de tiempo dada por $\frac{x}{v}$ donde $v$ es la velocidad de onda. Así, el movimiento desde un punto $\mathrm{x}$ a un tiempo dado es igual al movimiento desde $x=0$ en el momento $t-\frac{x}{v}$. Con lo anterior se tiene:

$$
y(x, t)=A \operatorname{sen}\left[\omega\left(t-\frac{x}{v}\right)\right]=A \operatorname{sen}\left[2 \pi f\left(t-\frac{x}{v}\right)\right]
$$

Si expresamos la función en términos del periodo $T=\frac{1}{f}$ y de $\lambda=\frac{v}{f}$ :

$$
y(x, t)=A \operatorname{sen}\left[2 \pi\left(\frac{t}{T}-\frac{x}{\lambda}\right)\right]
$$

Si además se define la cantidad $k$ llamada número de onda:

$$
k=\frac{2 \pi}{\lambda}
$$

Se substituye $\lambda=\frac{2 \pi}{k}$ y $f=\frac{\omega}{2 \pi}$ en la relación longitud de onda - frecuencia $v=\lambda f$ para una onda periódica:

$$
\omega=v k
$$

Se puede reescribir la ecuación inicial y se tiene la función de onda:

$$
y(x, t)=A \operatorname{sen}(\omega t-k x)
$$

De este modo, se obtiene la ecuación de onda para una onda periódica.

\subsubsection{Aceleración y velocidad de una partícula en una onda sinusoidal}

De la función de onda se pude obtener una expresión para la velocidad transversal de cualquier partícula en una onda transversal. A esto se le llama $v_{y}$ para diferenciarlo de la velocidad de propagación de la onda $v$. Para encontrar esa velocidad transversal en un punto $x$ tomamos la derivada de la función $y(x, t)$ con respecto de con respecto de $t$. Si la función de onda es:

Entonces:

$$
y(x, t)=A \operatorname{sen}(\omega t-k x)
$$

$$
v_{y}(x, t)=\frac{\partial y(x, t)}{\partial t}=\omega A \cos (\omega t-k x)
$$

El símbolo $\delta$ es una expresión modificada de $d$ usada para referenciar que $y(x, t)$ aunque es una función en dos variables, sólo se toma por variable a $t$. La otra variable $x$ queda como constante porque se busca en un punto particular de la cuerda. Esta derivada se conoce como derivada parcial. 
La ecuación anterior muestra la velocidad transversal de una partícula que varía con el tiempo como se espera en el movimiento armónico simple. La velocidad máxima de la partícula es $\omega A$; la cual puede ser mayor, menor o igual a la velocidad $v$ según la amplitud y la frecuencia de la onda.

La aceleración de cualquier partícula es la segunda derivada parcial de $y(x, t)$ con respecto a $t$

$$
a_{y}(x, t)=\frac{\partial^{2} y(x, t)}{\partial t^{2}}=-\omega^{2} A \operatorname{sen}(\omega t-k x)=-\omega^{2} y(x, t)
$$

La aceleración de una partícula es $-\omega^{2}$ veces el desplazamiento.

También se pueden computar derivadas parciales de $y(x, t)$ con respecto a $x$ manteniendo $t$ constante. Esto corresponde al estudio de la forma de la cuerda en un instante de tiempo. La primera derivada es la pendiente de la cuerda en cualquier punto. La segunda derivada es la curvatura de la cuerda:

$$
\frac{\partial^{2} y}{\partial x^{2}}=-k^{2} A \operatorname{sen}(\omega t-k x)=-k^{2} y(x, t)
$$

De la aceleración de la partícula, la curvatura de la cuerda y la relación $\omega=v k$ se tiene:

$$
\begin{gathered}
\frac{\partial^{2} y(x, t)}{\partial t^{2}} \\
\frac{\partial^{2} y(x, t)}{\partial x^{2}}=\frac{\omega^{2}}{k^{2}}=v^{2} \\
\frac{\partial^{2} y(x, t)}{\partial x^{2}}=\frac{1}{v^{2}} \frac{\partial^{2} y(x, t)}{\partial t^{2}}
\end{gathered}
$$

La ecuación de onda es una de las ecuaciones más importante de toda la física. En el momento que ocurra, se sabe que la perturbación puede propagarse como una onda a lo largo del eje $x$ a una velocidad $v$. La perturbación no debe ser necesariamente como onda sinusoidal, todas las formas válidas como función de onda satisfacen la ecuación de ondas. El concepto de función de onda es igual de útil con ondas longitudinales y todo lo mencionado con funciones de onda puede ser adaptado en este caso. La cantidad $y$ sigue midiendo el desplazamiento de una partícula en el medio desde su posición de equilibrio, la diferencia es que, en una onda longitudinal, el desplazamiento es paralelo al eje $x$ en lugar de perpendicular.

En esta práctica se verificarán experimentalmente los enunciados anteriores, para ello se recurrirá al prototipo de cubeta de ondas y al software de control desarrollado para el mismo. Desde el cual se podrá controlar variables como la frecuencia de las ondas generadas, se podrán obtener las imágenes necesarias para la determinación de cantidades como la longitud de onda y a partir de lo anterior será posible, haciendo uso de las ecuaciones mostradas, determinar las características restantes asociadas a una onda. 


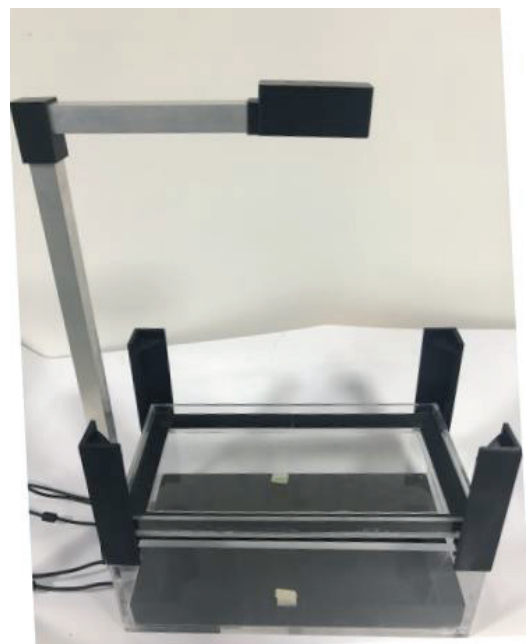

Figura 143 Prototipo Cubeta de Ondas [Autor].

\subsubsection{Procedimiento}

\subsubsection{Montaje del prototipo.}

i. Tome el prototipo de cubeta de ondas y realice las respectivas conexiones entre cada una de las componentes como lo indique el docente encargado. De lo contrario revise el manual de usuario para más información.

ii. Una vez realizadas las conexiones del prototipo, proceda a conectarlo al computador, asegúrese de conectar tanto el equipo como la cámara.

iii. Finalizado lo anterior conecte el equipo a la fuente de alimentación.

iv. Asegúrese que el actuador dispuesto en el generador de ondas se encuentre ubicado en el centro de la cubeta.

v. Llene la cubeta con la sustancia a estudiar hasta el nivel de los rompe olas.

\subsubsection{Manipulación del Software}

i. Una vez conectado el prototipo es necesario, acceder desde el computador a la aplicación llamada Software Cubeta de Ondas, una vez ejecutada la aplicación se debe seleccionar la opción "Software Cubeta de Ondas".

ii. En la pantalla encontrará tres secciones:

- Control generador: en esta sección se podrá encender (frecuencia diferente de 0) y apagar (frecuencia en 0) el generador de ondas. Así mismo, se dispone de un scroll que le permitirá variar la frecuencia de las ondas generadas.

- Control Estroboscopio: en esta sección se podrá encender (frecuencia diferente de 0) y apagar (frecuencia en 0) el LED del estroboscopio. Así mismo se dispone de un scroll que le permitirá variar la frecuencia del estroboscopio.

- Control carril: el control del carril permite configurar el dispositivo para realizar el experimento con el carril en un punto fijo, o para el carril en movimiento (esta opción para el análisis del efecto Doppler), para ello el usuario debe chequear alguna de las opciones.

Una vez definida la configuración deseada, se procede por parte del usuario a enviar las órdenes al dispositivo presionando el botón "Generar", para el caso en el cual el usuario quiera pausar la práctica debe presionar el botón "Detener". 
iii. El sistema iniciara su operación y se podrán apreciar las ondas mecánicas deseadas, a su vez el usuario podrá adquirir las imágenes de las ondas en la cubeta para su posterior estudio.

\subsubsection{Procedimiento experimental}

i. Asegúrese de que el dispositivo se encuentre según las recomendaciones de los numerales anteriores.

ii. Proceda a iniciar la práctica indicando la frecuencia que quiere programar para el generador y para la luz led que le permitirá observar de mejor forma las ondas.

iii. Active la visualización de la cámara presionando en el botón "Iniciar".

iv. Proceda a presionar el botón de "Generar" en la interfaz.

v. Las ondas en la cubeta se generarán,

vi. Cuando considere que las ondas a estudiar se aprecian claramente en la imagen mostrada por la cámara presione clic en el botón "Tomar Foto", una vez adquirida la imagen podrá realizar el procesamiento de esta.

vii. Primero defina los bordes de la imagen presionando en la pestaña bordes, en ese momento la imagen estará binarizada y podrá identificar los frentes de onda.

viii. Presione clic sobre un frente de onda y luego nuevamente clic sobre uno consecutivo para determinar la longitud de onda de la perturbación (la medición aparecerá en la parte inferior de la pantalla en la caja de texto "Medida Línea").

ix. Realice el mismo procedimiento 10 veces para cada configuración deseada.

x. Realice la toma de datos para 5 diferentes configuraciones (modificando la frecuencia del generador)

\subsubsection{Análisis}

i. Realice una tabla para cada una de las mediciones tomadas, obteniendo el promedio de la longitud de onda medida

ii. Determine la velocidad de propagación promedio de la onda en el medio.

iii. Encuentre la incertidumbre de la medición de la velocidad. Tenga en cuenta que las especificaciones para la frecuencia del generador es $0.1 \%$ y su resolución es de $0.1 \mathrm{~Hz}$. De igual forma para la medición de la longitud de onda tenga en cuenta una especificación de $0.2 \%$ y una resolución de $3 \mathrm{~mm}$.

iv. Realice para cada uno de los montajes una gráfica de longitud de onda en función de la frecuencia, ¿Describa cuál es el comportamiento de la gráfica? ¿Indique que puede concluir de este comportamiento?

v. Si en el numeral anterior el grafico obtenido no fue una línea recta realice una regresión polinómica. ¿Qué puede concluir de los resultados obtenidos? ¿Qué significado físico tiene dicho comportamiento?

\subsection{Guía Experimental para el Efecto Doppler}

\subsubsection{Introducción}

Cuando un emisor de ondas sonoras está en movimiento en relación con el medio donde se propagan, las ondas sonoras emitidas y detectadas por un observador tendrán una diferencia en frecuencia debido al Efecto Doppler, la cual permite calcular la velocidad de la fuente.

\subsubsection{Objetivos}

1. Medir la frecuencia emitida por la fuente y la frecuencia recibida por el receptor en reposo, donde la fuente esta sobre un carril la cual emite ondas de sonido e impulsada por un motor eléctrico y el observador representado por un sensor de sonido en reposo.

2. Graficar la frecuencia en función de la velocidad del móvil y calcular la velocidad del sonido.

3. Medir el desplazamiento Doppler para variar las frecuencias y velocidades para una fuente de sonido en movimiento y compararlo con lo teórico.

4. Utilizar las ecuaciones teóricas que describen el efecto Doppler y compararlas con los resultados de la práctica, la cual puede comprobar el efecto Doppler cuando la fuente se aleja del observador o cuando la fuente sonora se acerca al observador. 


\subsubsection{Marco Conceptual}

El efecto Doppler (o el cambio Doppler) es el cambio en la frecuencia o longitud de onda de una onda con respecto a un observador que se está moviendo en relación con la fuente de onda. Lleva el nombre del físico austriaco Christian Doppler, quien describió el fenómeno en 1842 .

El efecto Doppler se usa ampliamente para medir velocidades, generalmente mediante la reflexión de una onda transmitida desde el objeto en movimiento y se aplica en ultrasonido, radares ambulancias y tormentas eléctricas. Las velocidades de galaxias distantes se miden utilizando el efecto Doppler (el desplazamiento al rojo) usando el mismo efecto en ondas electromagnéticas (Lab, 2019)

Las ondas mecánicas tienen algunas características como podemos observar en la Figura 144, donde la velocidad de propagación en las ondas sonoras se da de forma radial a la fuente.

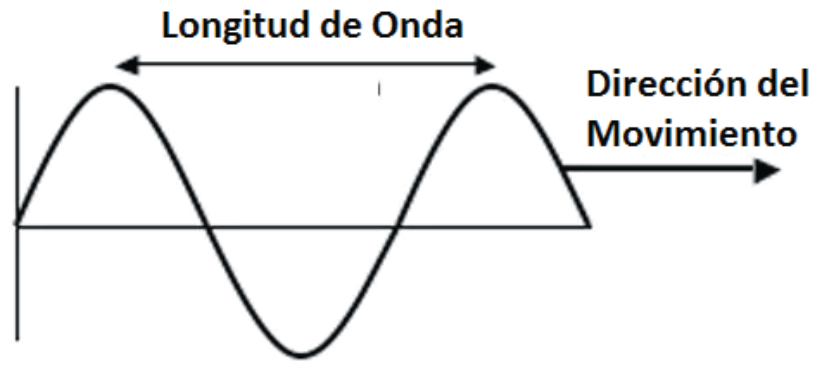

Figura 144 Onda y componentes (Lab, 2019)

La velocidad de propagación de las ondas sonoras se relaciona con la longitud de la onda y la frecuencia emitida.

$$
\mathrm{c}=\mathrm{f} \cdot \lambda
$$

C: Es la velocidad del sonido, cambia con las variaciones de temperatura.

$$
c=331.06+0.61 t
$$

t: Temperatura del ambiente

F: Es la frecuencia del sonido.

$\lambda$ : Longitud de onda del sonido

Se puede observar en la figura 145 , dos casos que se comprueban en la práctica de laboratorio, en otras palabras, se analizan dos casos: el primero de ellos es la fuente sonora alejándose del observador de la izquierda, lo cual implica una longitud mayor por lo tanto una frecuencia menor percibida, y el segundo caso la fuente sonora acercándose del observador de la derecha, lo cual implica una longitud menor y por lo tanto una frecuencia mayor percibida. 


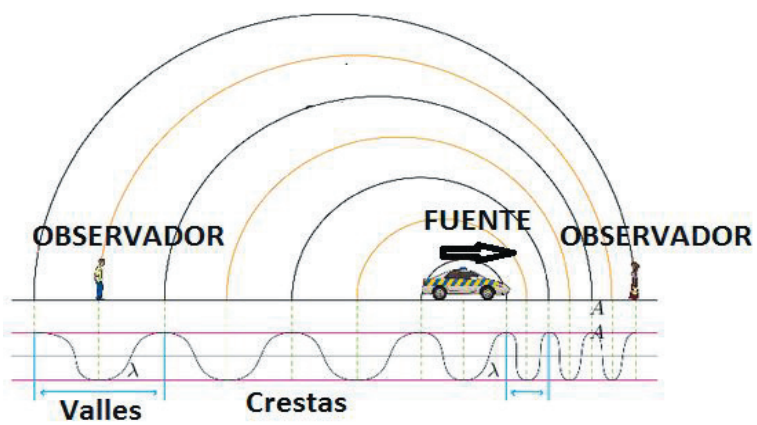

Figura 145 Efecto Doppler (Lab, 2019).

Cuando la fuente se aleja del observador debemos utilizar la siguiente ecuación:

$$
\mathrm{f}_{\text {observada }}=\left[\frac{\mathrm{v}}{\mathrm{v}+\mathrm{v}_{\text {fuente }}}\right] \mathrm{f}
$$

F: Frecuencia de la fuente

V: Velocidad de la fuente

F observada: frecuencia percibida por el receptor

Cuando la fuente acercándose al observador, debemos utilizar la siguiente ecuación:

$$
\mathrm{f}_{\text {observada }}=\left[\frac{\mathrm{v}}{\mathrm{v}-\mathrm{v}_{\text {fuente }}}\right] \mathrm{f}
$$

F: Frecuencia de la fuente

V: Velocidad de la fuente

F observada: frecuencia percibida por el receptor

\subsubsection{Análisis}

A continuación, se muestra la tabla de datos que se deberá completar durante la práctica experimental.

\begin{tabular}{|c|c|c|c|c|c|c|c|c|}
\hline & $\begin{array}{c}v_{-} \\
(\mathrm{m} / \mathrm{s})\end{array}$ & $\begin{array}{c}\Delta f \\
(\mathrm{~Hz})\end{array}$ & $\begin{array}{c}\Delta f \\
(\mathrm{~Hz})\end{array}$ & $\begin{array}{c}\Delta f \\
(\mathrm{~Hz})\end{array}$ & $\begin{array}{c}v_{+} \\
(\mathrm{m} / \mathrm{s})\end{array}$ & $\begin{array}{c}f \\
(\mathrm{kHz})\end{array}$ & $\begin{array}{c}f \\
(\mathrm{kHz})\end{array}$ & $\begin{array}{c}f \\
(\mathrm{kHz})\end{array}$ \\
\hline$f_{0}$ & & & & & & 5 & 10 & 12 \\
\hline 1 & & & & & & 2,11 & 4,5 & 5,6 \\
\hline 2 & & & & & & 2,01 & 4,3 & 5,0 \\
\hline 3 & & & & & & 2,00 & 4,9 & 5,1 \\
\hline 4 & & & & & & 1,88 & 4,1 & 5,3 \\
\hline 5 & & & & & & 2,09 & 4,3 & 5,3 \\
\hline \begin{tabular}{c} 
Promedio \\
\hline
\end{tabular} & & & & & & 2,02 & 4,5 & 5,3 \\
\hline Desviación & & & & & & 0,07 & 0,3 & 0,2 \\
\hline
\end{tabular}

Tabla 8 Efecto Doppler Datos de Laboratorio [Autor] 
1. El estudiante debe llenar la siguiente tabla en la cual se debe medir en el software la diferencia de frecuencia emitida con la frecuencia recibida, la cual puede ser tomada en el software del computador.

2. El estudiante pondrá la fuente a través del interruptor, para que se aleje o se acerque al observador.

3. El procedimiento de punto dos debe hacerse para las frecuencias que se observan en la tabla.

4. Graficar en papel milimetrado, escogiendo una escala adecuada la diferencia de frecuencia contra la frecuencia del emisor y calcular a través de una regresión lineal la ecuación de la recta.

5. ¿Qué significado tiene la pendiente de la curva? Compare este resultado con el dado por la pantalla HMI.

6. Hacer las gráficas cuando la fuente se aleja del observador y cuando la fuente se acerca del observador.

7. Compruebe utilizando Excel la tendencia de esta gráfica y calcule la ecuación.

8. ¿Compare el resultado de Excel con el resultado calculado en las tablas cuando se linealiza?

9. Encontrar la incertidumbre expandida de la velocidad del vehículo, ¿la velocidad del sonido (se debe tener en cuenta que son variables dependientes del espacio y del tiempo)? 


\section{REFERENCIAS BIBLIOGRÁFICAS}

Alonzo, M., \& Finn, E. J. (1970). Fundamental Universiy Physics, Voleme 2, Fields and Waves. Addison-Wesley Publising Company.

Arcos, H. I., Cruz Muñoz, Beatriz, Marín Ramírez, W., Quiroga Hurtado, J., \& Medina, M. (2011). Guías de Física Experimental III (p. 116). Pereira: Universidad Tecnológica de Periera.

Arduino, P. (2018). Arduino Pro Mini 328 5V. Extraído desde: https://www.electronicoscaldas.com/es/boards/744-sistemade-desarrollo-arduino-pro-mini-328-5v-clone.html

Arenas, E. (2018). Física Entretenida - Ondas Estacionarias - Extraído desde: https://www.youtube.com/ watch? $\mathrm{v}=\mathrm{dsLtOwq} 3 \mathrm{xm} 8$

Cruz Muñoz, B., Llamosa, L. E., \& Medina, M. (2019). Tratamiento estadístico de datos experimentales y aplicación del método general para el cálculo de incertidumbre de medición (medidas directas). En: Fisica Experimental UTP (Vol. 53). 
Dao, M. H., Chew, L. W., \& Zhang, Y. (2018). Modelling physical wave tank with flap paddle and porous beach in OpenFOAM. Ocean Engineering, 154(March 2018), 204-215. https://doi. org/10.1016/j.oceaneng.2018.02.02

DICOPED, G. de I. (2018). Equipo Experimental Ley de Snell. Pereira: Universidad Técnologica de Pereira

Electronica, A. P. (2018). Circuitos Integrados Generadores de Ondas - ABC Proyectos Electrónicos. Extraído desde: https:// www.abcelectronica.net/productos/circuitos-integrados/ generadores/

Feynman, R., Leighton, R., \& Sands, M. (1977). Lectures On Physics (Ed. 1). Massachusett: Addison-Wesley Publising Company.

Gómez, D., \& Welti, R. (2004). Sobre los cuasi-nodos en las oscilaciones de cuerdas reales. Revista Brasileira de Ensino de Física, 26(2), 139-144.

Gonzalez, R. C., \& Woods, R. E. (2002). Digital Image Processing (2a ed.). New Jersey: Prentice Hall Inc.

Lab, F. (2019). Efecto Doppler. Recuperado el 25 de noviembre de 2018, de https://www.fisicalab.com/apartado/efectodoppler\#contenidos

Laraja Vizcaíno, J. R., \& Pelegrí Sebastiá, J. (2011). LabVIEW: Entorno Gráfico de Programación (2a ed.). Barcelona: Marcombo S.A.

Magnetic, Duras, I. (2018). Voice Coil Motors (VCM) / Voice Coil Actuators | Dura Magnetics USA. Extraído desde: de https:// www.duramag.com/magnet-applications/voice-coil-motorsvcm-voice-coil-actuators-moving-coil-non-rotary/ 
Oliva, M. (2011). Ondas Superficiales En Un Líquido Con Confinamiento Elíptico. Revista Cubana de Física, 28(2), $100-104$.

Pasco. (2018). TecnoEdu - Excitador de ondas mecánicas para experimentar vibraciones resonantes en cuerdas. Extraído desde: https://tecnoedu.com/Pasco/WA9857A.php

Roatta, A., \& Welti, R. (2009). Efecto Doppler para pulsos y su representación en el plano $(\mathrm{x}, \mathrm{t})$. Revista Brasileira de Ensino de Fisica, 31(1), 1-7. https://doi.org/10.1590/S180611172009000100004

Rodriguez Zureta, G., Alvarado Bustos, R., Alvarado Bustos, R., \& Zavala Ramírez, L. E. (2002). Modos de oscilación en cuerdas homogéneas por tercios. Revista Mexicana de Física, 48(5), 463-474.

Ruben, F. V. (2017). Diseño de un generador de señales aplicado al laboratorio de electronica, electricidad y automatización (Universidad Mayor de San Andrés). Extraído desde:http:// repositorio.umsa.bo/bitstream/handle/123456789/11652/ TM-3925.pdf? sequence $=1$

Sergievskaya, I., Ermakov, S., \& Kapustin, I. (2010). Radar probing of steep gravity waves. Wave tank experiment. European Microwave Week 2010, EuMW2010: Connecting the World, Conference Proceedings - European Radar Conference, EuRAD 2010, (October), 17-20.

Serway, R. A., \& Beinncher, R. J. (2005). Física Para Ciencia e Ingeniería Volumen 1 (5a ed.; V. Olguín Campos \& A. E. García Hernandez, Eds.). Mc. Graw-Hill.

Serway, R. A., \& Jawett, J. W. jr. (2008a). Física para Ciencia e Ingenierías. (7a ed.). México D.F.: Cengace Learning. 
Serway, R. A., \& Jawett, J. W. jr. (2008b). Física para Ciencias e Ingenierías Volumen 1. México D.F.: Cengace Learning.

TecnoEdu. (2018). TecnoEdu - Impulsor de ondas mecánicas. Recuperado el 16 de noviembre de 2018, de https://tecnoedu. com/Pasco/SF9324.php

Travis, J., \& Kring, J. (2006). LabVIEW for Everyone: Graphical Programming Made Easy and Fun (3a ed.). New Jersey: Prentice Hall Inc.

Wikipedia The Free Enciclopedy. (2009). Studies at MIT: 19261931 " Harold "Doc" Edgerton. Extraído desde: http:// edgerton-digital-collections.org/docs-life/studies-at-mit

Wu, Y. T., \& Hsiao, S. C. (2018). Generation of stable and accurate solitary waves in a viscous numerical wave tank. Ocean Engineering, 167(August), 102-113. https://doi.org/10.1016/j. oceaneng.2018.08.043

Young, H. D., \& Freedman, R. A. (2000). University Physics (10a ed.). Massachusett: Wesley Publishing Company.

Young, H. D., \& Freedman, R. A. (2009). Física Universitaria Volumen 1 (Décimosegu). México: Addison-Wesley Publising Company.

Young, H. D., \& Freedman, R. A. (2013). Física Universitaria Volumen 1 (13a ed.). México: Pearson. 

El libro "Diseño y Construcción de Prácticas Para el Estudio de Movimiento Ondulatorio" es un documento que se caracteriza por tener cuatro capítulos los cuales describen paso a paso cada uno de los equipos de laboratorio de Física, involucrados en el proyecto de la convocatoria interna que se llevó a cabo a través de la Vicerrectoría de Investigaciones Innovación y Extensión, de nuestra Universidad en el periodo comprendido entre 2017 y 2019.

En cada capítulo se explica de manera detallada, la forma como se desarrolla, el prototipo, sus características más importantes y las partes más significativas de cada uno de los prototipos.

Es de notar que, dentro de la metodología realizada, cada fase de los experimentos se caracteriza por tener inicialmente una fundamentación teórica para comprender y entender los conceptos teóricos de los temas a tratar, en este caso, los temas de Cuerda Tensa en el capítulo 1, Cubeta de Ondas, en el capítulo 2 y Efecto Doppler, en el capítulo 3: Posteriormente se hace el análisis para el diseño y construcción de un modelo mecánico que permita la verificación experimental de cada uno de los prototipos.

La siguiente fase se caracteriza por el desarrollo electrónico y codificación de sistema electrónico de acuerdo a los requerimientos del montaje mecánico.

Finalmente se hace la guía del laboratorio, capítulo 4, la cual permite verificar y obtener los resultados esperados de acuerdo a la fundamentación teórica de cada una de los temas.

\section{Facultad de Ciencias Básicas}

